\title{
Integrative taxonomy of Metrichia Ross (Trichoptera: Hydroptilidae: Ochrotrichiinae) microcaddisflies from Brazil: descriptions of twenty new species
}

Allan PM Santos, Daniela M Takiya, Jorge L Nessimian

Metrichia is assigned to the Ochrotrichiinae, a group of almost exclusively Neotropical microcaddisflies. Metrichia comprises over 100 described species and, despite its diversity, only one species has been described from Brazil so far. In this paper, we provide descriptions for 20 new species from 8 Brazilian states: $M$. acuminata sp. nov., M. azul sp. nov., M. bonita sp. nov., M. bracui sp. nov., M. caraca sp. nov.., M. circuliforme sp. nov., M. curta sp. nov., M. farofa sp. nov., M. forceps sp. nov., M. formosinha sp. nov., M. goiana sp. nov., M. itabaiana sp. nov., M. longissima sp. nov., M. peluda sp. nov., $M$. rafaeli sp. nov., $M$. simples sp. nov., $M$. talhada sp. nov., $M$. tere sp. nov., M. ubajara sp. nov., and $M$. vulgaris sp. nov. DNA barcode sequences (577 bp of the mitochondrial gene COI) were generated for 13 of the new species and two previously known species of Metrichia resulting in 64 sequences. In addition, COl sequences were obtained for other genera of Ochrotrichiinae (Angrisanoia, Nothotrichia, Ochrotrichia, Ragatrichia, and Rhyacopsyche). DNA sequences and morphological data were integrated to evaluate species delimitations. K2P pairwise distances were calculated to generate a neighbor-joining tree. COI sequences also were submitted to ABGD and GMYC methods to assess 'potential species' delimitation. Analyses showed a conspicuous barcoding gap among Metrichia sequences (highest intraspecific divergence: 4.8\%; lowest interspecific divergence: $12.6 \%$ ). Molecular analyses also allowed the association of larvae and adults of Metrichia bonita sp. nov. from Mato Grosso do Sul, representing the first record of microcaddisfly larvae occurring in calcareous tufa (or travertine). ABGD results agreed with the morphological delimitation of Metrichia species, while GMYC estimated a slightly higher number of species, suggesting the division of two morphological species, each one into two potential species. Because this could be due to unbalanced sampling and the lack of morphological diagnostic characters, we have maintained these two species as undivided. 
1 Integrative taxonomy of Metrichia Ross (Trichoptera: Hydroptilidae:

2 Ochrotrichiinae) microcaddisflies from Brazil: descriptions of twenty new

3 species

4 ALLAN P M SANTOS ${ }^{1,2}$, DANIELA M TAKIYA ${ }^{2}$ \& JORGE L NESSIMIAN ${ }^{2}$

$5 \quad$ 'Departamento de Zoologia, Instituto de Biociências, Universidade Federal do Estado do Rio de

6 Janeiro, Rio de Janeiro, Rio de Janeiro, Brazil.

$7 \quad{ }^{2}$ Departamento de Zoologia, Instituto de Biologia, Universidade Federal do Rio de Janeiro, Rio

8 de Janeiro, Rio de Janeiro, Brazil.

9 Corresponding Author:

10 Laboratório de Entomologia, Depto. de Zoologia, Inst. de Biologia, Universidade Federal do Rio

11 de Janeiro, Caixa Postal 68044, Rio de Janeiro, RJ, 21941-971, Brazil.

12 Email address: allanpms@gmail.com 


\section{ABSTRACT}

Metrichia is assigned to the Ochrotrichiinae, a group of almost exclusively Neotropical microcaddisflies. Metrichia comprises over 100 described species and, despite its diversity, only one species has been described from Brazil so far. In this paper, we provide descriptions for 20 new species from 8 Brazilian states: M. acuminata sp. nov., M. azul sp. nov., M. bonita sp. nov., M. bracui sp. nov., M. caraca sp. nov., $M$. circuliforme sp. nov., . curta $\mathbf{s p . ~ n o v . , ~}$. farofa $\mathbf{s p .}$ nov., M. forceps sp. nov., M. formosinha sp. nov., $M$. goiana sp. nov., $M$. itabaiana sp. nov., $M$.

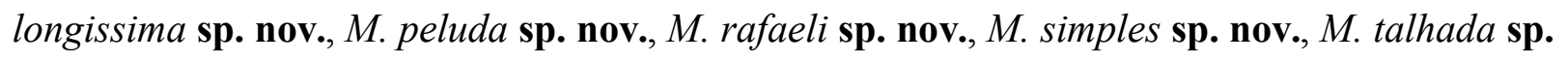
nov., M. tere sp. nov., M. ubajara sp. nov., and M. vulgaris sp. nov. DNA barcode sequences (577 bp of the mitochondrial gene COI) were generated for 13 of the new species and two previously known species of Metrichia resulting in 64 sequences. In addition, COI sequences were obtained for other genera of Ochrotrichiinae (Angrisanoia, Nothotrichia, Ochrotrichia, Ragatrichia, and Rhyacopsyche). DNA sequences and morphological data were integrated to evaluate species delimitations. K2P pairwise distances were calculated to generate a neighborjoining tree. COI sequences also were submitted to ABGD and GMYC methods to assess 'potential species' delimitation. Analyses showed a conspicuous barcoding gap among Metrichia sequences (highest intraspecific divergence: $4.8 \%$; lowest interspecific divergence: $12.6 \%$ ). Molecular analyses also allowed the association of larvae and adults of Metrichia bonita sp. nov. from Mato Grosso do Sul, representing the first record of microcaddisfly larvae occurring in calcareous tufa (or travertine). ABGD results agreed with the morphological delimitation of Metrichia species, while GMYC estimated a slightly higher number of species, suggesting the division of two morphological species, each one into two potential species. Because this could be due to unbalanced sampling and the lack of morphological diagnostic characters, we have maintained these two species as undivided.

\section{INTRODUCTION}


Ochrotrichiinae, which also includes Ochrotrichia Mosely, 1934, Angrisanoia Özdikmen, 2008,

Nothotrichia Flint, 1967, Rhyacopsyche Müller, 1879, and the recently erected Ragatrichia Oláh

\& Johanson, 2011, all of them exclusively from New World. Based on adult morphology, Harris

\& Armitage (1997) and Oláh \& Johanson (2011) also suggested three other genera to be included in this subfamily: Dibusa Ross, 1939, Caledonotrichia Sykora, 1967, and Maydenoptila Neboiss, 1977, from the U.S.A., New Caledonia, and Australia, respectively. However, because diversification of main lineages of hydroptilids has not been deeply studied, the placement of these genera remains dubious. As noted by Wells et al. (2013), relationships of these considered as a subgenus of Ochrotrichia due to similarities of adult morphology and almost indistinguishable larvae (Flint, 1968). This subgeneric status was followed by Marshall (1979), who also established the New World tribe that is now recognized as subfamily Ochrotrichiinae. Wiggins (1996) provided additional information on larval morphology of Metrichia and Ochrotrichia, reestablishing both as independent genera. undescribed species are found in collections or amongst recently collected material when examined by experts, even in localities previously studied by trichopterologists. This likely occurs because Hydroptilidae are very small and have complex male genitalia, making them difficult to observe by lower magnification microscopes and to understand homologies among some structures. Only one species of Metrichia has been described from Brazil so far, $M$. pernambucana Souza \& Santos, 2013, but larvae have been commonly identified from several 
63 that material studied herein recently collected from different river basins in Brazil (Fig. 1, Supp.

64 1, Supp. 2) revealed so many undescribed species.

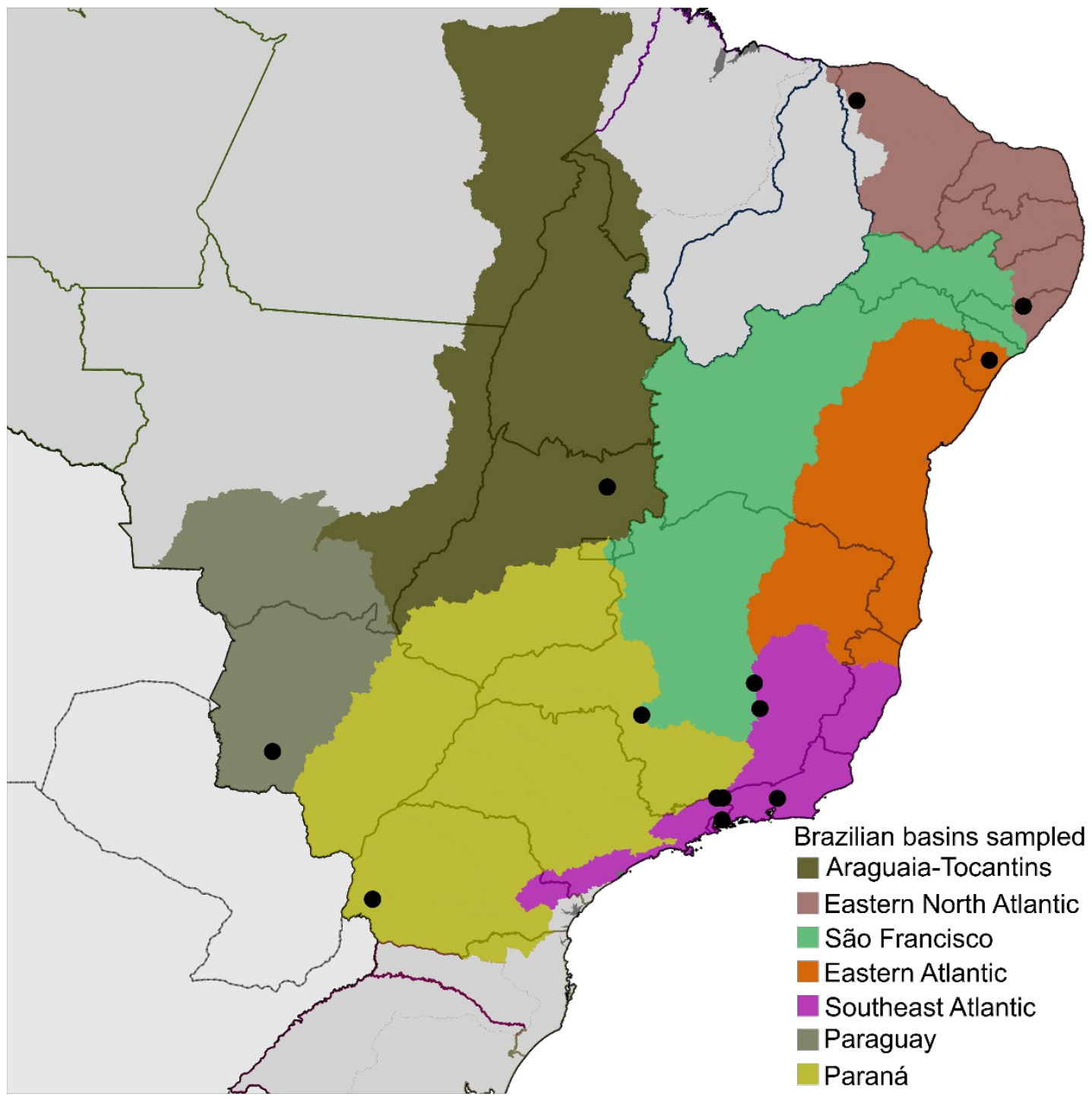

65 Figure 1. Localities (•), distributed on seven of the large river basins of Brazil, where Metrichia

66 specimens studied herein were collected. one species with a wide distribution in Brazil, occurring in three very distinctive biomes: Atlantic 
71 Brazil). Although such wide distributions are not common in Metrichia, similar examples are

72 known for other Neotropical microcaddisflies, as Oxyethira tica Holzenthal \& Harris, 1992,

73 recorded from Mexico, Central, and South America (Flint et al., 1999).

Although molecular tools have become common in taxonomic studies to help in species

75 delimitation, their use is still rare with Neotropical caddisflies. Using sequences of the

76 mitochondrial cytochrome oxidase I gene (COI), the standard DNA barcode region for animals

77 (Hebert et al., 2003), Pauls et al. (2010) were able to corroborate two new species of Smicridea

78 (Smicridea) McLachlan, 1871 from Chile, defined with morphological characters. In most studies

79 with caddisflies, divergence in COI sequences has shown clear differences between intraspecific

80 and interspecific variation, the so-called 'barcoding gap' (Zhou et al., 2007; Pauls et al., 2010;

81 Ruiter et al., 2013). Some species delimitation approaches rely solely in distinguishing intra- and

82 interspecific divergence, such as the Automatic Barcoding Gap Discovery (ABGD) (Puillandre et

83 al., 2012). More sophisticated methods invoke coalescence and speciation models, such as the

84 General Mixed Yule Coalescent (GMYC), and are considered more robust for identifying

85 lineages when intra- and interspecific divergences overlap (Pons et al., 2006). Integrating

86 independent data (e.g., morphology and DNA sequences) and using different approaches are

87 particularly interesting for the taxonomy of diverse and complex groups, such as

88 microcaddisflies. In this work, we applied both ABGD and GMYC methodologies to evaluate our

89 initial morphological identification.

90 Besides its use for species delimitation, DNA taxonomy has a valuable role in making

91 associations between immature and adult stages of caddisflies (Graf et al., 2005; Waringer et al.,

92 2007; Zhou et al., 2007; Ruiter et al., 2013). Traditional techniques to associate larvae and adults

93 are more difficult because they involve rearing larvae in the laboratory (not an easy task for many

94 caddisfly groups) or luck in finding pharate adults in field. Indirect association of stages, for 
95 example, by collecting adults and larvae at the same locality, can result in misidentification,

96 because different species of the same genus frequently co-occur.

97 Larvae of Metrichia have been associated for only two species: M. nigritta (Banks, 1907)

98 described by Edwards \& Arnold (1961) and illustrated by Wiggins (1996), and M. juana (Flint,

99 1964) by Flint (1964) in the original description. In addition, Botosaneanu and Flint (1982)

100 described a larva of Metrichia and its case from Venezuela and a pupal case from Ecuador; and

101 Pes et al. (2005) illustrated larvae from Brazil and three different types of cases. In both works,

102 specific names were not provided as authors did not have respective adults. Metrichia larvae

103 build a typical oval purse-like case, made of silk, usually covered with algae filaments (Wiggins,

104 1996; Pes et al., 2005), and sometimes also having sand grains (Botosaneanu \& Flint, 1982).

105 Cases of some larvae that have not yet been associated with adults show a pair of dorsal

106 "chimneys", an uncommon feature also described and illustrated by Müller $(1879,1880)$ for

107 Dicaminus ladislavii Müller, 1879, from Santa Catarina, Brazil. Based on larval cases from

108 Central and South America, Botosaneanu \& Flint (1982) pointed that Dicaminus is possibly

109 synonymous with Metrichia, but this question remains open, since there are no male specimens

110 from Müller's work.

111 Almost nothing is known about the biology of Metrichia larvae. According to Wiggins

112 (1996), larvae of M. nigritta were collected in association with filamentous algae on rock

113 surfaces. In Brazil, Metrichia occurs in fast flowing streams, usually with associated algae.

114 Herein, we report for the first time the occurrence of Metrichia in calcareous tufa. Calcareous

115 tufa or travertine is a terrestrial sedimentary rock, predominantly composed of carbonate

116 minerals, calcite, and aragonite (Drysdale, 1998). Travertines are formed by rapid precipitation of

117 these minerals, producing large alterations on river morphology (Drysdale \& Gale, 1997).

118 Although the importance of microbes on travertine formation is recognized by creating surfaces

119 for crystal nucleation, our knowledge of the importance of macroinvertebrates in this process is 
120

121

122

123

124

still poor (Drysdale, 1998; 1999; Paprocki et al., 2003). Studies by Drysdale $(1998,1999)$ pointed

out that aquatic insects play an important role in travertine biogenesis in Australian springs, especially Cheumatopsyche Wallengreen, 1891 (Hydropsychidae) larvae. Paprocki et al. (2003) also found another Hydropsychidae (Smicridea) to be an important organism in modifying travertine morphology in Venezuela.

\section{MATERIAL AND METHODS}

\section{Morphological study}

Specimens were collected manually (larvae or diurnal active adults) or using Malaise or light traps, and then fixed in 96\% ethanol. Collecting permits in Brazil were issued by Instituto Chico Mendes de Conservação da Biodiversidade (ICMBio) (SISBIO 43047 and 14591). To observe genital structures, abdomen of males were removed and cleared in a heated solution of $10 \% \mathrm{KOH}$ for 20 minutes. Then, abdomens were mounted in temporary slides, which were used to draw pencil sketches with compound microscope equipped with camera lucida. Vector graphics were traced in Adobe Illustrator CS6 (Adobe Systems Inc.) using pencil sketches as templates. Descriptions provided here were made with DELTA software (Description Language for Taxonomy) (Dallwitz et al., 1999). Terminology used throughout this paper follows that provided by Marshall (1979) and Bueno-Soria \& Holzenthal (2003). Types for newly described species are deposited at Coleção Entomológica Prof. José Alfredo Pinheiro Dutra, Departamento de Zoologia, Universidade Federal do Rio de Janeiro, Rio de Janeiro (DZRJ); Museu Nacional, Universidade Federal do Rio de Janeiro, Rio de Janeiro (MNRJ); Instituto Nacional de Pesquisas da Amazônia, Manaus (INPA); Coleção Zoológica do Maranhão (CZMA); and Museu de Zoologia da Universidade Federal da Bahia, Salvador (MZUFBA).

The electronic version of this article in Portable Document Format (PDF) will represent a published work according to the International Commission on Zoological Nomenclature (ICZN), 
144 and hence the new names contained in the electronic version are effectively published under that

145 Code from the electronic edition alone. This published work and the nomenclatural acts it

146 contains have been registered in ZooBank, the online registration system for the ICZN. The

147 ZooBank LSIDs (Life Science Identifiers) can be resolved and the associated information viewed

148 through any standard web browser by appending the LSID to the prefix http://zoobank.org/. The

149 LSID for this publication is: urn:Isid:zoobank.org:pub:D8D4049E-494B-4A30-92AC-

150 F8F42D2B54B9. The online version of this work is archived and available from the following

151 digital repositories: PeerJ, PubMed Central and CLOCKSS.

\section{DNA extraction, PCR, and sequencing}

Genomic DNA was extracted from head and thorax (or from the entire body) of fresh material using the DNeasy Blood and Tissue Kit (QIAGEN, Hilden, Germany), without tissue maceration. After extraction, specimens were returned to ethanol and deposited in DZRJ collection as a DNA voucher. COI fragments were amplified using pair of primers: HCO-2198 (5'-TAAACTTCAGGGTGACCAAAAAATCA-3') in combination with LCO-1490 (5'GGTCAACAAATCATAAAGATATTGG-3’) (Folmer et al., 1994) or C1-J-1718 (5’GGAGGATtTGGAAATTGATTAGTTCC-3’) (Simon et al., 1994). Polymerase chain reaction (PCR) conditions were as follows: initial denaturation at $94^{\circ} \mathrm{C}$ for $3 \mathrm{~min} ; 35$ cycles of denaturation at $94{ }^{\circ} \mathrm{C}$ for $1 \mathrm{~min}$, annealing at $50{ }^{\circ} \mathrm{C}$ for $1 \mathrm{~min}$, and extension at $72{ }^{\circ} \mathrm{C}$ for $2 \mathrm{~min}$; and final extension at $72{ }^{\circ} \mathrm{C}$ for $7 \mathrm{~min}$. PCR products were sent to Macrogen Inc., Seoul, for purification and sequencing reactions.

COI sequences of 64 specimens of 15 species of Metrichia were obtained. Additional sequences were obtained for specimens of Angrisanoia, Nothotrichia, Ochrotrichia, and Rhyacopsyche (Table 1), included as outgroup in different analyses, as described below. 
167 Table 1. Species of Metrichia and other hydroptilids with DNA barcodes sequenced and used in 168 this study, with respective information of specimen voucher and GenBank Accession Numbers.

\begin{tabular}{|c|c|c|c|}
\hline Species & $\begin{array}{l}\text { Voucher code } \\
\text { and life stage }\end{array}$ & Collection site & $\begin{array}{l}\text { GenBank } \\
\text { Accession } \\
\text { Number } \\
\end{array}$ \\
\hline $\begin{array}{l}\text { Angrisanoia cebollati (Angrisano, } \\
\text { 1995) }\end{array}$ & ENT 2199 ठ̊ & $\begin{array}{l}\text { Brazil: Goiás: Alto Paraíso de } \\
\text { Goiás }\end{array}$ & 1) \\
\hline Betrichia bispinosa Flint, 1974 & ENT 2337 ઢ & Brazil: Amapá & KU094961 ${ }^{\mathrm{b}}$ \\
\hline Nothotrichia cautinensis Flint, 1983 & - & - & $\mathrm{KC} 559534^{\mathrm{a}}$ \\
\hline $\begin{array}{l}\text { Nothotrichia tupi Holzenthal \& } \\
\text { Harris, } 1992\end{array}$ & ENT $2460 \hat{\jmath}$ & $\begin{array}{l}\text { Brazil: Minas Gerais: Catas } \\
\text { Altas }\end{array}$ & KU743400 \\
\hline $\begin{array}{l}\text { Ochrotrichia caatinga Souza, Santos } \\
\text { \& Takiya, } 2014\end{array}$ & ENT $2472 \lesssim$ & Brazil: Ceará: Ubajara & KU743401 \\
\hline $\begin{array}{l}\text { Ochrotrichia patulosa (Wasmund \& } \\
\text { Holzenthal, 2007) }\end{array}$ & ENT $2473 \curvearrowright$ & Brazil: Ceará: Ubajara & KU743402 \\
\hline Ochrotrichia sp. CR1 & ENT 2279 ఠ̊ & Costa Rica: Puntarenas & KU094950 b \\
\hline $\begin{array}{l}\text { Oxyethira tica Holzenthal \& Harris, } \\
1992\end{array}$ & ENT $0057 \hat{0}$ & Brazil: Pará: Carajás & KU094940 \\
\hline Ragatrichia sp. BR1 & ENT 2338 ఠ & Brazil: Amapá & KU743403 \\
\hline $\begin{array}{l}\text { Rhyacopsyche dikrosa Wasmund \& } \\
\text { Holzenthal, } 2007\end{array}$ & ENT 0122 ठૈ & $\begin{array}{l}\text { Brazil: Rio de Janeiro: } \\
\text { Teresópolis }\end{array}$ & KU094952 ${ }^{\mathrm{b}}$ \\
\hline Rhyacopsyche torulosa Flint, 1971 & ENT 2277 đ & Costa Rica: Puntarenas & KU743404 \\
\hline Metrichia acuminata sp. nov. & 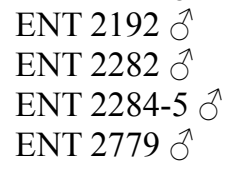 & Brazil: Alagoas: Quebrangulo & $\begin{array}{l}\text { KU743406 } \\
\text { KU743427 } \\
\text { KU743428-29 } \\
\text { KU743452 }\end{array}$ \\
\hline $\begin{array}{l}\text { Metrichia amplitudinis Bueno-Soria } \\
\text { \& Holzenthal, } 2003\end{array}$ & ENT 2278 ठ & Costa Rica: Puntarenas & KU743425 \\
\hline Metrichia bonita $\mathbf{s p . ~ n o v . ~}$ & $\begin{array}{l}\text { ENT 2200-4 } \\
\text { larvae }\end{array}$ & $\begin{array}{l}\text { Brazil: Mato Grosso do Sul: } \\
\text { Bonito }\end{array}$ & KU743409-13 \\
\hline Metrichia bonita sp. nov. & ENT 2208-10 ठ & $\begin{array}{l}\text { Brazil: Mato Grosso do Sul: } \\
\text { Bonito }\end{array}$ & KU743417-19 \\
\hline Metrichia bracui sp. nov. & ENT 2508-11 & Brazil: Rio de Janeiro: Itatiaia & KU743444-47 \\
\hline Metrichia caraca $\mathbf{s p . ~ n o v . ~}$ & $\begin{array}{l}\text { ENT } 2195 \hat{\jmath} \\
\text { ENT } 2280 \hat{\sigma} \\
\text { ENT 2461-5 }\end{array}$ & $\begin{array}{l}\text { Brazil: Minas Gerais: Catas } \\
\text { Altas }\end{array}$ & $\begin{array}{l}\text { KU743408 } \\
\text { KU743426 } \\
\text { KU743434-38 }\end{array}$ \\
\hline Metrichia caraca sp. nov. & ENT $2292 \pi$ & $\begin{array}{l}\text { Brazil: Minas Gerais: São } \\
\text { Roque de Minas }\end{array}$ & KU743432 \\
\hline Metrichia circuliforme sp. nov. & $\begin{array}{l}\text { ENT 2835-7 } 0 \\
\text { ENT 2839-40 } ત \\
\text { ENT 2843-4 } \sigma^{\lambda}\end{array}$ & Brazil: Rio de Janeiro: Itatiaia & $\begin{array}{l}\text { KU743455-57 } \\
\text { KU743459-60 } \\
\text { KU743462-63 }\end{array}$ \\
\hline Metrichia curta sp. nov. & $\begin{array}{l}\text { ENT } 2838 \AA \\
\text { ENT } 2846-8 \AA\end{array}$ & Brazil: Rio de Janeiro: Itatiaia & $\begin{array}{l}\text { KU743458 } \\
\text { KU743464-66 }\end{array}$ \\
\hline Metrichia formosinha sp. nov. & ENT 2205-7 ð & $\begin{array}{l}\text { Brazil: Mato Grosso do Sul: } \\
\text { Bonito }\end{array}$ & KU743414-16 \\
\hline Metrichia itabaiana sp. nov. & ENT $2190 \widehat{\jmath}$ & Brazil: Sergipe: Areia Branca & KU743405 \\
\hline Metrichia itabaiana sp. nov. & ENT 2220-1 ڤ̊ & $\begin{array}{l}\text { Brazil: Goiás: Alto Paraíso de } \\
\text { Goiás }\end{array}$ & KU743424 \\
\hline Metrichia juana (Flint, 1964) & ENT 2850-1 ð & Puerto Rico & KU743467-68 \\
\hline Metrichia longissima sp. nov. & ENT 2330 ఠ & $\begin{array}{l}\text { Brazil: Rio de Janeiro: } \\
\text { Teresópolis }\end{array}$ & KU743433 \\
\hline Metrichia longissima sp. nov. & ENT $2841 \hat{0}$ & Brazil: Rio de Janeiro: Itatiaia & KU743461 \\
\hline Metrichia rafaeli sp. nov. & ENT 2288-9 ઊ & Brazil: Ceará: Ubajara & KU743430-31 \\
\hline Metrichia talhada sp. nov. & 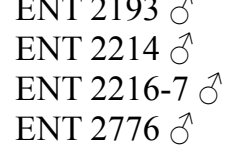 & Brazil: Alagoas: Quebrangulo & $\begin{array}{l}\text { KU743407 } \\
\text { KU743420-22 } \\
\text { KU743451 }\end{array}$ \\
\hline
\end{tabular}




\begin{tabular}{|c|c|c|c|}
\hline Metrichia tere sp. nov. & ENT 2773-5 へ & $\begin{array}{l}\text { Brazil: Rio de Janeiro: } \\
\text { Teresópolis }\end{array}$ & KU743448-50 \\
\hline Metrichia vulgaris sp. nov. & 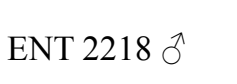 & $\begin{array}{l}\text { Brazil: Goiás: Alto Paraíso de } \\
\text { Goiás }\end{array}$ & KU743423 \\
\hline Metrichia vulgaris sp. nov. & ENT 2466-70 ठ & $\begin{array}{l}\text { Brazil: Minas Gerais: Catas } \\
\text { Altas }\end{array}$ & KU743439-43 \\
\hline Metrichia vulgaris sp. nov. & ENT 2833-4 ठే & Brazil: Rio de Janeiro: Itatiaia & KU743453-54 \\
\hline
\end{tabular}

Sequences obtained from GenBank: (a) Malm et al. 2013; (b) Santos et al. 2016.

\section{Sequence editing, alignment, and analyses}

Forward and reverse sequences of each sample were assembled and manually edited in Sequencher 4.1 (Gene Codes, Ann Arbor, Michigan, USA). Sequences were verified with the Blast tool in GenBank to check for contamination. Subsequently, COI sequences were aligned with ClustalW implemented in MEGA 6 (Tamura et al., 2013) and translated into amino-acid sequences to check for stop codons. The final alignment resulted in a matrix with $577 \mathrm{bp}$ (Supp. $3)$.

COI sequences were used to explore putative species limits with four different methodologies: (1) lineages recovered in neighbor-joining tree; (2) lineages recovered with Bayesian Inference; (3) ABGD; and (4) GMYC. The neighbor-joining tree was calculated in MEGA 6 using Kimura 2-Parameter (K2P) distances (Kimura, 1980), with partial deletion of missing information. Although the use of K2P distances in DNA barcoding is debated (Srivathsan \& Meier, 2012), to allow comparison with previous works we also used this evolutionary model because it is frequently used in studies of species delimitation based on COI sequences. Branch support of neighbor-joining tree was assessed with 1,000 pseudoreplicates of non-parametric bootstrap (Felsenstein, 1985).

BI analysis was conducted with MrBayes v. 3.2.2 (Ronquist et al., 2012) with four independent runs, each one with four MCMC chains running for 50,000,000 generations, with sample frequency of 5,000. Convergence of sampled parameters was checked in Tracer v. 1.5 (Rambaut \& Drummond, 2007) and the first 10\% of sampled trees and parameters discarded as 
190 burnin. GTR $+\mathrm{I}+\mathrm{G}$ was the best fit model selected by Akaike Information Criterion (AIC) with

191 jModeltest v. 0.1.1 (Posada, 2008) and it was applied in BI analysis in MrBayes. Branch support

192 was assessed by posterior probability (PP), presented on a 50\% majority consensus tree.

193 ABGD analysis was run using the on-line version available in

194 http://wwwabi.snv.jussieu.fr/public/abgd/, where the COI alignment was uploaded. The analysis

195 was conducted with the following settings: $\mathrm{Pmin}=0.001$; $\mathrm{Pmax}=0.1$; steps=20; relative gap

196 width=1.0, also based on K2P model. This method statistically infers the DNA barcode gap in a

197 single locus alignment, partitioning the data based on this gap in putative species (Puillandre et

198 al., 2012).

199 The GMYC analysis (Pons et al., 2006; Fujisawa \& Barraclough, 2013) was performed in

200 R (R Development Core Team 2010) using the SPLITS package (Ezard et al., 2009) with single-

201 threshold method. Basically, the method estimates branching patterns on an ultrametric tree,

202 identifying the most likely transition point from coalescent to speciation branching. The

203 ultrametric tree used here was obtained with BEAST v. 1.8 (Drummond et al., 2012) under a

204 relaxed uncorrelated molecular clock (Drummond et al., 2006). The node including Ochrotrichia

205 species was calibrated based on fossil evidence with a lognormal distribution offset at 20 mya

206 and $\log ($ mean $)=2.8$ to represent the possible range of 20-140 mya (Wells \& Wichard, 1989); and

207 the divergence of Ochrotrichiinae was calibrated based on Malm et al. (2013) with a normal

208 distribution with mean $82.17 \pm 12$ mya. The BEAST analysis ran for $200,000,000$ generations,

209 sampled every 10,000 generations. Convergence was verified with Tracer and a maximum

210 credibility tree was written using TreeAnotator, discarding the first $10 \%$ as burnin.

\section{RESULTS}

212 NJ (Fig. 2) and BI (Supp. 4) trees corroborated morphological identification, with all 14

213 species of Metrichia with more than a single specimen recovered as monophyletic lineages with 
$214100 \%$ bootstrap support. ABGD also returned the same species as they were previously delimited

215 based on morphological features. A robust 'barcoding gap' was found among Metrichia species

216 (Fig. 3, Table 2). The maximum intraspecific divergence was observed within Metrichia vulgaris

217 sp. nov. (0.048). The minimum interspecific divergence was found between specimens of

218 Metrichia talhada sp. nov. and Metrichia tere sp. nov. (0.126).

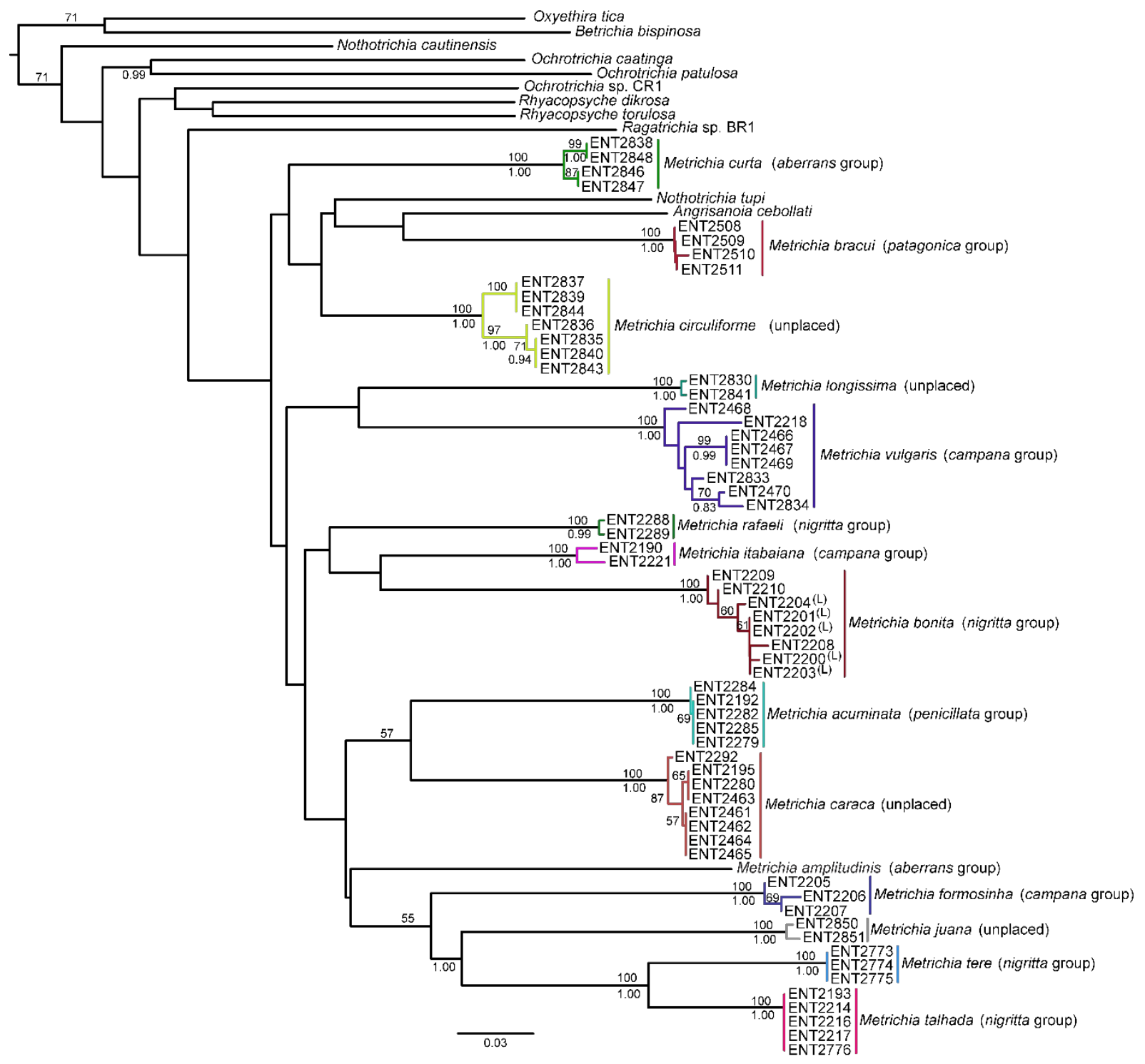

219 Figure 2. Neighbor-joining tree of COI sequences of Metrichia species based on K2P distances.

220 Numbers above and below branches are, respectively, NJ bootstrap support and posterior 
221 probabilities from BI analysis. Details of specimens are in Tables 1 and 2; K2P distances matrix 222 is in Supp. 5.

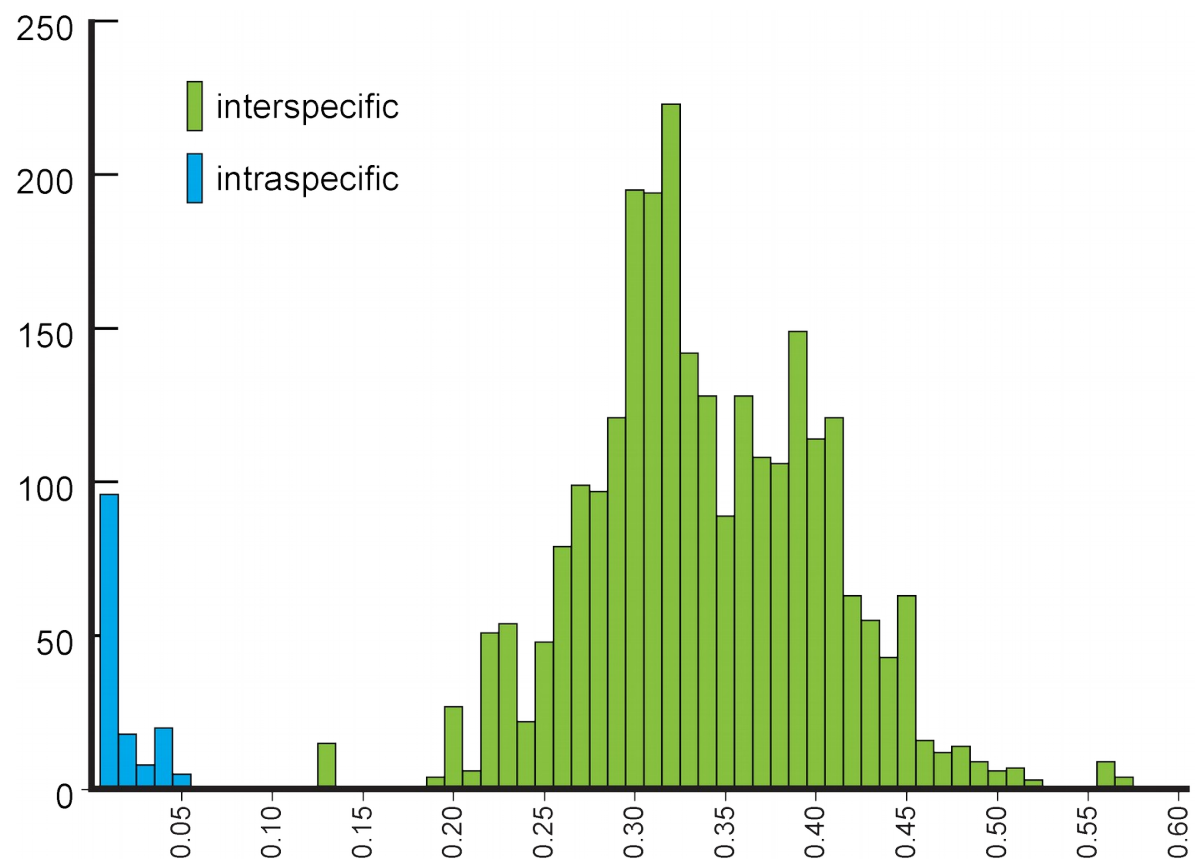

223 Figure 3. Histogram of the number of pairwise comparisons of intra- (blue) and interspecific

224 (green) K2P divergences among 15 Metrichia species with COI sequences sampled.

225 Table 2. Maximum intra- and minimum interspecific K2P divergences of COI sequences among 226 and within Metrichia species.

\begin{tabular}{llll}
\hline Species & $\begin{array}{l}\text { Number of } \\
\text { sequences }\end{array}$ & $\begin{array}{l}\text { Max. intra. } \\
\text { distance }\end{array}$ & $\begin{array}{l}\text { Min. inter. } \\
\text { Distance }\end{array}$ \\
\hline $\begin{array}{l}\text { M. acuminata } \text { sp. nov. } \\
\text { M. amplitudinis Bueno- }\end{array}$ & 5 & 0.000 & 0.217 \\
Soria \& Holzenthal, 2003 & 1 & - & 0.220 \\
M. bonita sp. nov. & 8 & 0.015 & 0.210 \\
M. bracui sp. nov. & 4 & 0.004 & 0.214 \\
M. caraca sp. nov. & 8 & 0.011 & 0.217 \\
M. circuliforme sp. nov. & 7 & 0.035 & 0.184 \\
M. curta sp. nov. & 4 & 0.015 & 0.184 \\
M. formosinha sp. nov. & 3 & 0.008 & 0.249 \\
M. itabaiana sp. nov. & 2 & 0.019 & 0.194 \\
M. juana (Flint, 1964) & 2 & 0.007 & 0.243
\end{tabular}




$\begin{array}{llll}\text { M. longissima } \text { sp. nov. } & 2 & 0.004 & 0.215 \\ \text { M. rafaeli } \text { sp. nov. } & 2 & 0.004 & 0.194 \\ \text { M. talhada } \text { sp. nov. } & 5 & 0.000 & 0.126 \\ \text { M. tere } \text { sp. nov. } & 3 & 0.000 & 0.126 \\ \text { M. } \text { vulgaris sp. nov. } & 8 & 0.048 & 0.246\end{array}$

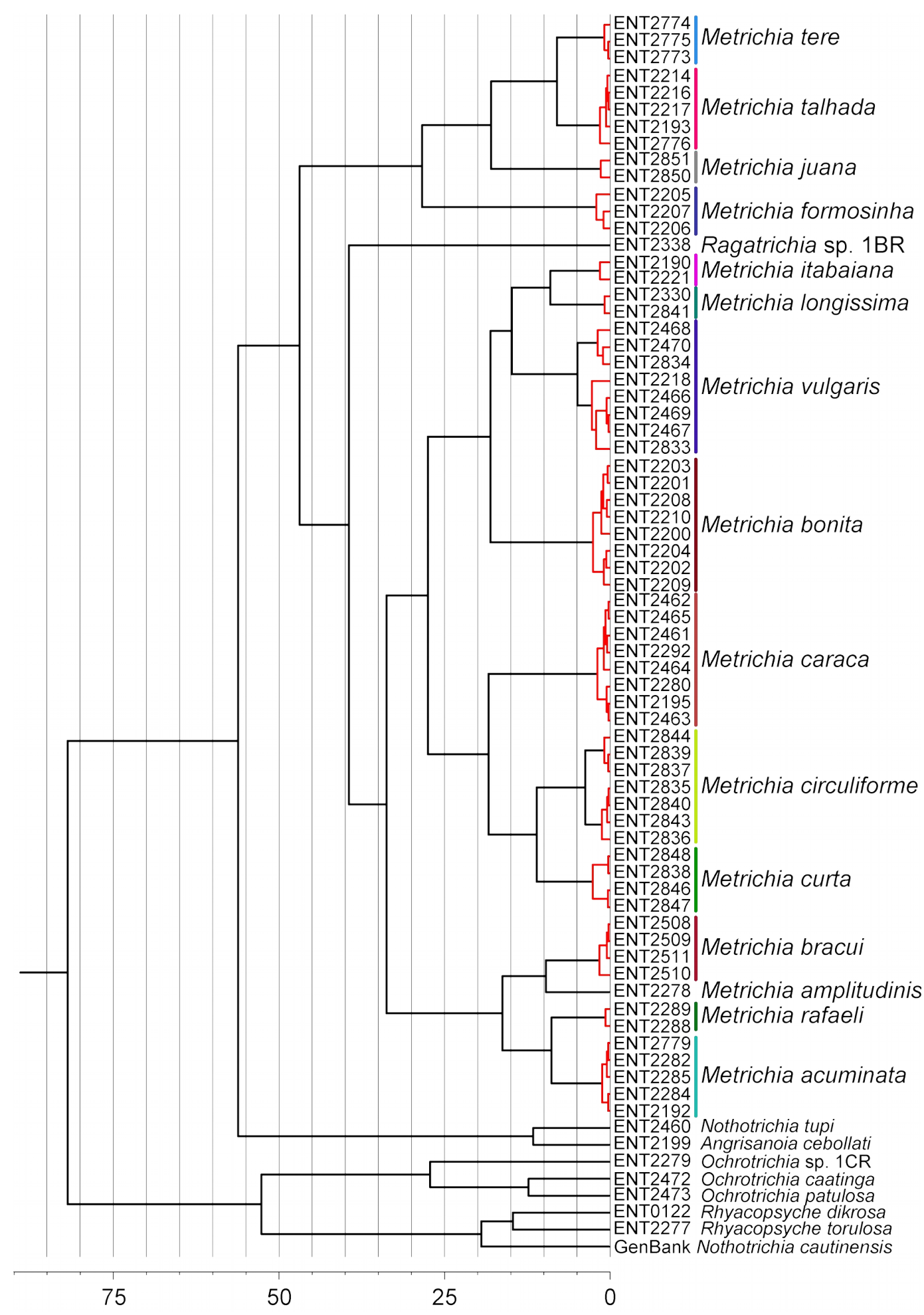


227 Figure 4. Maximum credibility time tree from the BEAST analysis based on COI sequences of

228 Metrichia and other Ochrotrichiinae. Red branches represent species estimated by GMYC using 229 single threshold in SPLITS. Timescale in millions of years.

230 GMYC analysis estimated a slightly higher number of putative species, with Metrichia

231 circuliforme sp. nov. and Metrichia vulgaris $\mathbf{s p . ~ n o v . ~ b e i n g ~ e a c h ~ f u r t h e r ~ d i v i d e d ~ i n t o ~ t w o ~ s p e c i e s ~}$

232 (Fig. 4). Regarding all other species, GMYC results were congruent with other methods and with 233 morphology.

234 In all analyses performed using DNA barcode, Metrichia larvae collected in calcareous 235 tufa were consistently associated with adult males of Metrichia bonita sp. nov. Therefore, in the 236 following section, we describe these larvae within that species.

\section{SPECIES DESCRIPTIONS}

238 Metrichia acuminata sp. nov.

239 urn:1sid:zoobank.org:act:01493211-CD39-4995-B2D7-8F3B44A0970E

240 (Fig. 5, Fig. 26A)

241 Adult male. Length 2.1-2.5 mm ( $\mathrm{n}=5)$. General color, in alcohol, brown. Head with no 242 modifications. Ocelli 3. Antenna simple, 18-articulated. Maxillary palpus 5-articulated; labial 243 palpus 3-articulated. Mesoscutellum with transverse suture. Metascutellum subtriangular.

244 Anterior femur without processes. Tibial spur formula 1-3-4. Wing venation reduced in both 245 wings. Abdominal segment IV with pair of internal pouches in posterior area; segment V with 246 pair of internal pouches; segment VI with tergum as a sclerotized rounded plate, surrounded by 247 long setae (Fig. 26A); segment VII bearing a brush of very long setae dorsolateraly (Fig. 26A). 248 Ventromesal process on segment VII present. Segment VIII shorter ventrally than dorsally and 249 bearing a brush of long setae dorsally. Male genitalia. Segment IX reduced dorsally; sternum 250 subrectangular, with anterior margin rounded (Fig. 5A); in lateral view narrower anteriorly than 
251 posteriorly (Fig. 5C). Inferior appendage covered by long setae; subtrapezoidal in ventral view

252 (Fig. 5A); in lateral view, subtrapezoidal, apex with acute corners (Fig. 5C). Dorsal hook short, 253 almost half length of inferior appendage; in lateral view, downturned (Fig. 5C). Preanal

254 appendage rounded in lateral view and bearing very long setae (Fig. 5C). Subgenital plate

255 apparently absent. Tergum X membranous and truncate (Fig. 5B). Phallus tubular, elongate and

256 slender, slightly constricted mesally, with two curved subapical spines, one short and another

257 long; apex truncate and sclerotized; ejaculatory duct sclerotized, sinuous, and protruding apically 258 (Fig. 5D).

259 Holotype. BRAZIL: Ceará: Ubajara, Parque Nacional de Ubajara, Cachoeira do Gameleira, 260 0350'21"S 4054'23"W, el. 880 m, 23.iv.2012, DM Takiya \& JA Rafael cols., light trap, male 261 (CZMA).

262 Paratypes. Same data as holotype, except, Rio das Minas, 0350’03”S 4054'18”W, el. 524 m, 263 13-17.ix.2012, JA Rafael et al., Malaise trap, 2 males (INPA); same data, except 14-16.ii.2013, 264 DM Takiya, JA Rafael, RR Cavichioli \& APM Santos, Malaise trap, 2 males (DZRJ). Alagoas: 265 Quebrangulo, Reserva Biológica de Pedra Talhada, Rio Caranguejo, 09¹5’26”S 36²5’08”W, el. 266550 m, 19-28.vi.2014, APM Santos, DM Takiya, WRM Souza, Malaise trap, 2 males (MNRJ), 3 267 males (MZUFBA), 13 males (DZRJ).

268 Etymology. The species is named in allusion to the pointed apices of inferior appendages (from 269 Latin, "acumin-" = "pointed").

270 Remarks. This new species belongs to the penicillata group based on: (1) internal pouches

271 between abdominal segments IV and V; (2) setal brushes on segments V, VI, and VII; and (3) 272 phallus with two subapical spines. The male genitalia and complex abdominal modifications 273 resemble $M$. penicillata (Flint, 1972) and M. trigonella (Flint, 1972). These three species have 274 inferior appendages with acute apices in lateral view; phallus with two subapical spines; and 275 abdominal terga with brushes of very long and stout setae. The new species can be distinguished 
276 by inferior appendages more trapezoidal in lateral view, with acute corners posteriorly and dorsal

277 hook only slightly downturned in lateral view; and phallus with one larger and stouter subapical 278 spine. Although the male genitalia of this new species superficially resemble that of M. bonita $\mathbf{s p .}$ 279 nov., M. acuminata sp. nov. is readily recognized by setose lobes on abdominal segments $\mathrm{V}$ and 280 VI.

281 We were not able to obtain COI sequences for individuals from Ceará State, so the five 282 sequences analyzed belong to specimens from Alagoas State, which shared the same haplotype. 283 Metrichia acuminata sp. nov. was recovered as closely related to M. caraca sp. nov. (Fig. 2), but 284 in both Bayesian approaches these two species were not recovered as sister taxa (Fig. 4, Supp. 1). 


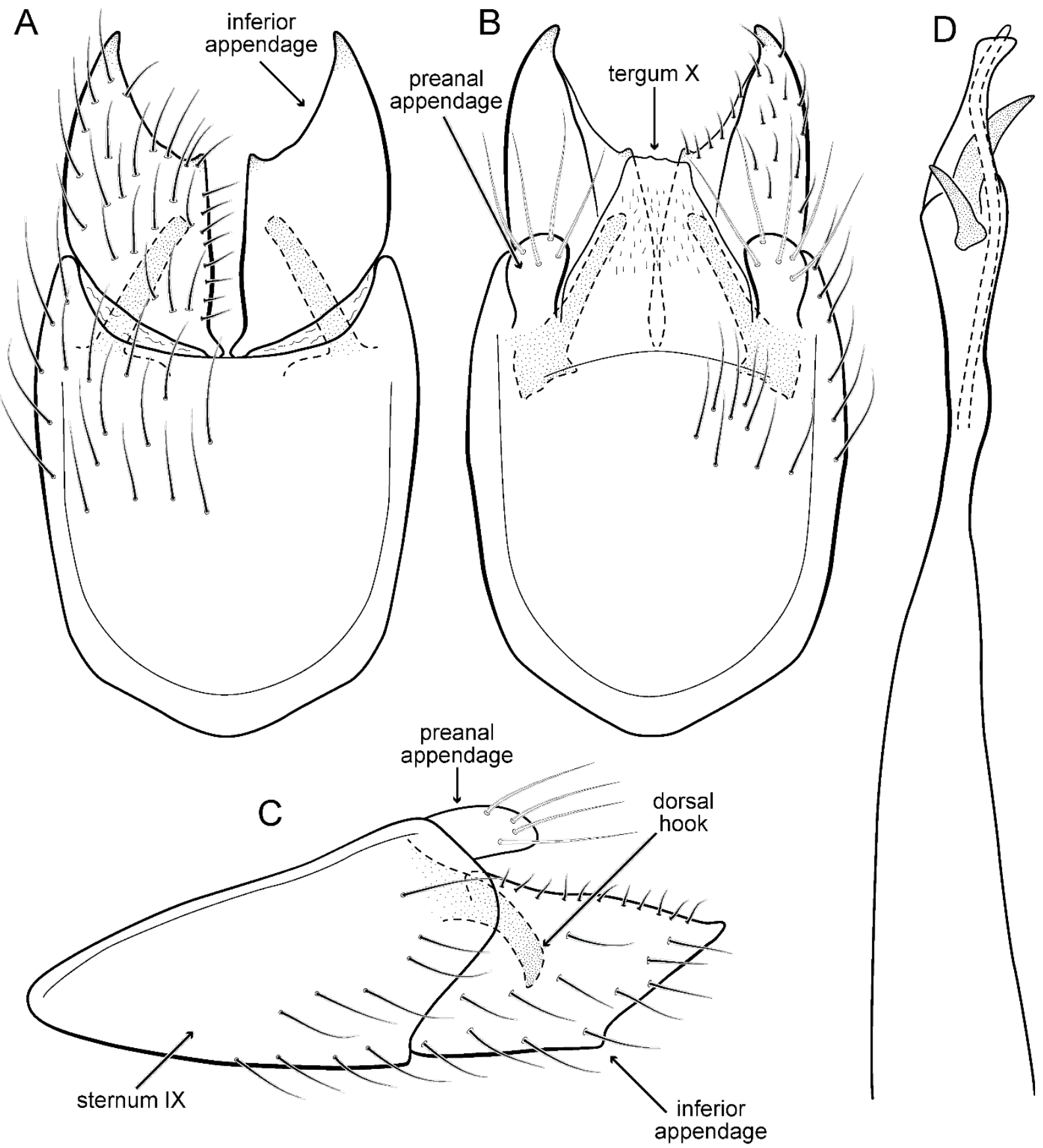

285 Figure 5. Metrichia acuminata sp. nov., male genitalia: (A) ventral view; (B) dorsal view; (C) 286 lateral view; (D) phallus, dorsal view.

288 urn:Isid:zoobank.org:act:E38ACAE9-61DC-4B61-A20D-1879520E1DD3

289 (Fig. 6) 
290 Adult male. Length 2.0-2.1 mm (n=4). General color, in alcohol, brown. Head with no

291 modifications. Ocelli 3. Maxillary palpus 5-articulated, article IV broad and darkened; labial 292 palpus 3-articulated. Mesoscutellum with transverse suture. Metascutellum subtriangular.

293 Anterior femur without processes. Tibial spur formula 1-3-4. Wing venation reduced in both 294 wings. Abdominal segment V with pair of internal pouches; segment VI with pair of internal 295 pouches and pair of lateral external sacs with specialized setae. Ventromesal process on segment 296 VII present. Segment VIII shorter ventrally than dorsally. Male genitalia. Segment IX reduced 297 dorsally; sternum subrectangular (Fig. 6A); in lateral view narrower anteriorly than posteriorly 298 (Fig. 6C). Inferior appendage covered by long setae and with scale-like setae; subrectangular in 299 ventral view (Fig. 6A); in lateral view, rounded, apex rounded (Fig. 6C). Dorsal hook long, more 300 than half length of inferior appendage; in lateral view, slightly downturned (Fig. 6C). Preanal 301 appendage elongate, but shorter than inferior appendage, and bearing very long setae (Fig. 6B). 302 Subgenital plate apparently absent. Tergum X membranous and subrectangular (Fig. 6B). Phallus 303 tubular, elongate and slender, slightly constricted mesally, with two long, curved, subapical 304 spines; apex rounded and sclerotized; ejaculatory duct sclerotized, sinuous, and protruding 305 apically (Fig. 6D).

306 Holotype. BRAZIL: Paraná: Céu Azul, Parque Nacional do Iguaçu, Rio Azul, 2509’21’S 307 5347’44’'W, el. 510 m, 6-8 ix.2012, APM Santos, DM Takiya, ALH Oliveira, GA Jardim \& 308 BHL Sampaio cols., Malaise trap, male (DZRJ).

309 Paratypes. Same data as holotype, 2 males (DZRJ), 1 male (MNRJ).

310 Etymology. The specific name refers to the type locality, Rio Azul in the municipality of Céu 311 Azul. 
A

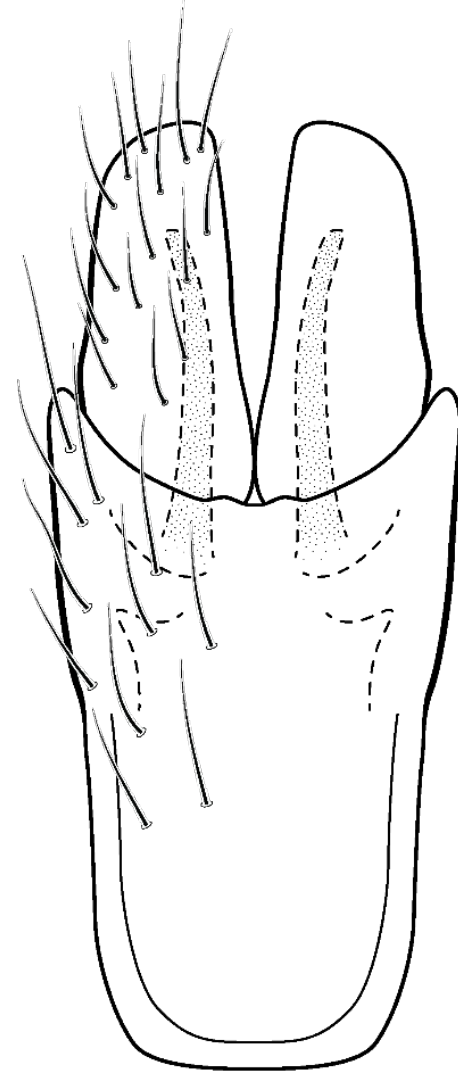

B

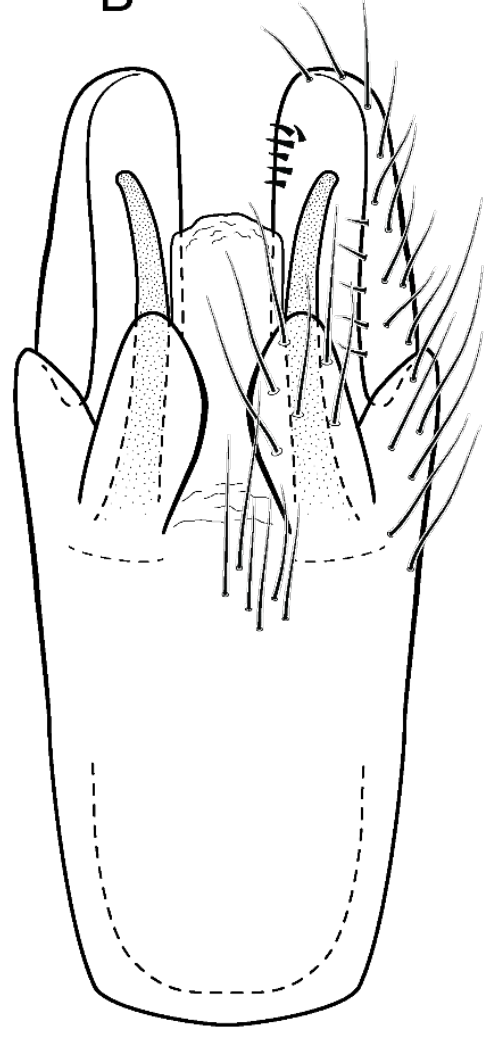

D

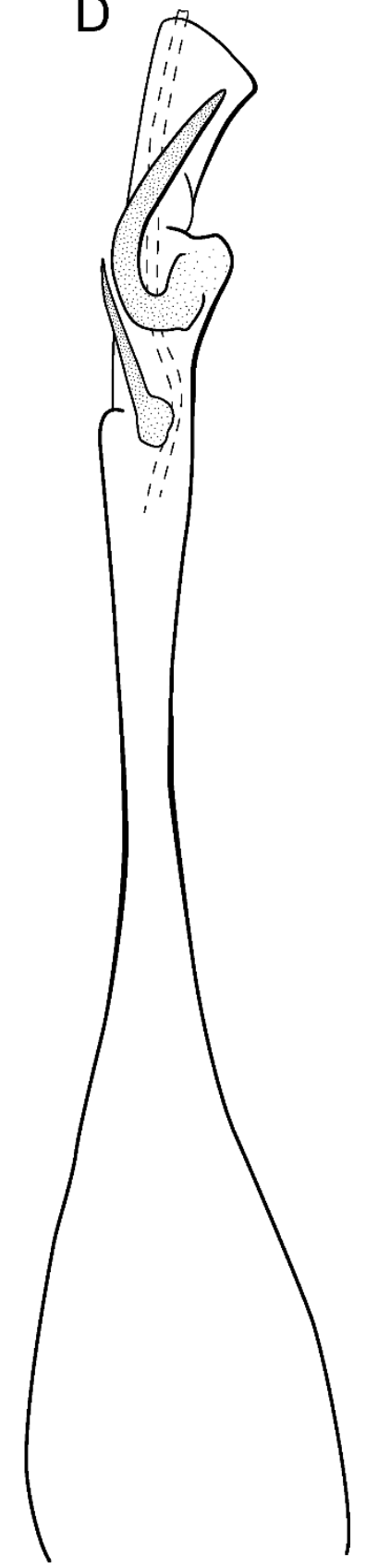

312 313

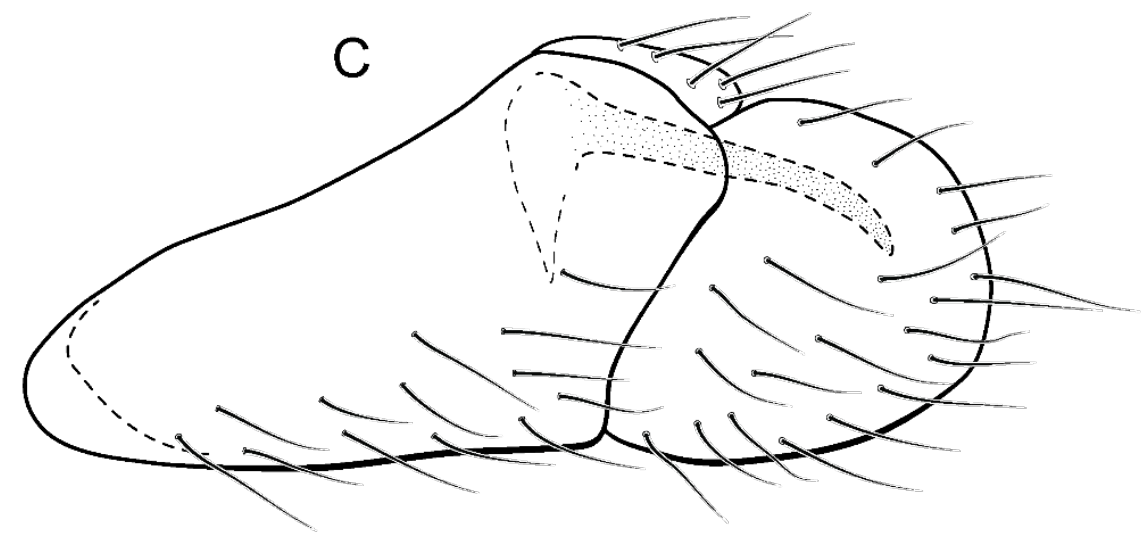

Figure 6. Metrichia azul sp. nov., male genitalia: (A) ventral view; (B) dorsal view; (C) lateral view; (D) phallus, dorsal view.

Remarks. This new species is another member of the penicillata group based on internal pouches between segment $\mathrm{V}$ and VI and the long subapical spines of the phallus. The new species shares similarities of the male genitalia with M. biungulata (Flint, 1972) and M. decora Bueno-Soria \& 
317 Holzenthal, 2003 particularly the rounded aspect of inferior appendages, but can be easily

318 distinguished from those species by the absence of tooth-like processes on inferior appendages;

319 more elongate preanal appendages; and dorsal hook only slightly downturned in lateral view.

320 Metrichia bonita sp. nov.

urn:lsid:zoobank.org:act:622BCD51-CC39-4D1F-BDCB-84A7DFF4F071

322 (Fig. 7, Fig. 8)

323 Adult male. Length 2.3-2.5 mm (n=4). General color, in alcohol, brown. Head with no

324 modifications. Ocelli 3. Antenna simple, 21-articulated. Maxillary palpus 5-articulated; labial

325 palpus 3-articulated. Mesoscutellum with transverse suture. Metascutellum subtriangular.

326 Anterior femur without processes. Tibial spur formula 1-3-4. Wing venation reduced in both

327 wings. Abdominal segment VI with dorsal pouches covered with setae directed inward.

328 Ventromesal process on segment VII absent. Segment VIII shorter ventrally than dorsally. Male

329 genitalia. Segment IX reduced dorsally; sternum subrectangular, with anterior margin rounded

330 (Fig. 7A); in lateral view narrower anteriorly than posteriorly (Fig. 7C). Inferior appendage

331 covered by long setae, subtrapezoidal in ventral view (Fig. 7A); in lateral view, with an acute

332 projection, apex with acute corners (Fig. 7C). Dorsal hook short, almost half length of inferior

333 appendage; in lateral view, slightly downturned (Fig. 7C). Preanal appendage short, rounded and

334 bearing very long setae (Fig. 7B). Subgenital plate apparently absent. Tergum X membranous and

335 with a shallow U-shaped incision (Fig. 7B). Phallus tubular, elongate and slender, slightly

336 constricted mesally, with a median process; with two curved subapical spines, one short and

337 another long; apex truncate and sclerotized; ejaculatory duct sclerotized and not protruding

338 apically (Fig. 7D).

339 Larva $\left(5^{\text {th }}\right.$ instar $)$. Length $1.5-1.9 \mathrm{~mm}(\mathrm{n}=10)$. Head dark brown, unpigmented around stemmata

340 (Fig. 8C); slightly longer than broad; frontoclypeal and coronal sulci indistinct; with a few long 
341 setae (Fig. 7F). Antenna short, apparently 2-articulated and with no apical setae (Fig. 7F).

342 Labrum with pair of stout setae (Fig. 7F). Mandibles with inner margin sinuous and darkened.

343 Thoracic nota sclerotized, dark brown, with a row of stout setae on anterior margin. Pro-, meso-,

344 and metanotum with middorsal ecdysial line. Thoracic segments with small pleurites (Fig. 7E).

345 Thoracic legs brown, short and stout, almost the same size of each other. Foreleg with stout setae;

346 tibia with a posteroventral lobe with a spine-like seta (Fig. 7G); femur bearing a spine-like setae;

347 tarsal claw simple. Mid- and hind legs with stout setae on posteroventral margin. Abdomen

348 almost white, with dark brown sclerites. Abdominal segment I with ellipsoid tergite; segments I-

$349 \mathrm{~V}$ with pair of long, dorsal setae and pair of dorsolateral setae; segment VI with two pairs of long 350 dorsal setae and two pairs of dorsolateral setae; segments VII and VIII with three pairs of dorsal,

351 long setae and two pair of dorsolateral setae; segment IX with sclerotized tergite and several long 352 setae. Abdominal segments I, III, IV, and IX with pair of ventral, long setae; segment II with two 353 pairs of ventral, long setae and globose process on ventrolateral area (Fig. 7E). Anal proleg very 354 short not projecting prominently; with basal sclerite bearing long setae; anal claw simple.

355 Larval case. Length $1.5-2.0 \mathrm{~mm}(\mathrm{n}=10)$. General color white (Figs. 8B, 8C). Constructed with 356 calcareous particles (with no algal filaments added), forming two rigid and lateral valves, poorly 357 closed dorsally and ventrally (Fig. 8C). External surface rugose.

358 Biology. Larvae were collected on calcareous tufa in a fast flowing river, approximately 10 359 meters wide (Fig. 8A). No pupae were found and adults were not seen active during the day. 


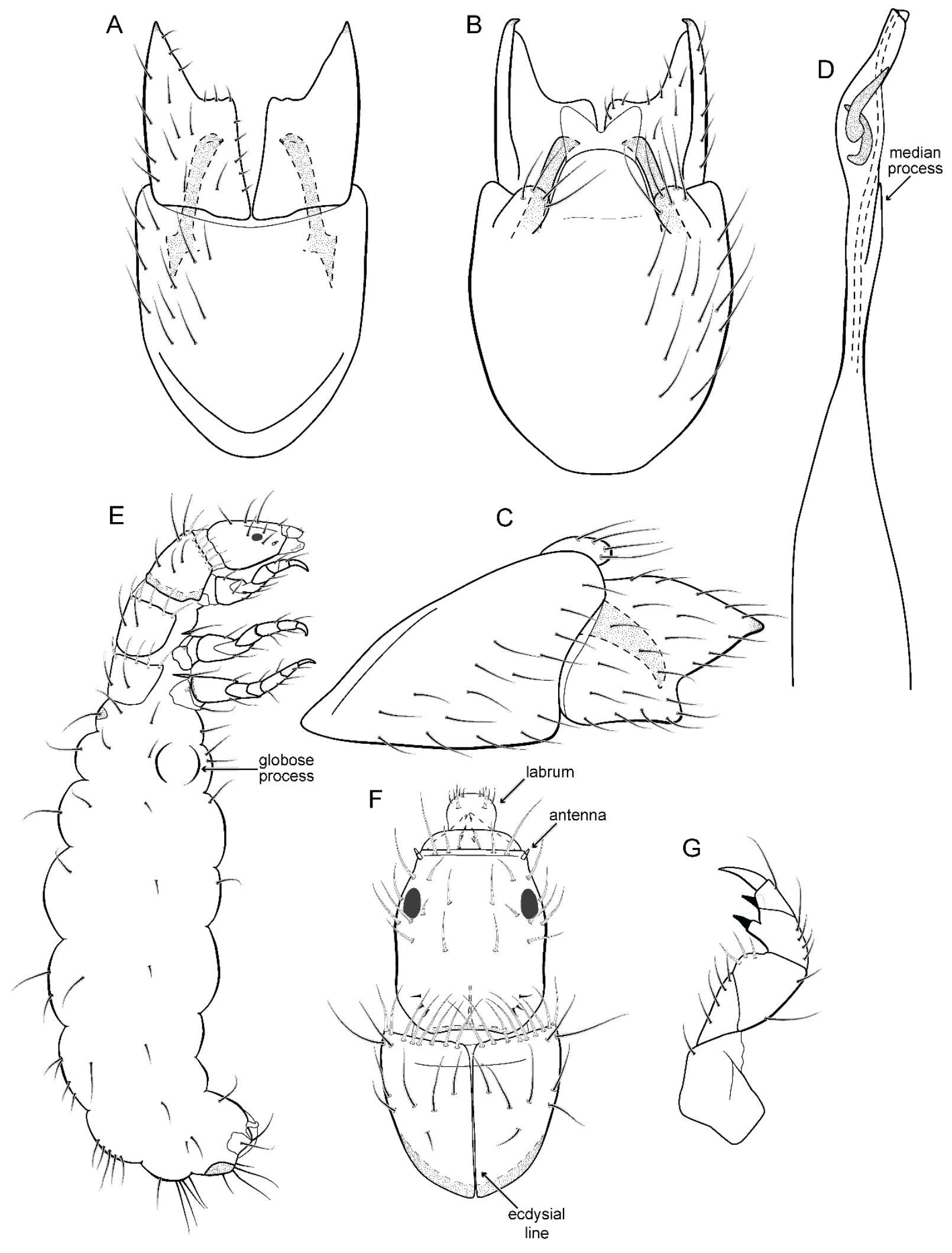


360 Figure 7. Metrichia bonita sp. nov.: (A) male genitalia, ventral view; (B) male genitalia, dorsal

361 view; (C) male genitalia, lateral view; (D) phallus, dorsal view; (E) larva, habitus, lateral view;

362 (F) larva, head and pronotum, dorsal view; (G) larva, foreleg, ventral view.

363 Holotype. BRAZIL: Mato Grosso do Sul: Bonito, Rio Formosinho, 21¹0’16”S 56²6’47'W

364 el. 275 m, 08-13.ix.2013, APM Santos \& DM Takiya cols., Malaise trap, male (DZRJ).

365 Paratypes. Same data as holotype, 3 males (DZRJ), 1 male (MNRJ).

366 Additional material. Same data as holotype, except 13.ix.2013, manual, 10 larvae (DZRJ), 10

367 larvae (MNRJ).

368 Etymology. This species is named in reference to the type locality (Fig. 8), the municipality of

369 Bonito in the state of Mato Grosso do Sul. In Portuguese, the word "bonita" (the feminine form)

370 means "beautiful".

371 Remarks. Metrichia bonita sp. nov. has features of the nigritta group: internal pouches between

372 segment V-VI and phallus with 2 spines and an acute process on distal portion. This new species

373 can be easily distinguished from other species in this group based on the shape of inferior

374 appendages, subtrapezoidal in ventral view, with dorsal corners acute and darkened. In addition,

375 inferior appendages have dorsal hooks, which are broad basally and slightly downturned in lateral

376 view. COI sequences showed maximum intraspecific distance of $1.5 \%$ and minimum interspecific

377 distance of $21.0 \%$ to its closest neighbor, $M$. itabaiana sp. nov. Although the male genitalia of

378 both species show some superficial resemblance, based on the abdominal modifications and

379 phallic aspect, $M$. bonita sp. nov. belongs to the nigritta group, whereas $M$. itabaiana fits better

380 in the campana group.

Larvae of Metrichia bonita sp. nov. are very similar to those previously described or

illustrated, including M. nigritta, M. juana, and unassociated larvae illustrated by Botosaneanu \&

383 Flint (1982) from Venezuela and Ecuador; and by Pes et al. (2005) from Brazil. Actually, main 
384 differences seem to be the shape and the material of larval cases. In this respect, larvae of

385 Metrichia bonita sp. nov. are unusual and easily recognized by having their case made entirely of 386 calcareous particles, without typical algal elements (Fig. 8). 


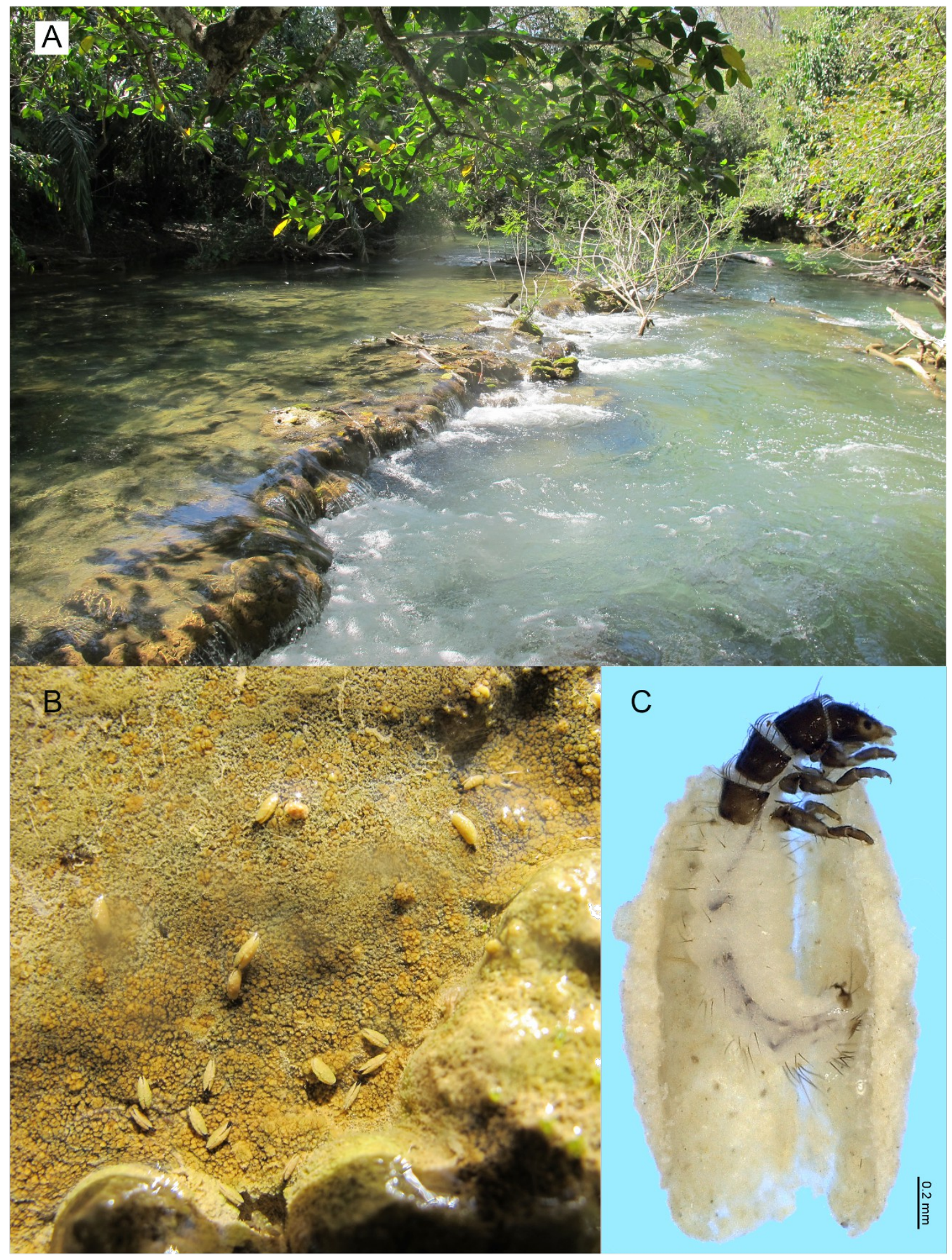

387 Figure 8. Metrichia bonita sp. nov., larva: (A) type locality, Rio Formosinho, Bonito

388 municipality, Mato Grosso do Sul, Brazil; (B) larvae on calcareous substrate; (C) larva and its calcareous case. 
Paprocki et al. (2003) discussed the role of Smicridea travertinera Paprocki, Holzenthal

$391 \&$ Cressa, 2003 in calcareous tufa formation (travertine). According to these authors, larvae of

392 that species interfere in the deposition and erosion of the calcareous substrate by their net-

393 building activities (Paprocki et al., 2003). Cyanobacteria and diatoms are known to participate in

394 travertine formation, but the role played by macroinvertebrates is poorly understood (Drysdale,

395 1998; 1999). It is possible that cases of Metrichia bonita sp. nov. are impregnated passively with

396 calcareous particles, but as commented by Drysdale (1999) for other aquatic insects, they could

397 be important in travertine biogenesis by producing new nucleation sites or eroding other ones.

398 Metrichia bonita sp. nov. is the only microcaddisfly known to inhabit (Fig. 8) and build cases

399 with calcareous tufa so far.

\section{Metrichia bracui sp. nov.}

401 urn:1sid:zoobank.org:act:07B44840-CAB0-4BBE-BD01-B62E885BE418

402 (Fig. 9)

403 Adult male. Length 1.8-2.2 mm (n=3). General color, in alcohol, light brown. Head with no

404 modifications. Ocelli 3. Antenna simple, 18-articulated. Maxillary palpus 5-articulated; labial

405 palpus 3-articulated. Mesoscutellum with transverse suture. Metascutellum subtriangular.

406 Anterior femur without processes. Tibial spur formula 1-3-4. Wing venation reduced in both

407 wings. Abdomen without modifications. Ventromesal process on segment VII absent. Segment

408 VIII shorter ventrally than dorsally. Male genitalia. Segment IX reduced dorsally; sternum

409 subpentagonal in ventral view (Fig. 9A); in lateral view narrower anteriorly than posteriorly (Fig.

410 9C). Inferior appendage covered by long setae and with scale-like setae, subrectangular in ventral

411 view (Fig. 9A); in lateral view, rounded, apex rounded (Fig. 9C). Dorsal hook long, more than

412 half length of inferior appendage; in lateral view, downturned (Fig. 9C). Preanal appendage 
413 elongate and bearing very long setae (Fig. 9B). Subgenital plate apparently absent. Tergum X

414 membranous and with shallow U-shaped incision (Fig. 9B). Phallus tubular, elongate and slender,

415 slightly constricted mesally; without spines, but with a sclerotized process arising from a

416 subapical constriction; apex rounded and folded; ejaculatory duct sclerotized, straight and not

417 protruding apically (Fig. 9D).

418 Holotype. BRAZIL: Rio de Janeiro: Angra dos Reis, Rio Bracuí, 2300'23’S 44²9'15’W, el.

41975 m, 10-11.v.2002, JL Nessimian col., light trap, male (DZRJ).

420 Paratypes. Same data as holotype, 2 males (MNRJ). Rio de Janeiro: Parque Nacional do

421 Itatiaia, Córrego do Maromba, 22²5’32”S 44³7’03”W, el. 1250 m, 04.iv.15, APM Santos \& DM

422 Takiya cols., Malaise trap, 4 males (DZRJ).

423 Etymology. The species is named in allusion to the river where the holotype was collected.

424 Remarks. This new species can be assigned to the patagonica group because of the absence of 425 curved spines of the phallus. The general aspect of the male genitalia resembles $M$. patagonica

426 (Flint, 1983), M. pernambucana, and M. pseudopatagonica Bueno-Soria \& Holzenthal, 2003.

427 Metrichia bracui sp. nov. differs from these species and others in the group specially by the

428 phallus bearing a sclerotized process on a constricted region.

429 The four COI sequences generated for M. bracui sp. nov. were from specimens collected

430 in a locality at Parque Nacional do Itatiaia, Rio de Janeiro, Brazil. The highest pairwise

431 intraspecific divergence between sequences was $0.4 \%$, and the lowest interspecific divergence

432 was 21.4\% between M. bracui sp. nov. and Angrisanoia cebollati (Angrisano, 1995). Until now,

433 there have been no formal studies on the relationships among species or genera included in

434 Ochrotrichiinae. However, to infer phylogenetic hypothesis for the entire subfamily is beyond the

435 scope of this work, and also much more data and taxa sampling are necessary to generate robust

436 hypotheses. 

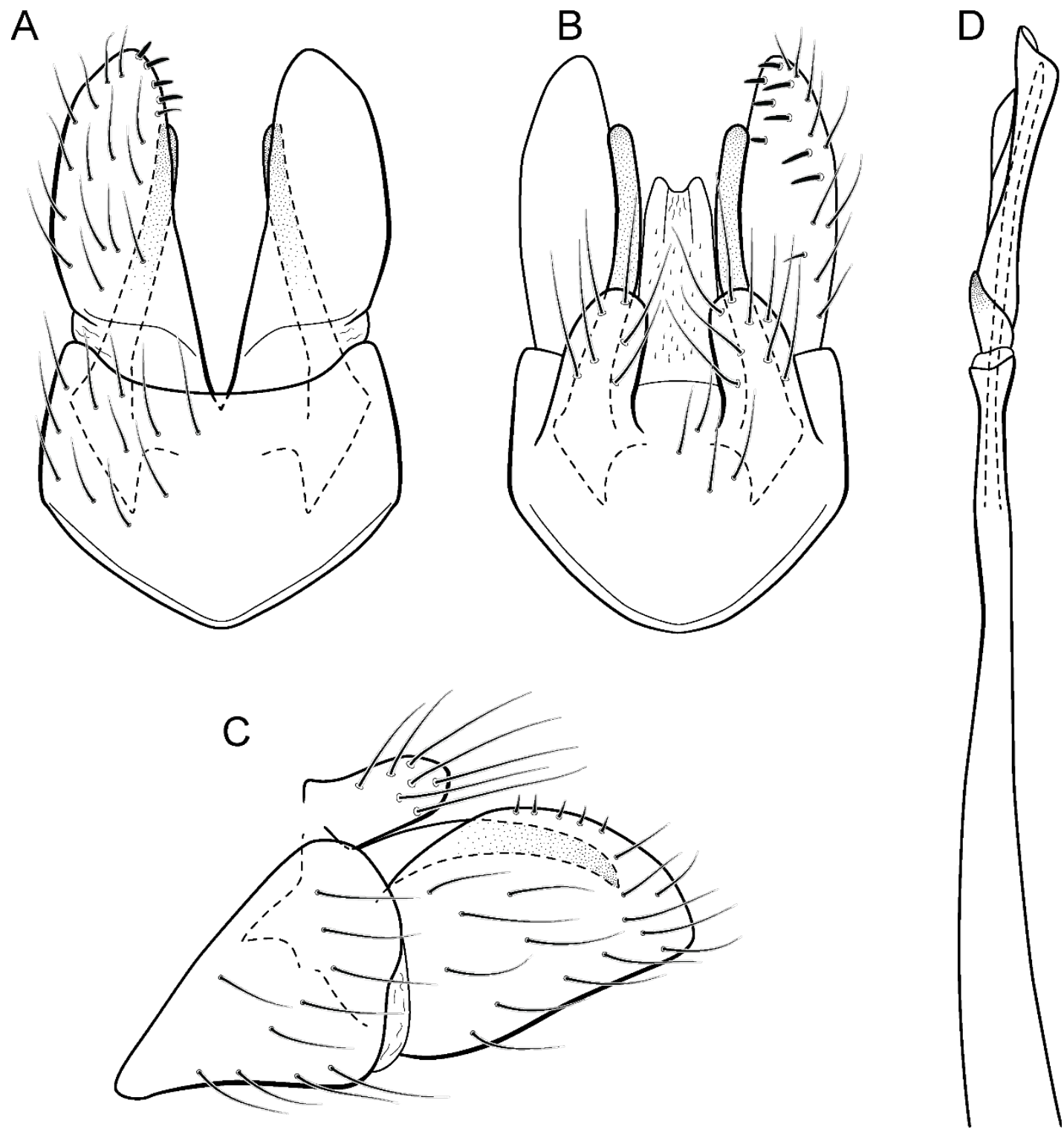

Figure 9. Metrichia bracui sp. nov., male genitalia: (A) ventral view; (B) dorsal view; (C) lateral

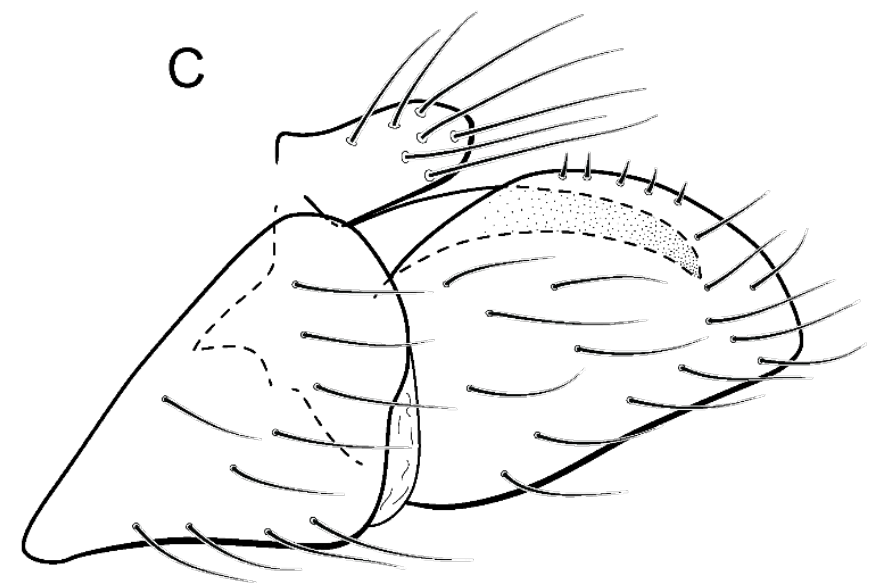

view; (D) phallus, dorsal view.

440 urn:1sid:zoobank.org:act:34F912BC-1069-433E-AF16-A1B19D7FA622

441 (Fig. 10)

Adult male. Length 2.5-3.0 mm ( $\mathrm{n}=7)$. General color, in alcohol, brown. Head with no

443 modifications. Ocelli 3. Antenna simple, 18-articulated. Maxillary palpus 5-articulated; labial 
444 palpus 3-articulated. Mesoscutellum with transverse suture. Metascutellum subtriangular.

445 Anterior femur without processes. Tibial spur formula 1-3-4. Wing venation reduced in both

446 wings. Abdominal segment VI bearing brush of very long setae dorsolateraly; segment VII

447 bearing brush of very long setae dorsolateraly. Ventromesal process on segment VII absent.

448 Segment VIII shorter ventrally than dorsally and bearing brush of long setae dorsally. Male

449 genitalia. Segment IX reduced dorsally; sternum subrectangular, with anterior margin rounded

450 (Fig. 10A); in lateral view narrower anteriorly than posteriorly (Fig. 10C). Inferior appendage

451 covered by long setae, subtrapezoidal in ventral view (Fig. 10A), apex oblique and projected

452 mesad into a large process bearing a stout spine-like setae. Dorsal hook short and straight; in

453 lateral view, truncate and broader apically (Fig. 10C). Preanal appendage short, truncate and

454 bearing very long setae (Fig. 10B). Subgenital plate apparently absent. Tergum X membranous

455 and truncate (Fig. 10B). Phallus tubular, elongate and slender, slightly constricted mesally; with

456 two curved subapical spines, one short and another long; apex emarginate; ejaculatory duct

457 sclerotized and not protruding apically (Fig. 10D).

458 Holotype. BRAZIL: Minas Gerais: Catas Altas, RPPN Santuário do Caraça, Ribeirão Caraça,

459 11-13.vi.2013, ML Monné \& JP Botero cols., Malaise trap, male (DZRJ).

460 Paratypes. Same data as holotype, 3 male (DZRJ). Minas Gerais: São Roque de Minas, Parque

461 Nacional da Serra da Canastra, Fazenda Velha, Córrego dos Pombos, 20¹4'57'S 46³8'05’W, el.

462997 m, 02.iv.2014, JL Nessimian, ALH Oliveira, LL Dumas \& SP Gomes, light trap cols., 1 male

463 (MNRJ).

464 Etymology. This species is named in reference to the stream where type specimens were

465 collected.

466 Remarks. This new species has very distinctive male genitalia. Based on the dorsoapically

467 produced inferior appendages, it resembles M. lenophora (Flint, 1991). However, M. caraca sp. 
468 nov. is easily recognized by the obliquely truncate and mesad directed process of inferior

469 appendages and dorsal hook, in lateral view, with apex broad and truncate.

470

COI distances within this species reached only $1.1 \%$ and the lowest interspecific distance

471 (21.7\%) was found between specimens of M. caraca $\mathbf{s p . ~ n o v . ~ a n d ~ M . ~ a c u m i n a t a ~}$ sp. nov., which

472 are very distinct based on morphological features.
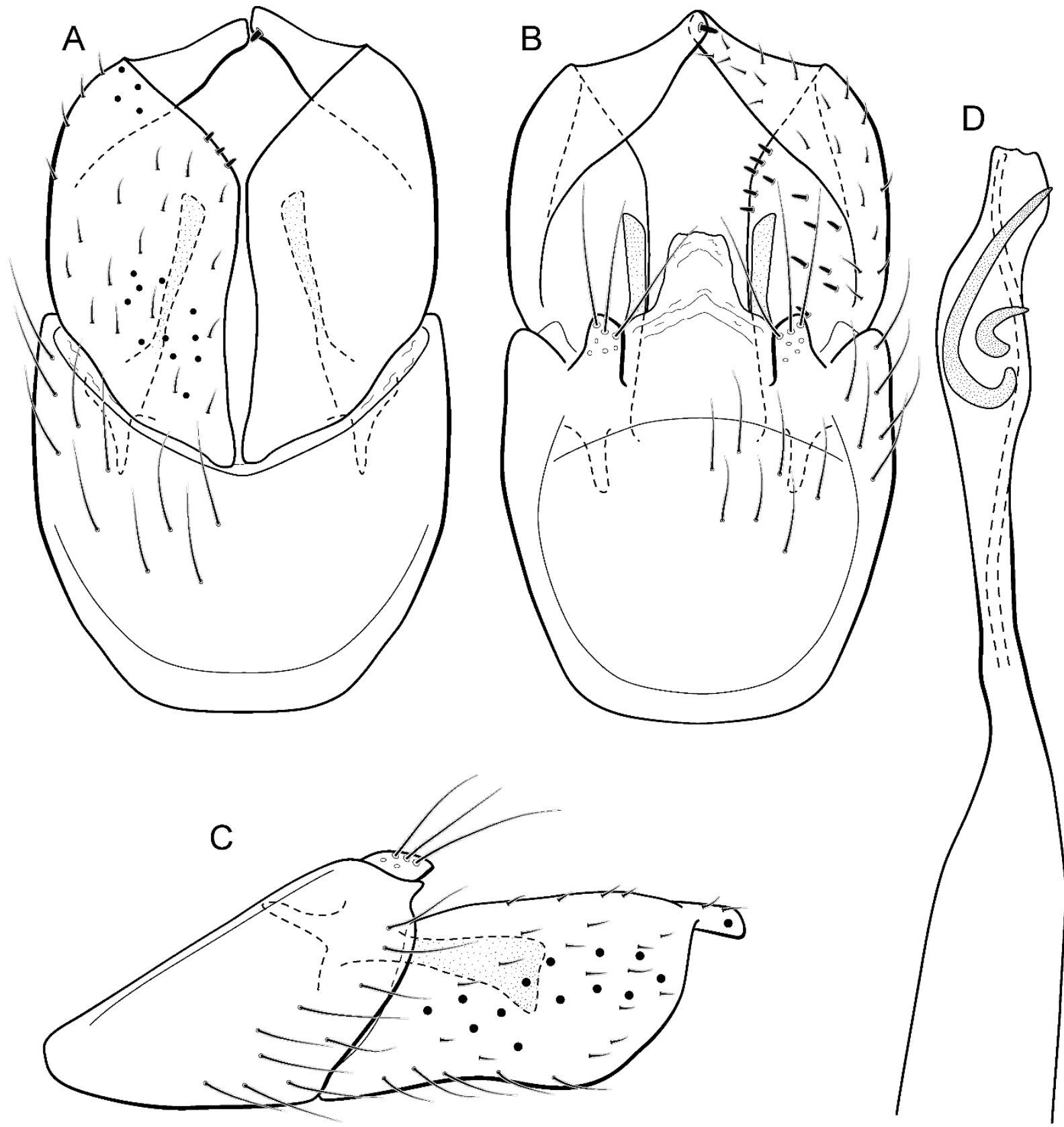
473 Figure 10. Metrichia caraca sp. nov., male genitalia: (A) ventral view; (B) dorsal view; (C)

474 lateral view; (D) phallus, dorsal view.

\section{Metrichia circuliforme sp. nov.}

476 urn:1sid:zoobank.org:act:E539EF55-F963-433C-BB25-C9177339ED54

477 (Fig. 11)

478 Adult male. Length 2.5-2.7 mm (n=4). General color, in alcohol, brown. Head with no

479 modifications. Ocelli 3. Antenna simple, 18-articulated. Maxillary palpus 5-articulated; labial

480 palpus 3-articulated. Mesoscutellum with transverse suture. Metascutellum subtriangular.

481 Anterior femur without processes. Tibial spur formula 1-3-4. Wing venation reduced in both

482 wings. Abdominal segment VI bearing brush of very long setae dorsolateraly; segment VII

483 bearing a brush of very long setae dorsolateraly. Ventromesal process on segment VII present.

484 Segment VIII shorter ventrally than dorsally. Male genitalia. Segment IX reduced dorsally;

485 sternum subpentagonal (Fig. 11A); in lateral view narrower anteriorly than posteriorly (Fig. 11C).

486 Inferior appendage short, covered by long setae, subrectangular in ventral view (Fig. 11A); in

487 lateral view, rounded (Fig. 11C), apex slightly truncate and bearing short spine-like setae. Dorsal

488 hook long, almost reaching the inferior appendage apex; in lateral view, downturned (Fig. 11C).

489 Preanal appendage elongate, but shorter than inferior appendage, and bearing very long setae

490 (Fig. 11B). Subgenital plate apparently absent. Tergum X membranous and truncate (Fig. 11B).

491 Phallus tubular, elongate and slender, slightly constricted mesally and with a median process;

492 with two short subapical spines; apex rounded and sclerotized; ejaculatory duct sclerotized,

493 straight and not protruding apically (Fig. 11D).

494 Holotype. BRAZIL: Rio de Janeiro: Itatiaia, Rio das Pedras, Cachoeira de Deus, $22^{\circ} 25^{\prime} 00^{\prime \prime} S$

495 44³2'50"W, el. 689 m, 06.iii.2008, JL Nessimian, LL Dumas \& MR de Souza cols., light trap,

496 male (DZRJ). 
497 Paratypes. Same data as holotype, except Rio das Pedras, 22²4’33’S 44³3'08’W, el. 706 m,

498 06.iii.2008, LL Dumas, JL Nessimian \& MR de Souza cols., light trap, 1 male (DZRJ), 1 male

499 (MNRJ); Parque Nacional do Itatiaia, Córrego Simon, 22²6’16”S 44³6’20”W, el. 1033 m,

500 15.iv.07, LL Dumas, APM Santos, N Ferreira-Jr. \& JL Nessimian cols., light trap, 1 male (DZRJ).

501 Etymology. The new species name is an allusion to the rounded and simple inferior appendages,

502 derived from the Latin, "circuli-" and "form" meaning "rounded shape".

503 Remarks. This species has simple male genitalia and abdomen with only brushes of long setae

504 on segments VI and VII. General aspect of the male genitalia is similar to M. riva (Bueno-Soria,

505 1983) and M. quadrata (Flint, 1972), particularly their inferior appendages short and

506 subrectangular and phallus with two subapical spines. However, M. circuliforme sp. nov. can be

507 easily distinguished from M. quadrata by the absence of internal sacs in the abdomen. It can be

508 distinguished from $M$. riva by the elongate preanal appendages and phallus with subequal hook

509 spines subapically.

510 We obtained seven COI sequences for $M$. circuliforme sp. nov. and although all of them

511 came from specimens collected at the same locality, intraspecific divergences were relatively

512 high, reaching 3.5\%. Besides that, GMYC estimated two species for these sequences instead of

513 one. Re-analysis of the morphology of these specimens did not reveal any conspicuous variation

514 that could justify splitting this species into two taxonomic groups. Compared to other studies

515 using DNA barcodes of caddisflies, this genetic distance is still low, for example Pauls et al.

516 (2010) found intraspecific divergences (K2P distance) up to 5.9\% for Chilean Smicridea. Zhou et

517 al. (2011) found even higher intraspecific distances among caddisflies, reaching up to 14\%.

518 GMYC is known to be more sensitive to geographic range coverage and/or other sampling

519 schemes, resulting in oversplitting (Lohse, 2009; Talavera et al., 2013). Therefore, we consider

520 M. circuliforme sp. nov. as a robust species based on morphology as well as based on barcode

521 divergences. Minimum interspecific COI distances of $M$. circuliforme sp. nov. to $M$. curta sp. 
522 nov. were $18.4 \%$, and again, these two species are very distinct based on morphological features 523 and apparently are not even closely related to each other (Fig. 2).
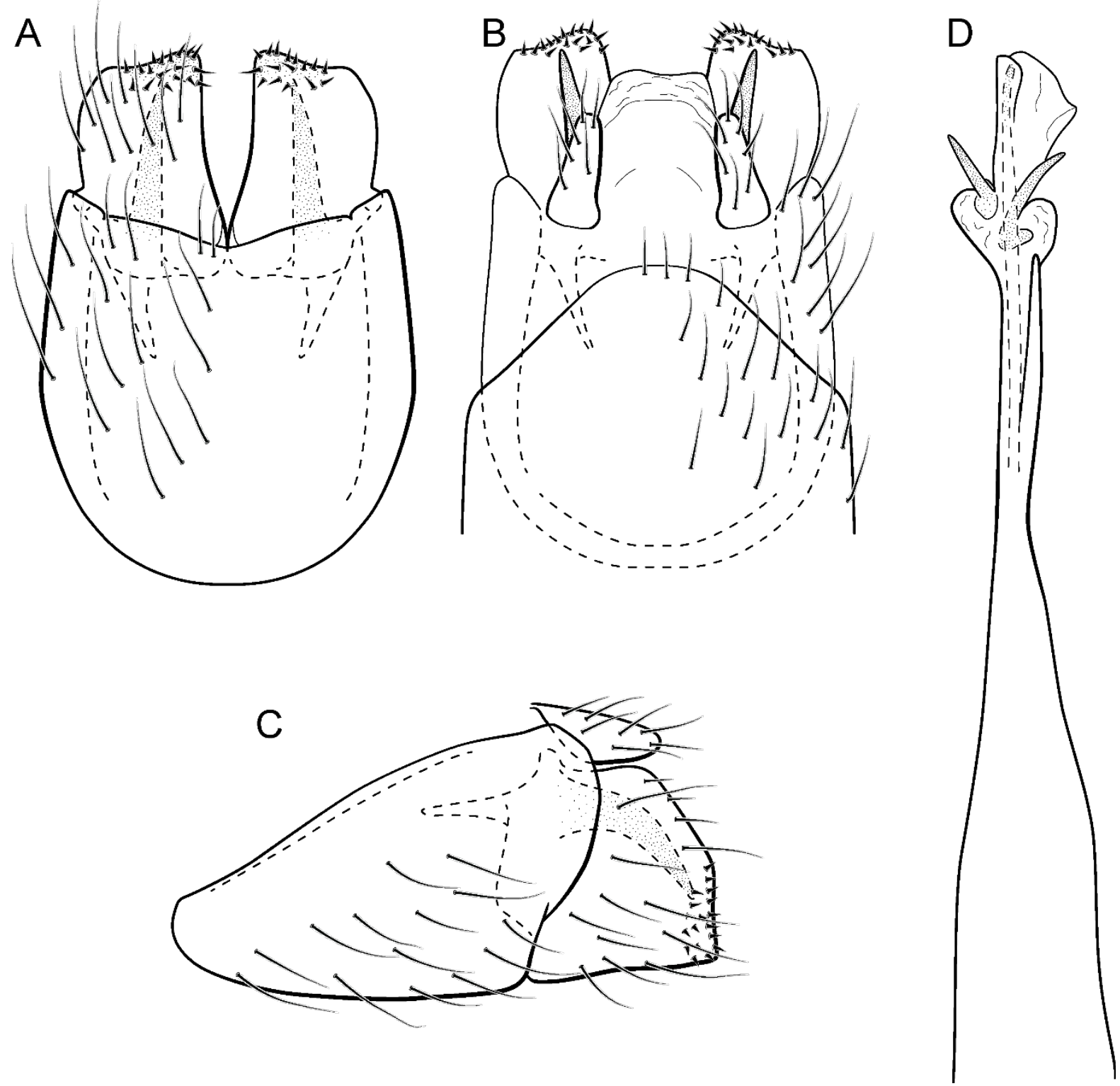

524

Figure 11. Metrichia circuliforme sp. nov., male genitalia: (A) ventral view; (B) dorsal view; (C)

525 lateral view; (D) phallus, dorsal view. 
528 (Fig. 12)

529 Adult male. Length 2.4-2.5 mm (n=9). General color, in alcohol, light brown. Head with no 530 modifications. Ocelli 3. Antenna simple, 18-articulated. Maxillary palpus 5-articulated; labial 531 palpus 3-articulated. Mesoscutellum with transverse suture. Metascutellum subtriangular.

532 Anterior femur without processes. Tibial spur formula 1-3-4. Wing venation reduced in both 533 wings. Abdomen without modifications. Ventromesal process on segment VII present. Segment 534 VIII shorter ventrally than dorsally. Male genitalia. Segment IX reduced dorsally; sternum 535 subpentagonal (Fig. 12A); in lateral view, narrower anteriorly than posteriorly (Fig. 12C). 536 Inferior appendage covered by long setae, subtrapezoidal in ventral view (Fig. 12A); in lateral 537 view, subtriangular (Fig. 12C), apex rounded. Dorsal hook long, more than half length of inferior 538 appendage; in lateral view, with apex slightly broader, downturned, and truncate (Fig. 12C). 539 Preanal appendage elongate, but shorter than inferior appendage, and bearing very long setae 540 (Fig. 12B). Subgenital plate apparently absent. Tergum X membranous and rounded (Fig. 12B).

541 Phallus tubular, elongate and slender, slightly constricted mesally; with a stout subapical spine; 542 apex rounded and folded; ejaculatory duct sclerotized, straight and protruding apically (Fig. 543 12D).

544 Holotype. BRAZIL: Rio de Janeiro: Itatiaia, Rio das Pedras, 22²4'33’'S 44³3'08’'W, el. 706 545 m, 06.iii.2008, LL Dumas, JL Nessimian \& MR de Souza cols., light trap, male (DZRJ).

546 Paratypes. Same data as holotype, 3 males (DZRJ), 3 males (MNRJ).

547 Etymology. The specific name is a reference to the very short inferior appendage; in Portuguese 548 "curta" means "short".

549 Remarks. Based on the absence of modifications on abdominal segments, this new species can 550 be assigned to the aberrans group. Its phallus is similar to that of M. amplitudinis Bueno-Soria \& 551 Hozenthal, 2003, with a long spine and an apical flap. The new species can be distinguished by 552 the triangular inferior appendages in lateral view and phallus with a strongly curved spine 
553 subapically. Metrichia amplitudinis and M. curta sp. nov. share the widened dorsal hook, but in

554 the new species this structure is only slightly wider and also truncate in lateral view. Maximum

555 intraspecific divergence of COI sequences was $1.5 \%$ for $M$. curta $\mathbf{s p .}$ nov. and minimum

556 interspecific was to $M$. circuliforme, as mentioned above.

A
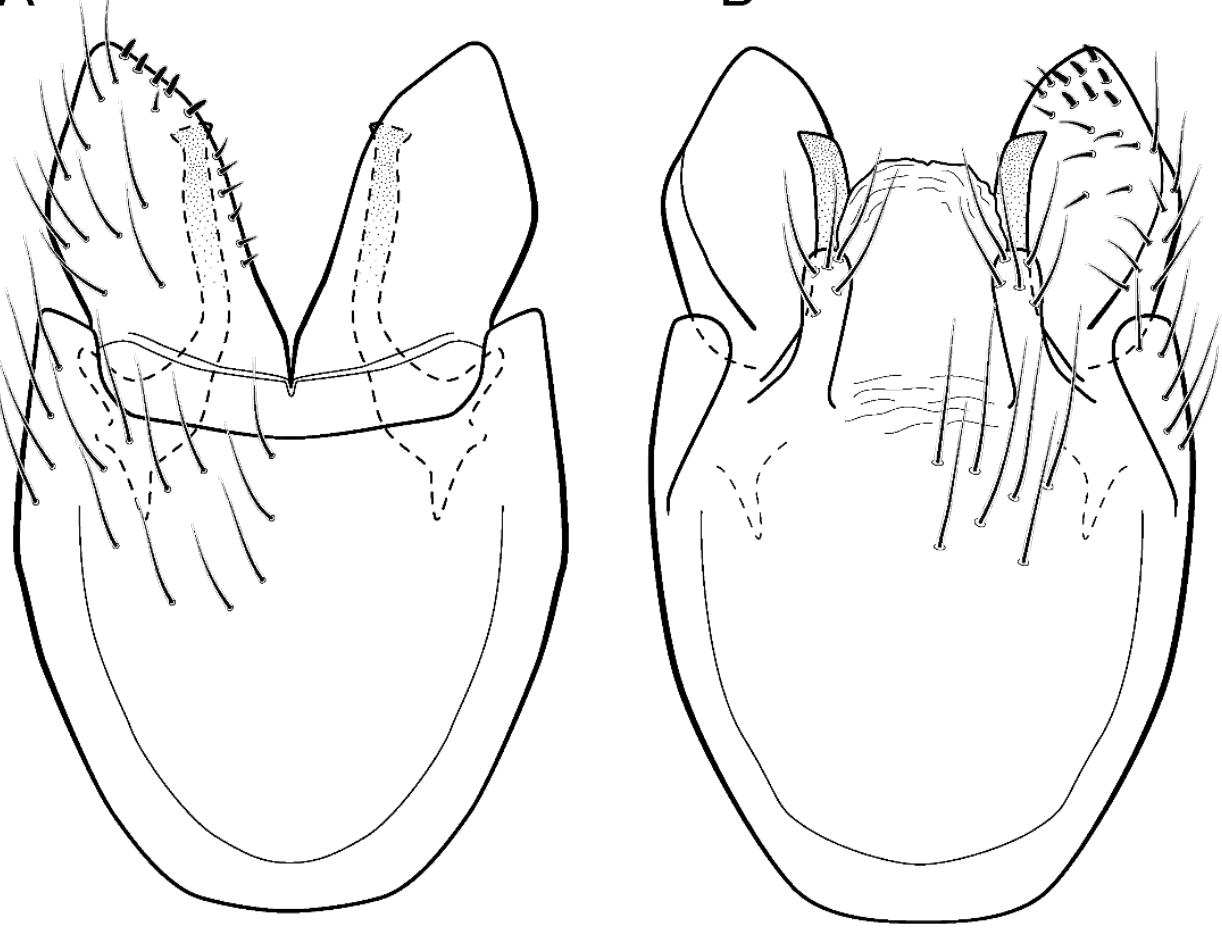

B 
557 Figure 12. Metrichia curta sp. nov., male genitalia: (A) ventral view; (B) dorsal view; (C) lateral 558 view; (D) phallus, dorsal view.

\section{Metrichia farofa sp. nov.}

560 urn:1sid:zoobank.org:act:BC4FF095-32BE-46A9-BEAB-28854E2F5BC7

561 (Fig. 13)

562 Adult male. Length 1.8-2.1 mm ( $\mathrm{n}=27)$. General color, in alcohol, light brown. Head with no 563 modifications. Ocelli 3. Antenna simple, 18-articulated. Maxillary palpus 5-articulated; labial 564 palpus 3-articulated. Mesoscutellum with transverse suture. Metascutellum subtriangular.

565 Anterior femur without processes. Tibial spur formula 1-3-4. Wing venation reduced in both 566 wings. Abdomen without modifications; segment VII bearing specialized setae dorsally.

567 Ventromesal process on segment VII absent. Segment VIII shorter ventrally than dorsally. Male 568 genitalia. Segment IX reduced dorsally; sternum subrectangular (Fig. 13A); in lateral view 569 narrower anteriorly than posteriorly (Fig. 13C). Inferior appendage covered by long setae, 570 subrectangular in ventral view (Fig. 13A); in lateral view, subrectangular (Fig. 13C), apex

571 slightly truncate and bearing short spine-like setae. Dorsal hook long, almost reaching the inferior 572 appendage apex; in lateral view, downturned (Fig. 13C). Preanal appendage elongate, as long as 573 inferior appendage, and bearing very long setae (Fig. 13B). Subgenital plate apparently absent. 574 Tergum X membranous and rounded (Fig. 13B). Phallus tubular, elongate and slender, slightly 575 constricted mesally; with a stout subapical spine; apex rounded and sclerotized; ejaculatory duct 576 sclerotized, sinuous, and protruding apically (Fig. 13D).

577 Holotype. BRAZIL: Minas Gerais: Jaboticatubas, Parque Nacional da Serra do Cipó, 578 Cachoeira da Farofa, 19²2’47’S 43³4’36”W, el. 811 m, 23.iv.2010, APM Santos \& DM Takiya 579 cols., manual, male (DZRJ). 
580

581

582

583

584

Paratypes. Same data as holotype, 18 males (DZRJ), 8 males (MNRJ), 5 males (MZUFBA);

same data, except Ribeirão Mascates, 19²4’02”S 43³4’35”W, el. 820 m, 09-11.xii.2011, APM

Santos \& DM Takiya cols., manual, 84 males (DZRJ).

Etymology. This new species is named in reference to the waterfall where specimens were
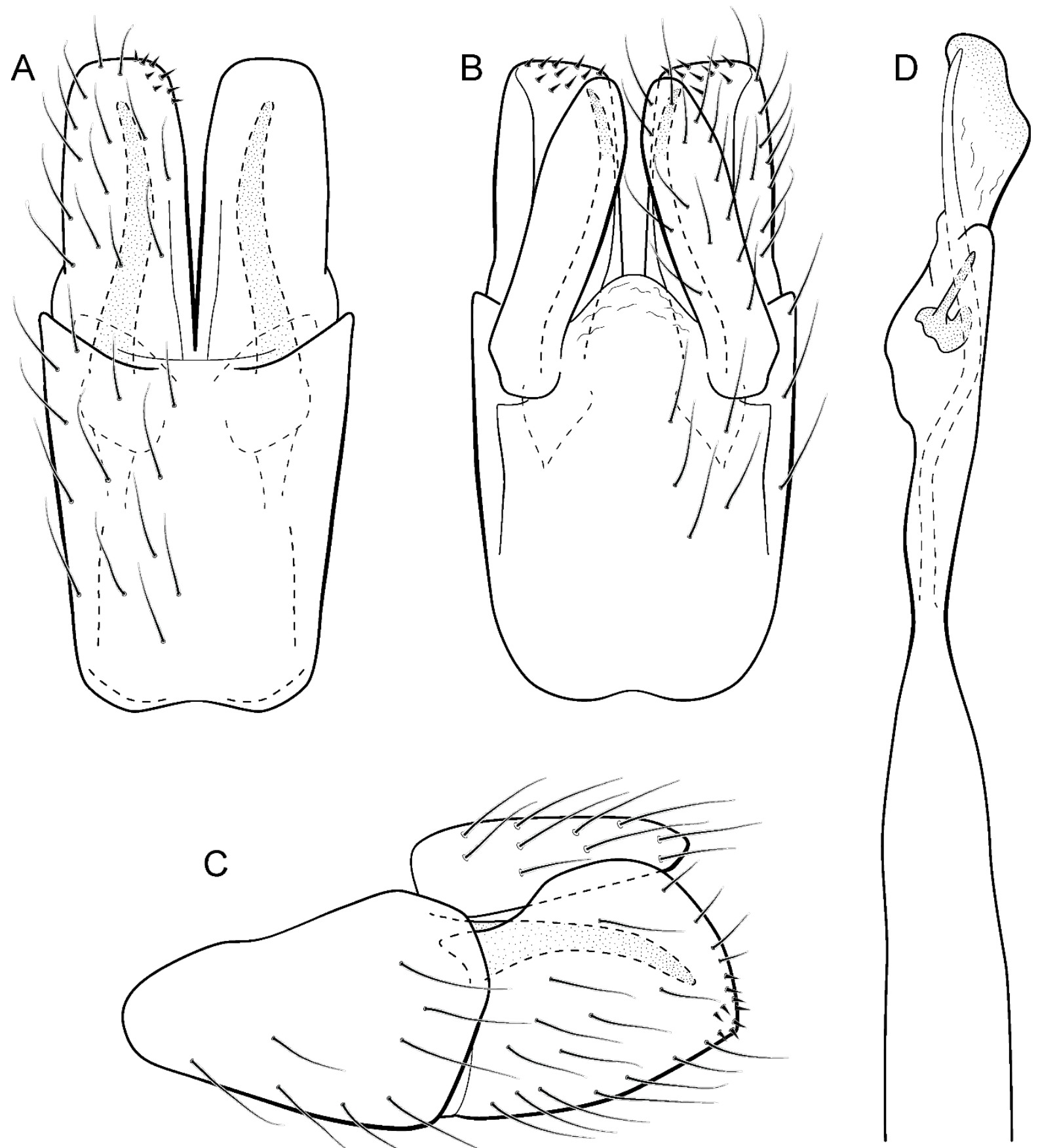
585 Figure 13. Metrichia farofa sp. nov., male genitalia: (A) ventral view; (B) dorsal view; (C)

586 lateral view; (D) phallus, dorsal view.

587 Remarks. Due to absence of pouches in abdominal segments, Metrichia farofa sp. nov. can also

588 be included in the aberrans group. However, the new species has a single subapical spine in 589 phallus, like those species included in the exclamationis group. The new species can be easily 590 distinguished from all other Metrichia species by the very long preanal appendages, reaching 591 apices of inferior appendages in dorsal and lateral views.

592 Although more than 10 specimens of $M$. farofa sp. nov. were submitted to DNA 593 extraction and many attempts of COI amplification via PCR were conducted, but we were not 594 able to obtain sequences of this species, even using recent material collected after 2013.

\section{Metrichia forceps sp. nov.}

596 urn:Isid:zoobank.org:act:8F25D006-D59B-4C83-8CDE-2398368917AD

597 (Fig. 14)

598 Adult male. Length 2.7-3.0 $\mathrm{mm}(\mathrm{n}=2)$. General color, in alcohol, brown. Head with no 599 modifications. Ocelli 3. Antenna simple, 23-articulated. Maxillary palpus 5-articulated; labial 600 palpus 3-articulated. Mesoscutellum with transverse suture. Metascutellum subtriangular.

601 Anterior femur with small acute apical process. Tibial spur formula 1-3-4. Wing venation reduced 602 in both wings. Abdominal segment VII bearing internal pouches in anterior area. Ventromesal 603 process on segment VII absent. Segment VIII shorter ventrally than dorsally. Male genitalia. 604 Segment IX reduced dorsally; sternum subpentagonal (Fig. 14A); in lateral view, narrower 605 anteriorly than posteriorly (Fig. 14C). Inferior appendage covered by long setae, subrectangular 606 in ventral view (Fig. 14A); in lateral view, with posterior margin excavated and with two acute 607 and sclerotized process (Fig. 14C). Dorsal hook long, almost reaching the inferior appendage 
608 apex; in lateral view, downturned (Fig. 14C). Preanal appendage short, rounded and bearing very 609 long setae (Fig. 14B). Subgenital plate apparently absent. Tergum X sclerotized, deeply notched 610 mesally, forming lateral curved processes (Fig. 14B). Phallus tubular, elongate and slender, 611 slightly constricted mesally; with two short subapical spines; apex rounded and folded; 612 ejaculatory duct sclerotized, straight and protruding apically (Fig. 14D). 
A
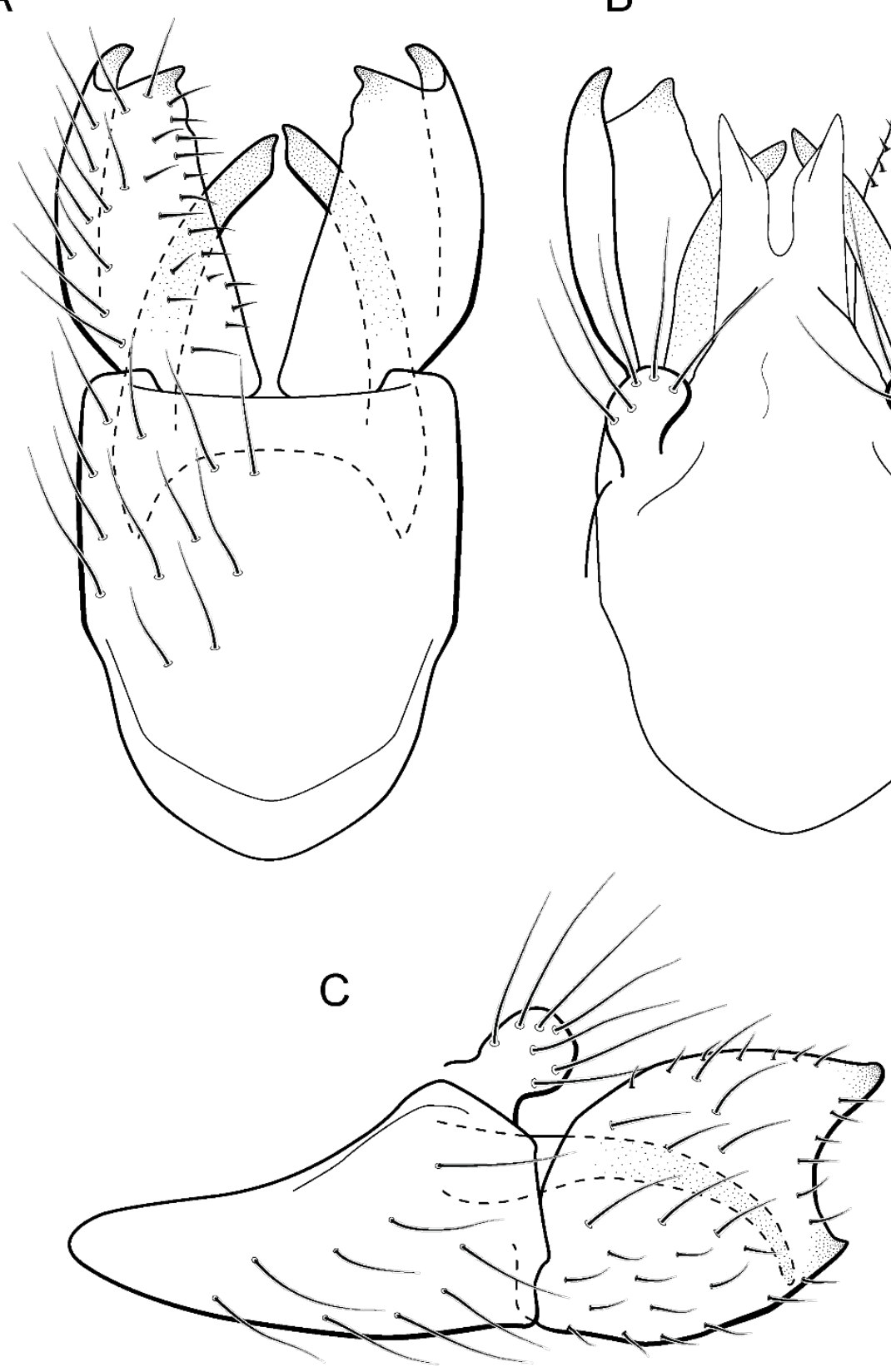

B

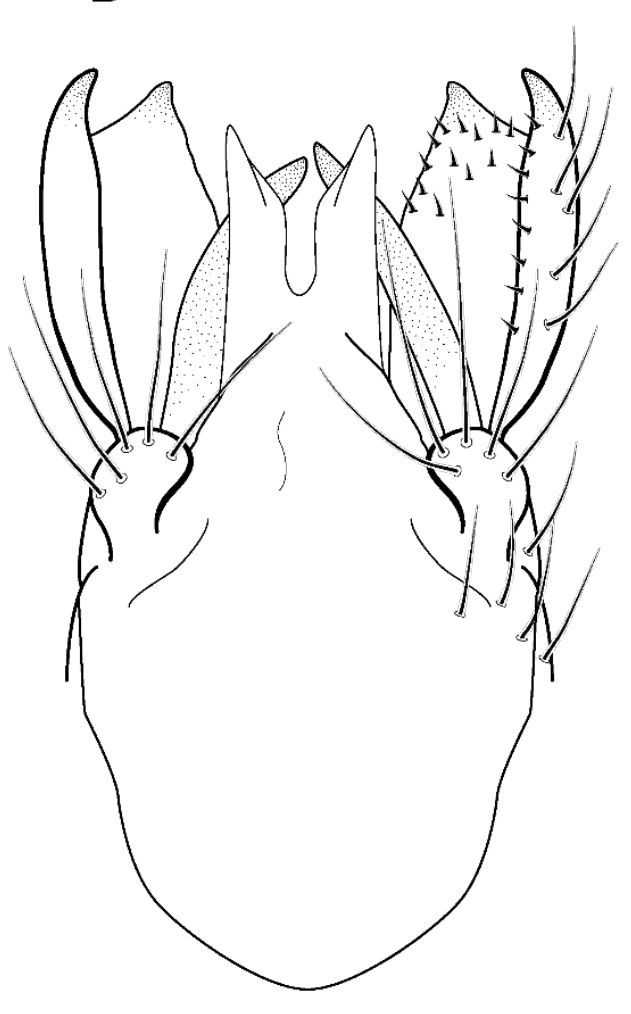

D

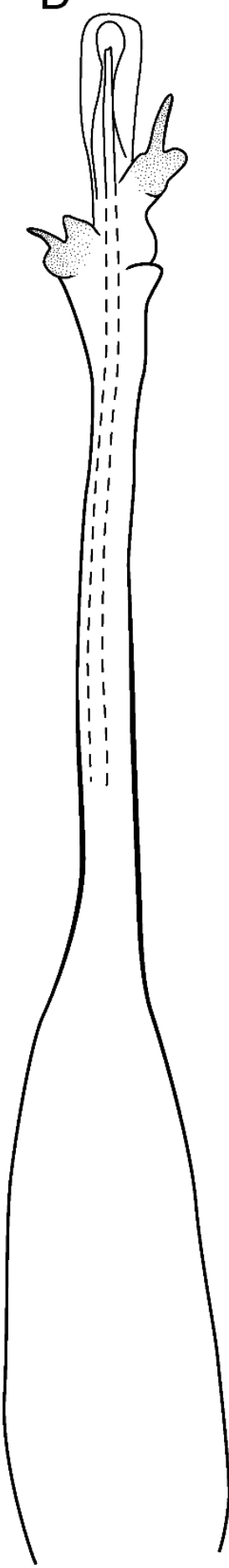

613 Figure 14. Metrichia forceps sp. nov., male genitalia: (A) ventral view; (B) dorsal view; (C) 614 lateral view; (D) phallus, dorsal view. 
615 Holotype. BRAZIL: Paraná: Céu Azul, Parque Nacional do Iguaçu, Rio Azul, 2509'21”S 616 5347’44”W, el. 510 m, 6-8 ix.2012, APM Santos, DM Takiya, ALH Oliveira, GA Jardim \&

617 BHL Sampaio cols., Malaise trap, male (DZRJ).

618 Paratypes. Same data as holotype, 1 male (MNRJ).

619 Etymology. The name of this species is in reference to the dorsal hooks of inferior appendages, 620 which in ventral view resemble forceps.

621 Remarks. This new species belongs to the campana group, sharing the diagnostic internal 622 pouches between segments VI and VII, reduced spines on subapical region of phallus, and the 623 sclerotized and elongate tergum X. Within this group, $M$. forceps sp. nov. is most similar to $M$. 624 campana (Flint, 1968), M. similis (Flint, 1968), and M. continentalis (Flint, 1972), particularly by 625 their inferior appendages with excavate posterior margins, forming two pointed processes, one 626 ventral and another dorsal. The new species can be distinguished from the others by its deeply 627 notched tergum X; dorsal hook of inferior appendages elongate and downturned, and phallus 628 apex bearing two small spines and a sclerotized flap surrounding the protruding ejaculatory duct.

\section{Metrichia formosinha sp. nov.}

630 urn:1sid:zoobank.org:act:B8971D9B-7013-4213-970E-50A42CA0D1B7

631 (Fig. 15)

632 Adult male. Length 2.5-2.8 mm (n=2). General color, in alcohol, dark brown. Head with no 633 modifications. Ocelli 3. Antenna simple, 20-articulated. Maxillary palpus 5-articulated; labial 634 palpus 3-articulated. Mesoscutellum with transverse suture. Metascutellum subtriangular.

635 Anterior femur with small acute apical process. Tibial spur formula 1-3-4. Wing venation reduced 636 in both wings. Abdominal segment VI with pair of internal pouches in posterodorsal area.

637 Ventromesal process on segment VII present. Segment VIII shorter ventrally than dorsally. Male 638 genitalia. Segment IX reduced dorsally; sternum subrectangular, with anterior margin rounded 
639 (Fig. 15A); in lateral view narrower anteriorly than posteriorly (Fig. 15C). Inferior appendage

640 with peg-like setae, subrectangular in ventral (Fig. 15A) and lateral (Fig. 15C) views; apex with

641 acute corners. Dorsal hook long, almost reaching the inferior appendage apex; in lateral view,

642 with apex slightly broader, almost straight, and truncate (Fig. 15C). Preanal appendage short,

643 rounded and bearing very long setae (Fig. 15B). Subgenital plate apparently absent. Tergum X

644 membranous and rounded (Fig. 15B). Phallus tubular, elongate and slender, slightly constricted

645 mesally; with two curved subapical spines, one short and another one very long; apex rounded

646 and sclerotized; ejaculatory duct sclerotized, sinuous, and not protruding apically (Fig. 15D).

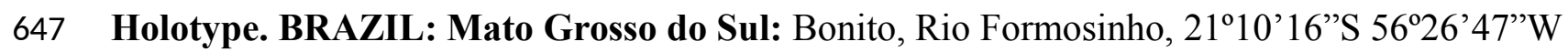

648 el. 275 m, 08-13.ix.2013, APM Santos \& DM Takiya cols., Malaise trap, male (DZRJ).

649 Paratypes. Same data as holotype, 3 males (DZRJ).

650 Etymology. This species is named in allusion to the river where type specimens were collected.

651 Remarks. This new species appears to be a member of the campana group because of internal

652 pouches between abdominal segments VI-VII and phallus with two subapical spines. General

653 aspect of the male genitalia of Metrichia formosinha sp. nov. is similar to M. forceps sp. nov.,

654 particularly in the inferior appendages with acute corners. However, M. formosinha sp. nov.

655 differs from the latter by dorsal hooks almost straight and capitate (strongly curved and acute in

$656 M$. forceps sp. nov. and in other species of the campana group) and phallus with a very long

657 subapical spine.

658 COI sequences of $M$. formosinha sp. nov. showed intraspecific divergences up to $0.8 \%$

659 and minimum interspecific divergences of $24.9 \%$ compared to M. talhada sp. nov. 

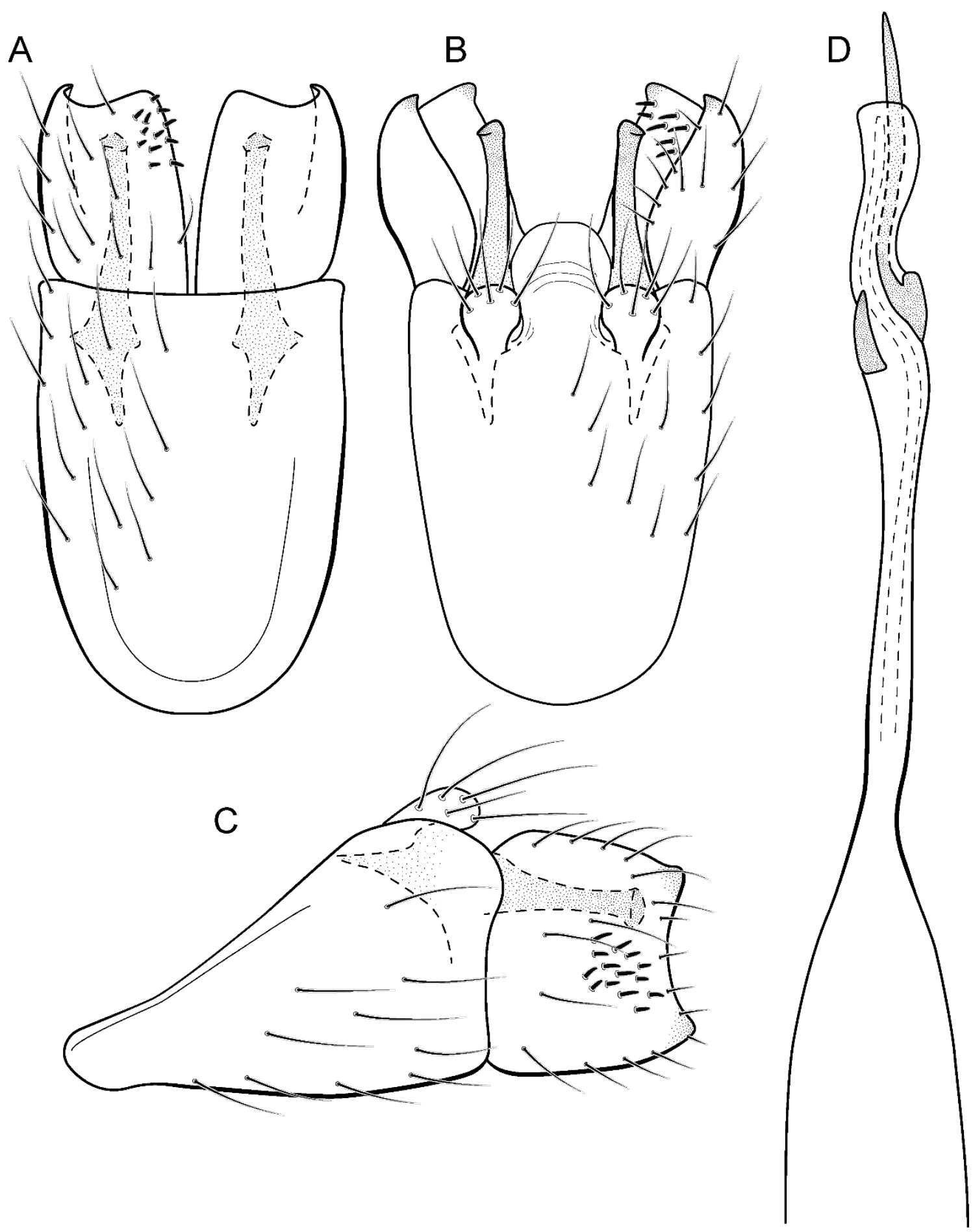

660 Figure 15. Metrichia formosinha sp. nov., male genitalia: (A) ventral view; (B) dorsal view; (C) 661 lateral view; (D) phallus, dorsal view. 
Metrichia goiana sp. nov.

663 urn:1sid:zoobank.org:act:8726E665-1093-42EF-A1B6-E06178B2DAD1

664 (Fig. 16)

665 Adult male. Length 1.8-2.0 mm $(\mathrm{n}=6)$. General color, in alcohol, dark brown. Head with no

666 modifications. Ocelli 3. Antenna simple, 18-articulated. Maxillary palpus 5-articulated, article IV

667 broad and darkened; labial palpus 3-articulated. Mesoscutellum with transverse suture.

668 Metascutellum subtriangular. Anterior femur with small acute apical process. Tibial spur formula

669 1-3-4. Wing venation reduced in both wings. Abdominal segment $\mathrm{V}$ with pair of internal pouches

670 and pair of dorsolateral brushes; segment VI with a transverse sclerotized plate posteriorly on

671 dorsum; segment VII bearing specialized setae dorsally. Ventromesal process on segment VII

672 absent. Segment VIII shorter ventrally than dorsally. Male genitalia. Segment IX reduced

673 dorsally; sternum subrectangular, with anterior margin rounded (Fig. 16A); in lateral view

674 narrower anteriorly than posteriorly (Fig. 16C). Inferior appendage covered by long setae,

675 elongate and narrow in ventral view (Fig. 16A); in lateral view, rounded (Fig. 16A), apex

676 rounded and bearing a tooth-like projection (Fig. 16A). Dorsal hook short, less than half length of

677 inferior appendage; in lateral view, downturned (Fig. 16A). Preanal appendage short and bearing

678 very long setae (Fig. 16B). Subgenital plate apparently absent. Tergum X membranous and

679 truncate (Fig. 16B). Phallus tubular, elongate and slender, slightly constricted mesally; with two

680 long, curved, subapical spines; apex ending into two sclerotized and keel shaped processes;

681 ejaculatory duct sclerotized, straight and not protruding apically (Fig. 16D).

682 Holotype. BRAZIL: Goiás: Alto Paraíso de Goiás, Rio Bartolomeu tributary, 1407’25”S

683 47³0’30’W, el. 1165 m, 22-25.iii.2013, APM Santos \& DM Takiya cols., Malaise trap, male

684 (DZRJ).

685 Paratypes. Same data as holotype, 2 males (MNRJ), 1 male (DZRJ). 
686 Etymology. The species is named in reference to Goiás State. "Goiana” is a Portuguese adjective 687 for people from Goiás.

688 Remarks. This is another member of nigritta group. Male genitalia of this species are similar to 689 M. potosina Bueno-Soria, 2002 and M. ubajara sp. nov., due to rounded and elongate inferior 690 appendages in lateral view. This new species differs from M. ubajara sp. nov. by the presence of 691 an apical tooth on inferior appendages, also present in M. potosina. Metrichia goiana sp. nov. can 692 be distinguished from M. potosina by the two long subapical spines on phallus, whereas $M$. 693 potosina has three. 


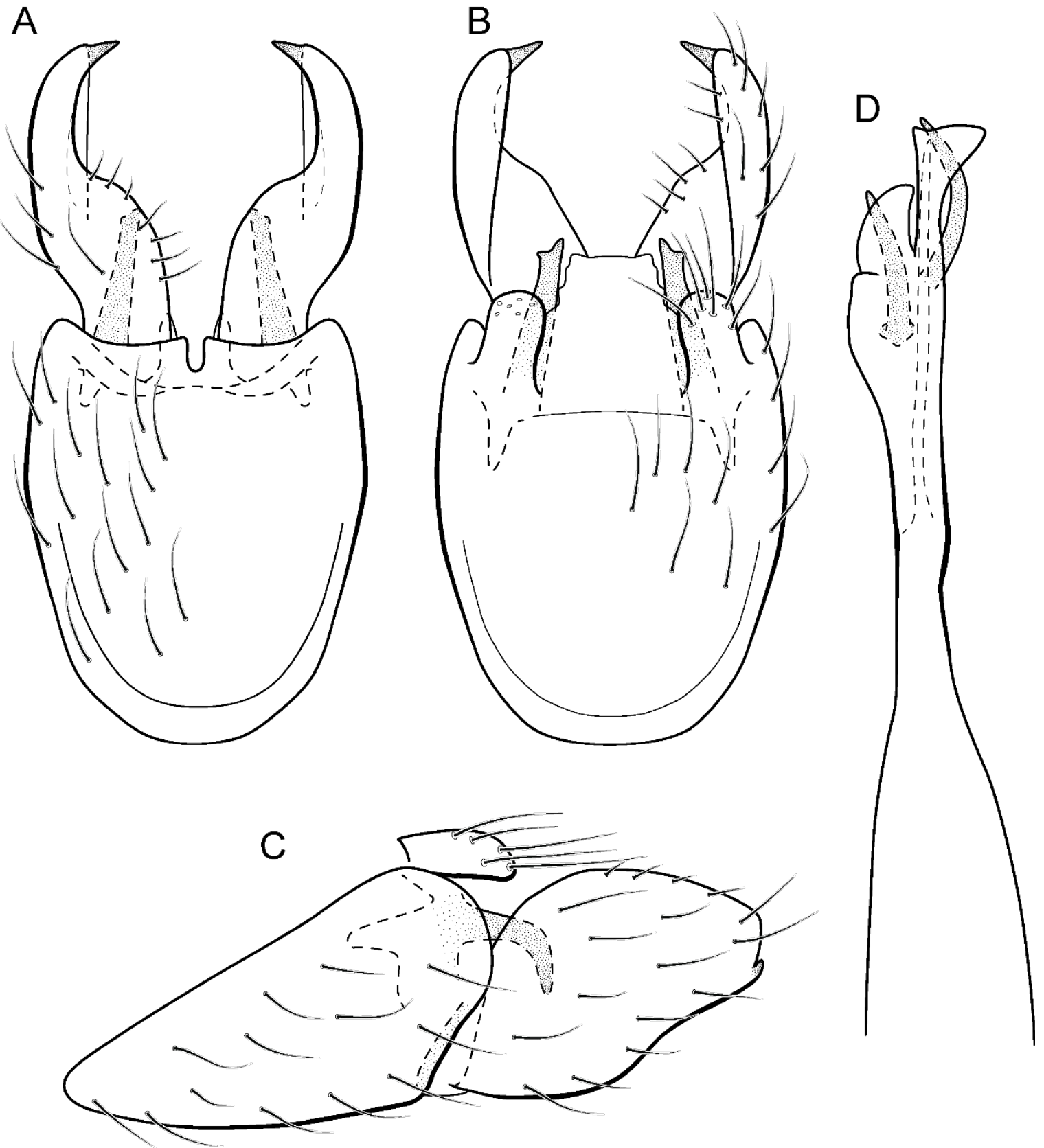

694 Figure 16. Metrichia goiana sp. nov., male genitalia: (A) ventral view; (B) dorsal view; (C) 695 lateral view; (D) phallus, dorsal view.

697 urn:Isid:zoobank.org:act:1C902E75-7ECD-4875-A680-6440A3E5E9E9

698 (Fig. 17, Fig. 26B) 
699 Adult male. Length 1.8-2.1 mm (n=3). General color, in alcohol, brown. Head with no

700 modifications. Ocelli 3. Antenna simple, 20-articulated. Maxillary palpus 5-articulated; labial

701 palpus 3-articulated. Mesoscutellum with transverse suture. Metascutellum subtriangular.

702 Anterior femur without processes. Tibial spur formula 1-3-4. Wing venation reduced in both

703 wings. Abdominal segment V ventrally with a mesal brush of long setae; segment VI with tergum

704 as a sclerotized triangular plate surrounded by specialized setae (Fig. 26B), internally with pair of

705 internal pouches; segment VII bearing specialized setae ventrally and dorsally (Fig. 26B).

706 Ventromesal process on segment VII present. Segment VIII shorter ventrally than dorsally and

707 bearing a brush of long setae dorsally. Male genitalia. Segment IX reduced dorsally; sternum

708 subpentagonal (Fig. 17A); in lateral view narrower anteriorly than posteriorly (Fig. 17C). Inferior

709 appendage short, covered by long setae (Fig. 17A); in lateral view, subtrapezoidal (Fig. 17C),

710 apex excavated and with two acute and sclerotized process (Figs. 17A, 17B). Dorsal hook short,

711 almost half length of inferior appendage; in lateral view, slightly downturned (Fig. 17C). Preanal

712 appendage elongate, but shorter than inferior appendage, and bearing very long setae (Fig. 17B).

713 Subgenital plate apparently absent. Tergum X membranous and truncate (Fig. 17B). Phallus

714 tubular, elongate and slender, slightly constricted mesally; with two long, curved, subapical

715 spines; apex truncate and slightly sclerotized; ejaculatory duct sclerotized, sinuous, and

716 protruding apically (Fig. 17D).

717 Holotype. Sergipe: Areia Branca, Parque Nacional da Serra de Itabaiana, Rio dos Negros,

718 1044'51'S 37²0’24’W, el. 208 m, 17.vi.2014, APM Santos, DM Takiya \& WRM Souza cols.,

719 light trap, male (DZRJ).

720 Paratypes. Same data as holotype, 1 male (DZRJ), 1 male (MZUFBA); same data, except

721 Riacho Água Fria, 1045'17’S 37²0’32’W, el. 196 m, 17-19.vi.2014, APM Santos, DM Takiya,

722 WRM Souza cols., Malaise trap, 2 males (MNRJ). Goiás: Alto Paraíso, Rio Bartolomeu tributary, 
$72314^{\circ} 07^{\prime} 25^{\prime}$ S 47³0’30”W, el. 1165 m, 22-25.iii.2013, APM Santos \& DM Takiya cols., Malaise 724 trap, 1 male (DZRJ).

A

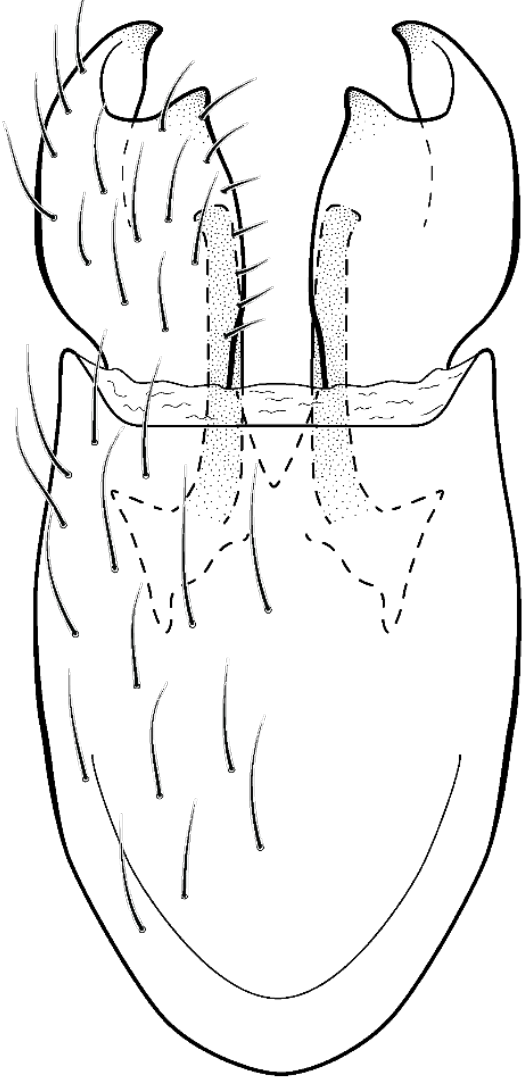

B
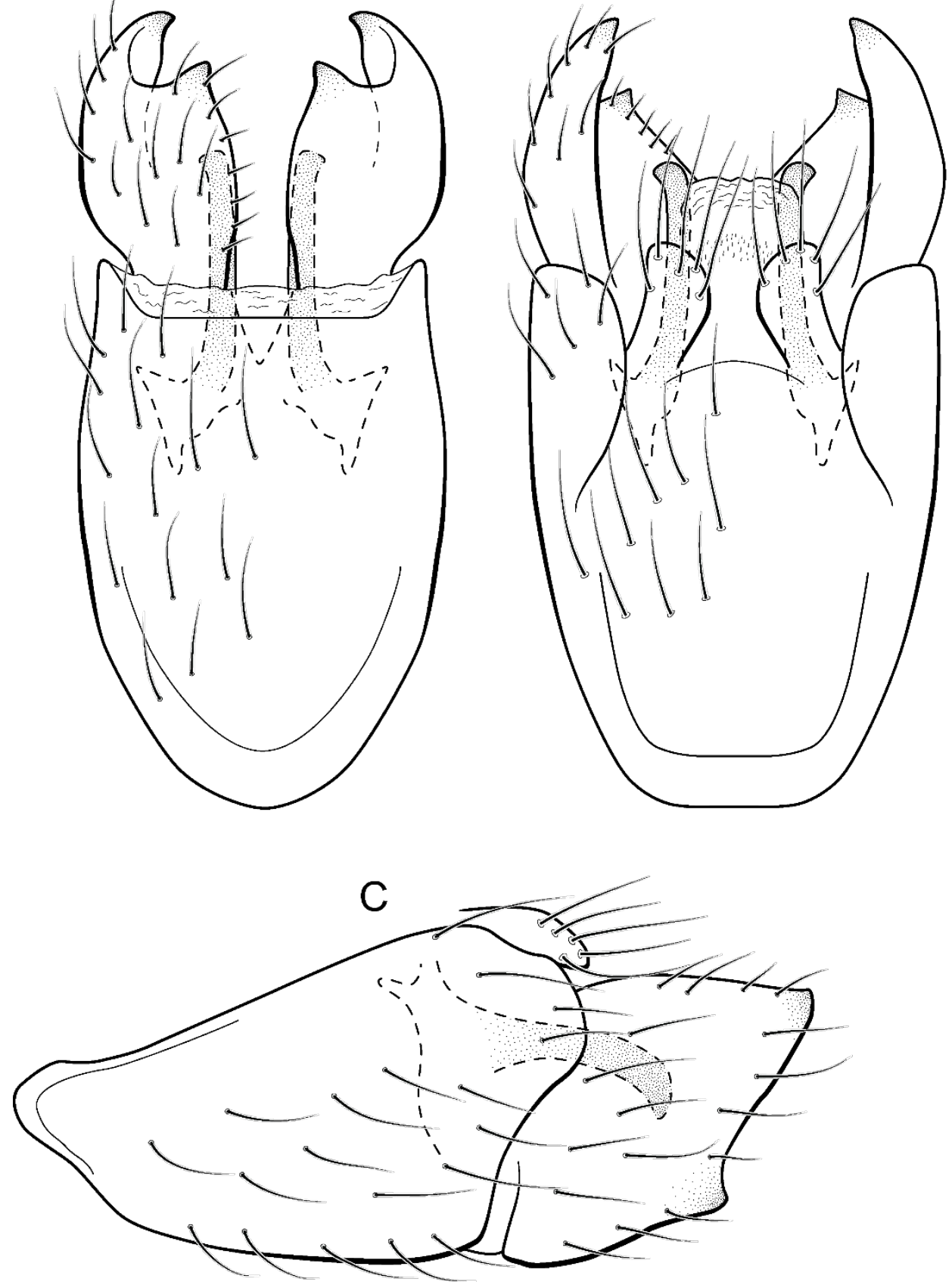

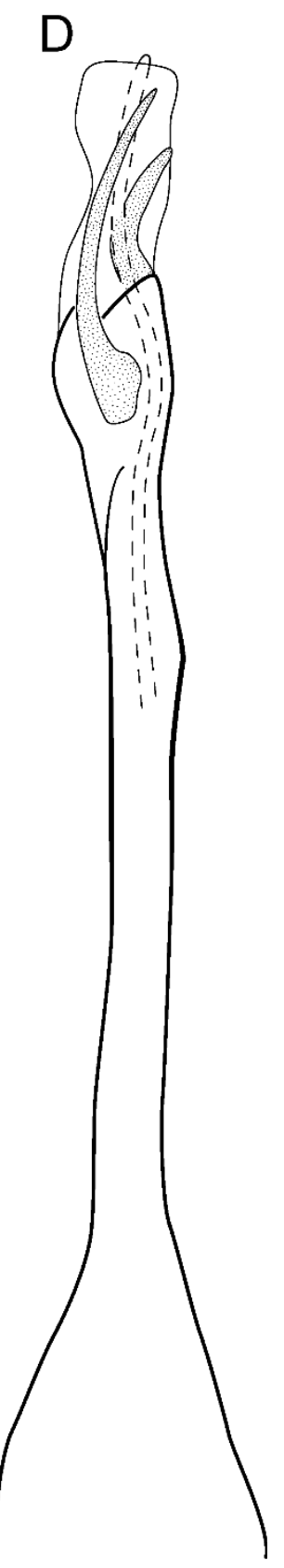

Figure 17. Metrichia itabaiana sp. nov., male genitalia: (A) ventral view; (B) dorsal view; (C)

726 lateral view; (D) phallus, dorsal view. 
727 Etymology. This species is named in reference to Serra de Itabaiana, Sergipe, where the holotype

728 was collected.

729 Remarks. This new species appears to be a member of the campana group because of internal

730 pouches between abdominal segments VI and VII and pair of long subapical spines on phallus,

731 but it lacks the acute process on the mesal area of phallus. Male genitalia of M. itabaiana sp. nov.

732 resemble those of $M$. campana and $M$. vulgaris sp. nov., particularly, in the excavated inferior

733 appendages, with acute and darkened corners. However, the new species can be recognized by

734 very long curved subapical spines on phallus and subtrapezoidal aspect of inferior appendages in 735 lateral view.

736 Only two COI sequences were obtained for M. itabaiana sp. nov., one from Sergipe

737 (Northeastern Brazil) and another from Goiás (Centralwestern Brazil). The COI divergence

738 between these two samples was $1.9 \%$ and minimum interspecific distance was $19.4 \%$ in relation

739 to M. rafaeli sp. nov., which belongs to a different species group based on morphological

740 features.

741 Metrichia longissima sp. nov.

742 urn:1sid:zoobank.org:act:F87C549F-6F84-4466-AFCE-940729F32F46

743 (Fig. 18, Fig. 26C)

744 Adult male. Length 2.5-2.7 mm (n=2). General color, in alcohol, brown. Head with no

745 modifications. Ocelli 3. Antenna simple, 18-articulated. Maxillary palpus 5-articulated; labial

746 palpus 3-articulated. Mesoscutellum with transverse suture. Metascutellum subtriangular.

747 Anterior femur with small acute apical process. Tibial spur formula 1-3-4. Wing venation reduced

748 in both wings. Abdominal segment IV with dorsal area expanded posteriorly bearing stout setae;

749 segment VI with stout and striate setae (Fig. 26C); segment VII with stout and striate setae (Fig.

750 26C). Ventromesal process on segment VII absent. Segment VIII shorter ventrally than dorsally. 
751 Male genitalia. Segment IX reduced dorsally; sternum subpentagonal (Fig. 18A); in lateral view

752 narrower anteriorly than posteriorly (Fig. 18C). Inferior appendage bearing scale-like setae, very

753 elongate; in ventral view, curved inward apically (Fig. 18A); in lateral view, tapering to a

754 rounded apex (Fig. 18C). Dorsal hook short and straight; in lateral view, slightly downturned

755 (Fig. 18C). Preanal appendage elongate, but shorter than half length of inferior appendage, and

756 bearing stout and striate setae (Fig. 18B). Subgenital plate apparently absent. Tergum X

757 membranous and truncate (Fig. 18B). Phallus tubular, elongate and slender, slightly constricted

758 mesally, with a median process; with two long, curved, subapical spines; apex rounded and

759 sclerotized; ejaculatory duct sclerotized and protruding apically (Fig. 18D).

760 Holotype. BRAZIL: Rio de Janeiro: Itatiaia, Rio Palmital, 22²5’34’S 44³2'52’'W, el. 637 m,

761 07.iii.2008, LL Dumas, JL Nessimian \& MR de Souza cols., light trap, male (DZRJ).

762 Paratype. Brazil: Rio de Janeiro: Teresópolis, Parque Nacional da Serra dos Órgãos, Rio

763 Paquequer, 22²7’25’S 4259'52”W, el. 1100 m, 15-18.ix.2011, APM Santos, DM Takiya, BM

764 Vasconcelos \& RA Carvalho cols., Malaise trap, 1 male (MNRJ).

765 Etymology. The species name is an allusion to the elongate inferior appendages, unusual for

766 Metrichia species.

767 Remarks. The new species is most similar to M. sesquipedalis Bueno-Soria \& Holzenthal, 2003,

768 sharing with it very long inferior appendages with very short dorsal hooks. The new species is

769 easily distinguished from the latter by their internal pouches in the male abdominal segment VI

770 and phallus with only two subapical spines (three in M. sesquipedalis).

771 Two COI sequences were generated for M. longissima sp. nov., one from a specimen from

772 Itatiaia and the other from Teresópolis in Rio de Janeiro State, localities in distinct mountain

773 ranges, Serra da Mantiqueira and Serra do Mar, respectively. The genetic distance between

774 sequences of $M$. longissima sp. nov. was $0.4 \%$. The minimum interspecific distance was found to

775 M. itabaiana sp. nov. with $21.5 \%$ divergence. 
A
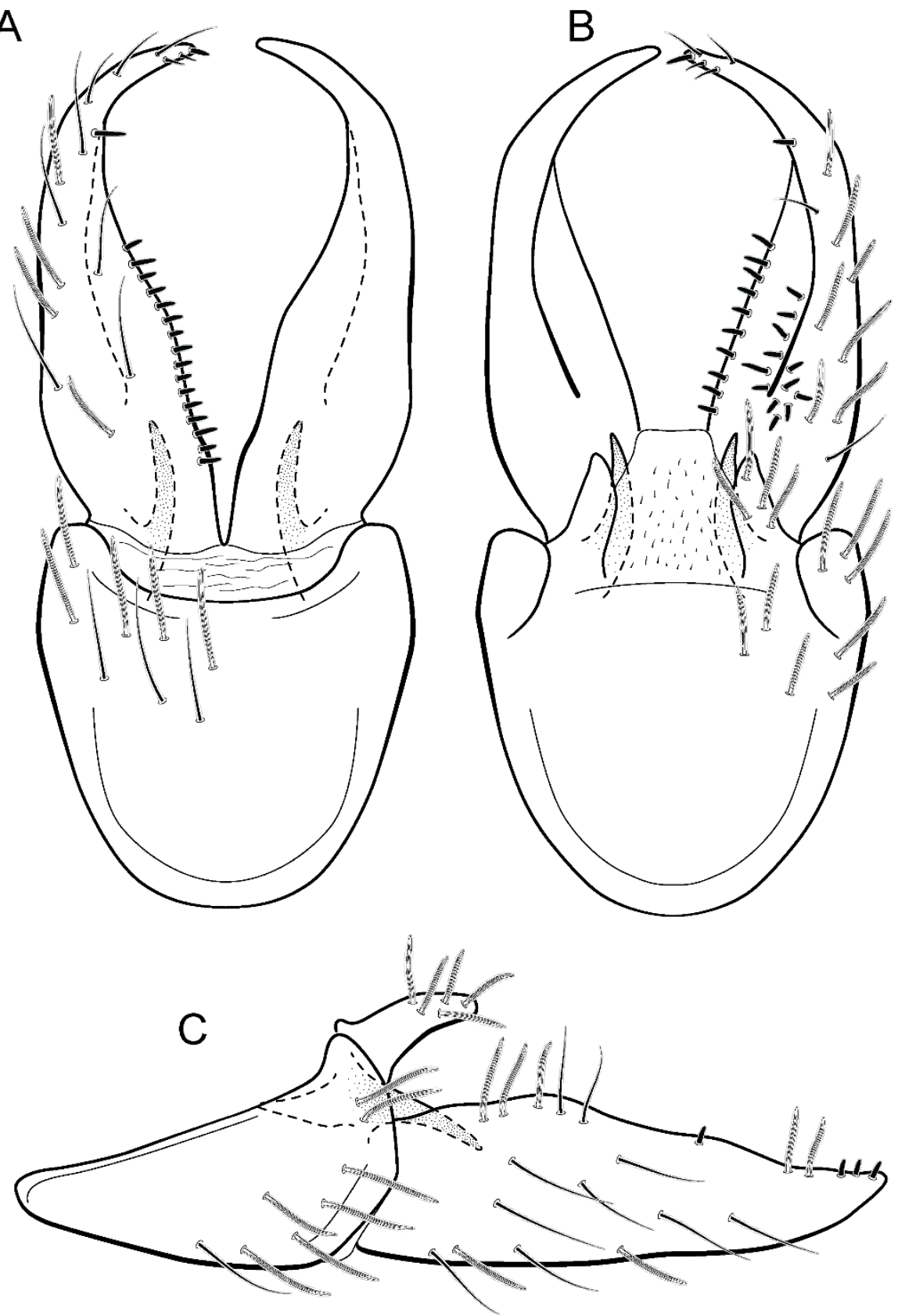

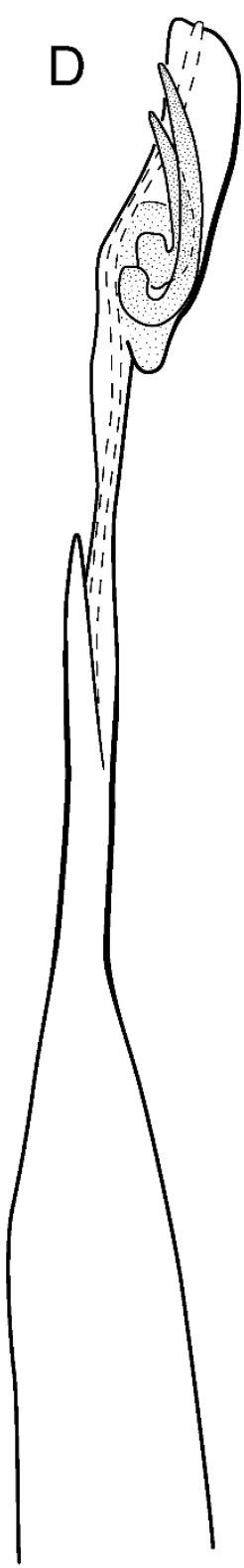

776

777

Figure 18. Metrichia longissima sp. nov., male genitalia: (A) ventral view; (B) dorsal view; (C) lateral view; (D) phallus, dorsal view.

Metrichia peluda sp. nov.

779 urn:Isid:zoobank.org:act:E1B7E1AE-5751-4D10-9B07-47A8CF849C7F

780 (Fig. 19, Fig. 26D) 
781 Adult male. Length 2.7-3.0 mm ( $\mathrm{n}=3)$. General color, in alcohol, dark brown. Head with no

782 modifications. Ocelli 3. Antenna simple, 18-articulated. Maxillary palpus 5-articulated; labial

783 palpus 3-articulated. Mesoscutellum with transverse suture. Metascutellum subtriangular.

784 Anterior femur without processes. Tibial spur formula 1-3-4. Wing venation reduced in both

785 wings. Abdominal segment V with dorsolateral brushes of long setae; segment VI with

786 dorsolateral brushes of long setae (Fig. 26D). Ventromesal process on segment VII present.

787 Segment VIII shorter ventrally than dorsally. Male genitalia. Segment IX reduced dorsally;

788 sternum subrectangular, with anterior margin rounded (Fig. 19A); in lateral view narrower

789 anteriorly than posteriorly (Fig. 19C). Inferior appendage covered by long setae, subtrapezoidal

790 in ventral view (Fig. 19A); apex excavated; in lateral view, rounded (Fig. 19C). Dorsal hook

791 short, almost half length of inferior appendage; in lateral view, slightly downturned (Fig. 19C).

792 Preanal appendage short and bearing very long setae (Fig. 19B). Subgenital plate apparently

793 absent. Tergum X membranous and truncate (Fig. 19B). Phallus tubular, elongate and slender,

794 slightly constricted mesally; with two curved subapical spines, one short and another long; apex

795 rounded and folded; ejaculatory duct sclerotized, straight and protruding apically (Fig. 19D).

796 Holotype. BRAZIL: Rio de Janeiro: Itatiaia, 1st order tributary of Rio Palmital, 22²5’40”S

797 44³2’46”W, el. 584 m, 07.iii.2008, JL Nessimian, LL Dumas \& MR de Souza cols., light trap,

798 male (DZRJ).

799 Paratypes. Same data as holotype, 1 male (MNRJ); same data, except Rio Palmital, 22²5'34”S

800 44³2’52”W, el. 637 m, 07.iii.2008, LL Dumas, JL Nessimian \& MR de Souza cols., light trap, 4

801 males (DZRJ).

802 Etymology. The name of this species refers to dense brushes of setae on the dorsal area of the

803 male abdomen. In Portuguese "peluda" means "hairy". 


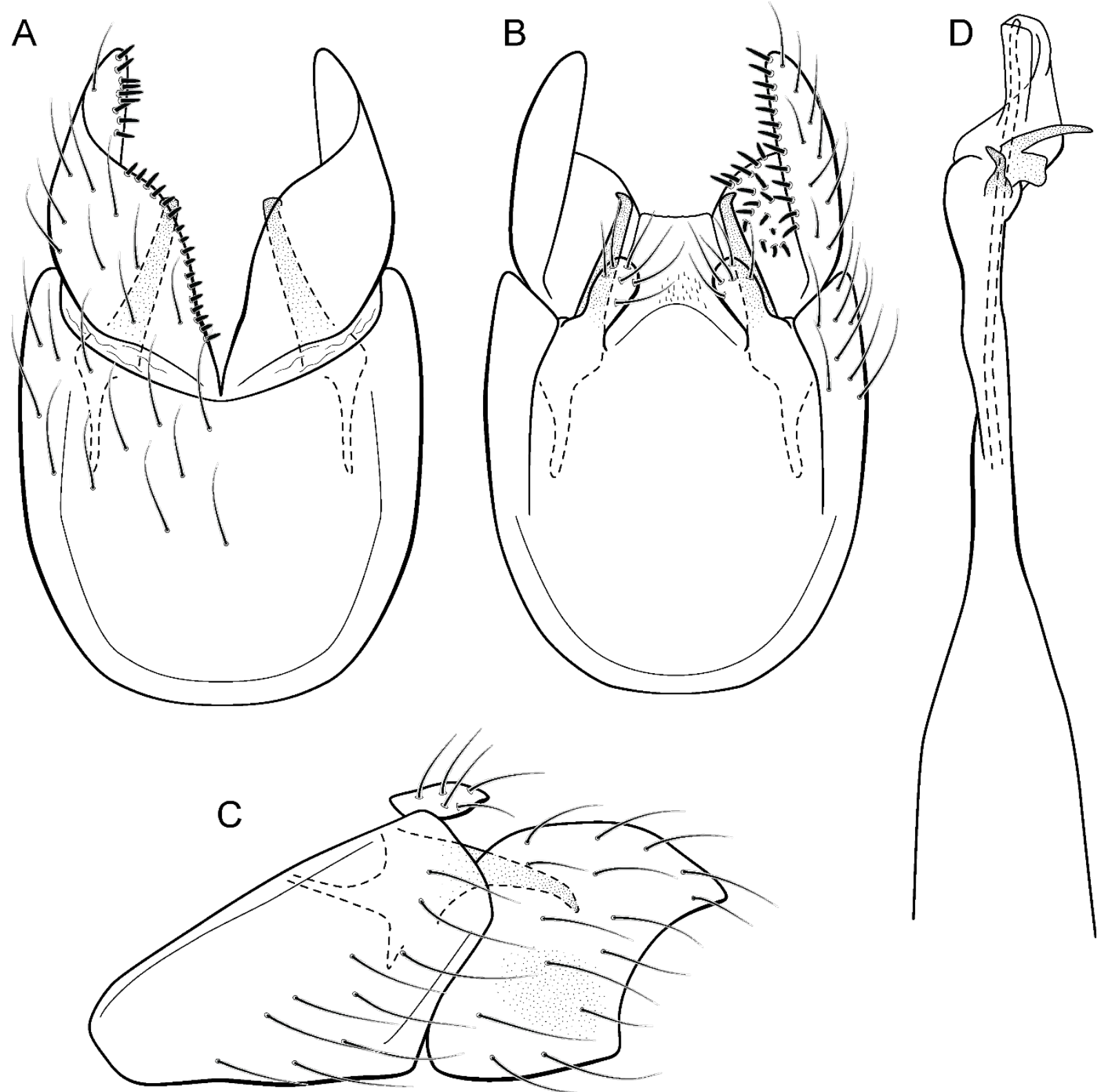

804

Figure 19. Metrichia peluda sp. nov., male genitalia: (A) ventral view; (B) dorsal view; (C)

805 lateral view; (D) phallus, dorsal view.

806

807

808

809

810

Remarks. Modifications on male abdominal segments V, VI, and VII suggest that this new species belongs to the campana group. The general aspect of inferior appendages is somewhat

similar to $M$. forceps sp. nov. and $M$. formosinha sp. nov., which are excavate posteriorly.

However, M. peluda sp. nov. is readily identified by the dense brushes of setae on the dorsum of abdominal segments V, VI, and VII. Besides, the male genitalia of this new species differ from 
811 those described for M. forceps sp. nov. and M. formosinha sp. nov. by the rounded corners of

812 inferior appendages instead of acute and by phallus with two subapical spines with unequal sizes.

\section{Metrichia rafaeli sp. nov.}

814 urn:1sid:zoobank.org:act:CBCADBB8-2C79-49AB-8345-CC1E6FA2AEE9

815 (Fig. 20)

816 Adult male. Length $2.0-2.5 \mathrm{~mm}(\mathrm{n}=7)$. General color, in alcohol, dark brown. Head with no 817 modifications. Ocelli 3. Antenna simple, 20-articulated. Maxillary palpus 5-articulated; labial 818 palpus 3-articulated. Mesoscutellum with transverse suture. Metascutellum subtriangular.

819 Anterior femur without processes. Tibial spur formula 1-3-4. Wing venation reduced in both 820 wings. Abdominal segment V with pair of internal pouches; segment VI with pair of internal 821 pouches and pair of lateral external sacs with specialized setae; segment VII bearing specialized 822 setae dorsally. Ventromesal process on segment VII present. Segment VIII shorter ventrally than 823 dorsally. Male genitalia. Segment IX reduced dorsally; sternum subrectangular, with anterior 824 margin rounded (Fig. 20A); in lateral view narrower anteriorly than posteriorly (Fig. 20C).

825 Inferior appendage covered by long setae, short and rounded, with apex slightly excavated (Fig. 826 20A); in lateral view, rounded (Fig. 20C). Dorsal hook long, more than half length of inferior 827 appendage; in lateral view, downturned (Fig. 20C). Preanal appendage elongate, but shorter than 828 half length of inferior appendage, and bearing stout and striate setae (Fig. 20B). Subgenital plate 829 apparently absent. Tergum X membranous and truncate (Fig. 20B). Phallus tubular, elongate and 830 slender, slightly constricted mesally, with a median process; with two long, curved, subapical

831 spines, and a membranous lobe; apex rounded and sclerotized; ejaculatory duct sclerotized, 832 sinuous, and not protruding apically (Fig. 20D). 
833 Holotype male. BRAZIL: Ceará: Ubajara, Parque Nacional de Ubajara, Rio das Minas,

834 0350'03”S 4054'18”'W, el. 524, 17-18.ii.2013, DM Takiya, JA Rafael, RR Cavichioli \& APM

835 Santos cols., Malaise trap (CZMA).

836 Paratypes. Same data as holotype, 1 male (MZUFBA); same data, except Rio das Minas, 837 0349'58’S 4053'53”W, el. 420 m, 20-23.iv.2012, F Limeira-de-Oliveira et al. cols., Malaise 838 trap, 1 male (CZMA); same data, except 14-16.ii.2013, DM Takiya, JA Rafael, RR Cavichioli \& 839 APM Santos cols., 1 male (DZRJ).

840 Etymology. This species is named in honor of the Brazilian entomologist Dr. José Albertino 841 Rafael (INPA), who has collected many interesting caddisflies, including some species described 842 here.

843 Remarks. This new species belongs to the nigritta group due to internal pouches between 844 abdominal segments V and VI and long and acute process on phallus. The male genitalia of $M$. 845 rafaeli sp. nov. are more similar to M. magna Bueno-Soria \& Holzenthal, 2003 with short and 846 simple inferior appendages. However, the new species can be easily distinguished from the latter 847 and other Metrichia species in this group by the posterior margin of inferior appendages slightly 848 excavated and very long subapical spines of phallus.

849 Although specimens with barcode sequences of $M$. rafaeli sp. nov. were collected at the 850 same locality, haplotypes were not identical having intraspecific divergence of $0.4 \%$. The lowest 851 interspecific distance was $19.4 \%$ when compared with M. itabaiana sp. nov. 


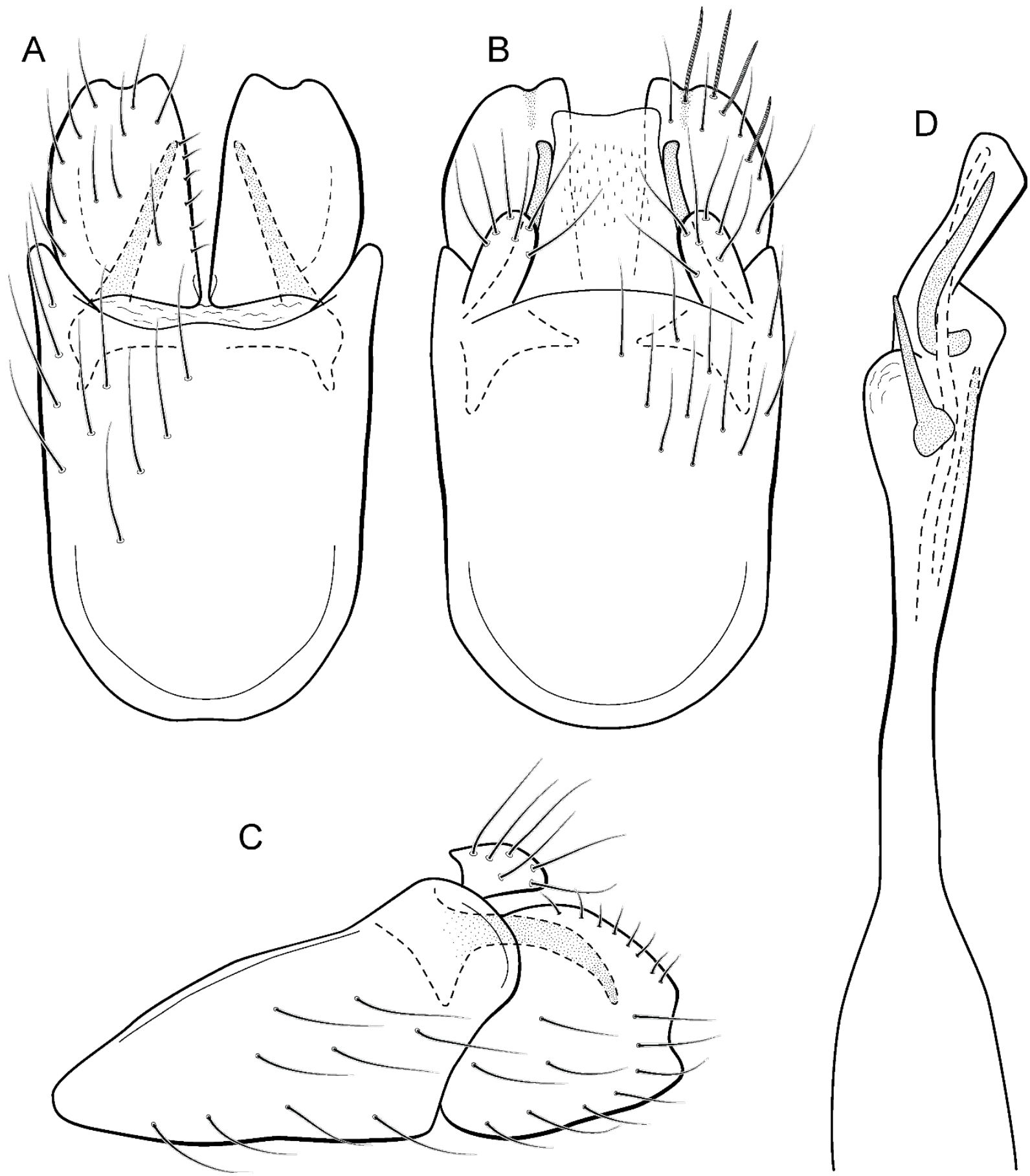

852 Figure 20. Metrichia rafaeli sp. nov., male genitalia: (A) ventral view; (B) dorsal view; (C) 853 lateral view; (D) phallus, dorsal view.

\section{Metrichia simples sp. nov.}

855 urn:1sid:zoobank.org:act:05933E6E-A6FF-49DE-982E-54B263830D10 
856 (Fig. 21, Fig. 26E)

857 Adult male. Length 2.1-2.2 mm (n=2). General color, in alcohol, brown. Head with no

858 modifications. Ocelli 3. Antenna simple, 19-articulated. Maxillary palpus 5-articulated; labial

859 palpus 3-articulated. Mesoscutellum with transverse suture. Metascutellum subtriangular.

860 Anterior femur without processes. Tibial spur formula 1-3-4. Wing venation reduced in both

861 wings. Abdominal segment IV with dorsal area expanded posteriorly bearing stout setae; segment

862 VI bearing very long setae laterally, with a brush of short setae covered dorsally by a triangular

863 plate (Fig. 26E); segment VII with a brush of short setae dorsally (Fig. 26E). Ventromesal process

864 on segment VII present. Segment VIII shorter ventrally than dorsally. Male genitalia. Segment

865 IX reduced dorsally; sternum subpentagonal (Fig. 21A); in lateral view narrower anteriorly than

866 posteriorly (Fig. 21C). Inferior appendage covered by long setae, with apex obliquely truncate;

867 subtrapezoidal in ventral view (Fig. 21A); in lateral view, subtrapezoidal (Fig. 21C). Dorsal hook

868 short, almost half length of inferior appendage; in lateral view, slightly downturned (Fig. 21C).

869 Preanal appendage short, rounded and bearing very long setae (Fig. 21B). Subgenital plate

870 apparently absent. Tergum X membranous and rounded (Fig. 21B). Phallus tubular, elongate and

871 slender, slightly constricted mesally; with four subapical spines, three short and one long and

872 straight; apex rounded with a small sclerite; ejaculatory duct sclerotized and not protruding

873 apically (Fig. 21D).

874 Holotype. BRAZIL: Paraná: Céu Azul, Parque Nacional do Iguaçu, Rio Azul, 2509'21”S

875 5347’44’'W, el. 510 m, 6-8 ix.2012, APM Santos, DM Takiya, ALH Oliveira, GA Jardim \&

876 BHL Sampaio cols., Malaise trap, male (DZRJ).

877 Paratypes. Same data as holotype, 1 male (MNRJ).

878 Etymology. This species is named in reference to the simple aspect of the male genitalia and

879 abdomen, without modifications and processes seen in other Metrichia species. 
880 Remarks. This species can be assigned to the campana group because of pouches in abdominal

881 segments VI and VII. The new species shares the general aspect of the genitalia with $M$.

882 quadrata, particularly, in the quadrangular or rectangular shape of inferior appendages and the

883 short subapical spines on phallus. Metrichia simples sp. nov. can be recognized by the short

884 dorsal hook, reaching up to midlength of inferior appendages (subequal to inferior appendages in

885 M. quadrata), obliquely truncate apex of the inferior appendages, and strongly curved spines on 886 phallus. 


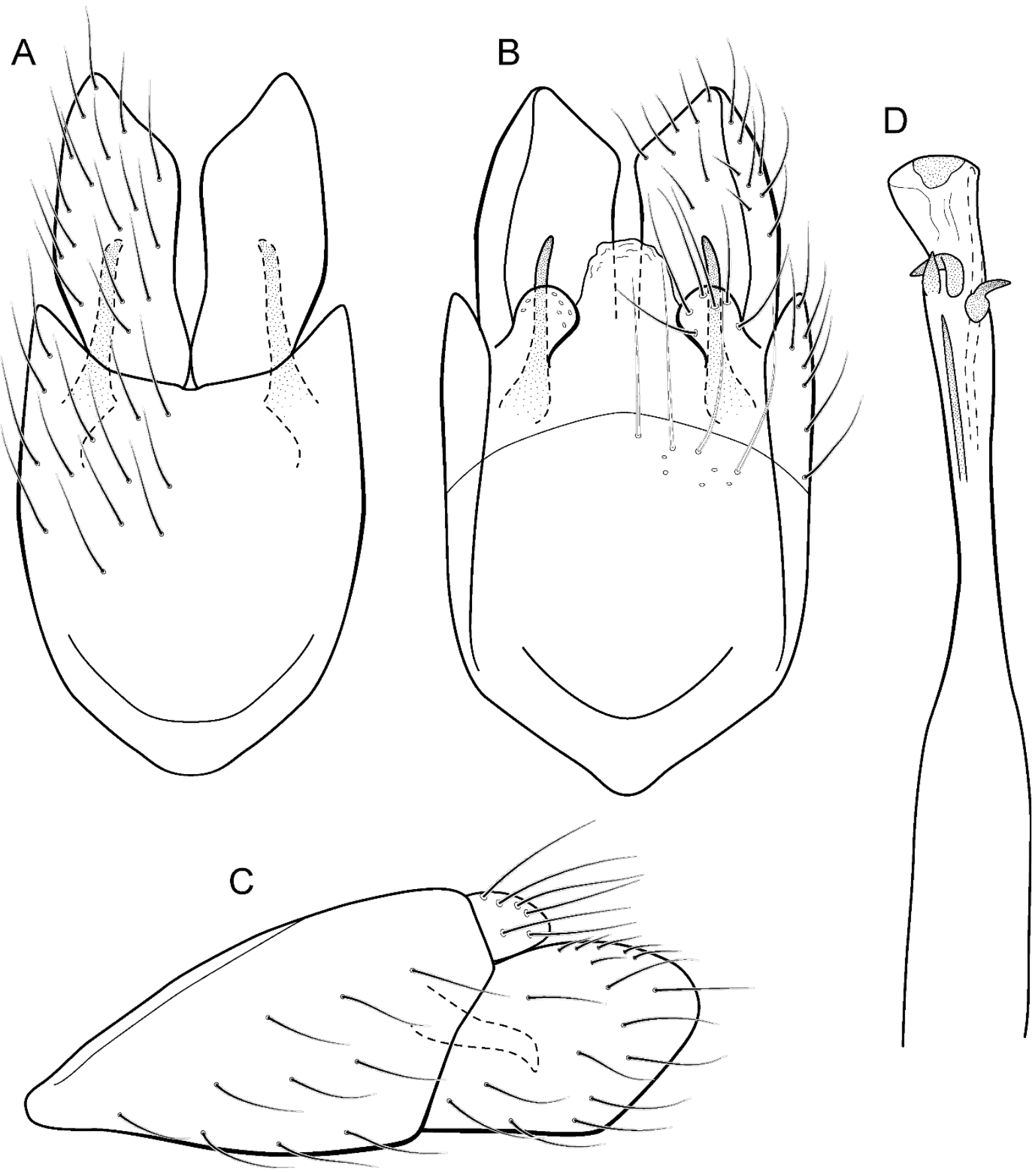

Figure 21. Metrichia simples sp. nov., male genitalia: (A) ventral view; (B) dorsal view; (C)

888 lateral view; (D) phallus, dorsal view.

890 urn:Isid:zoobank.org:act: 5456FEB8-5193-46DD-A10F-9FFADFCB59EC

891 (Fig. 22) 
892 Adult male. Length 1.8-2.0 mm $(\mathrm{n}=10)$. General color, in alcohol, brown. Head with no

893 modifications. Ocelli 3. Antenna simple, 18-articulated. Maxillary palpus 5-articulated; labial

894 palpus 3-articulated. Mesoscutellum with transverse suture. Metascutellum subtriangular.

895 Anterior femur with small acute apical process. Tibial spur formula 1-3-4. Wing venation reduced

896 in both wings. Abdominal segment V with pair of internal pouches and pair of dorsolateral

897 brushes; segment VI with dorsolateral brushes of long setae; segment VII bearing specialized

898 setae dorsally. Ventromesal process on segment VII absent. Segment VIII shorter ventrally than

899 dorsally. Male genitalia. Segment IX reduced dorsally; sternum subpentagonal (Fig. 22A); in

900 lateral view, narrower anteriorly than posteriorly (Fig. 22C). Inferior appendage elongate, apex

901 rounded and bearing a tooth-like projection; with a deep C-shaped notch in ventral view (Fig.

902 22A); in lateral view, with an acute projection (Fig. 22C). Dorsal hook short, less than half length

903 of inferior appendage (Fig. 22A); in lateral view, downturned. Preanal appendage short, rounded

904 and bearing very long setae (Fig. 22B). Subgenital plate apparently absent. Tergum X

905 membranous and truncate (Fig. 22B). Phallus tubular, elongate and slender, slightly constricted

906 mesally, with a median process; with two curved subapical spines, one short and another long;

907 apex rounded and sclerotized; ejaculatory duct sclerotized, straight and protruding apically (Fig.

908 22D).

909 Holotype. BRAZIL: Alagoas: Quebrangulo, Reserva Biológica de Pedra Talhada, Rio

910 Caranguejo, 09¹5'26”S 36²5'08’W, el. 550 m, 19-28.vi.2014, APM Santos, DM Takiya, WRM

911 Souza cols., Malaise trap, male (DZRJ).

912 Paratypes. Same data as holotype, 8 males (DZRJ), 7 males (MZUFBA).

913 Etymology. This species is named in reference to its type locality, the Reserva Biológica de

914 Pedra Talhada. 

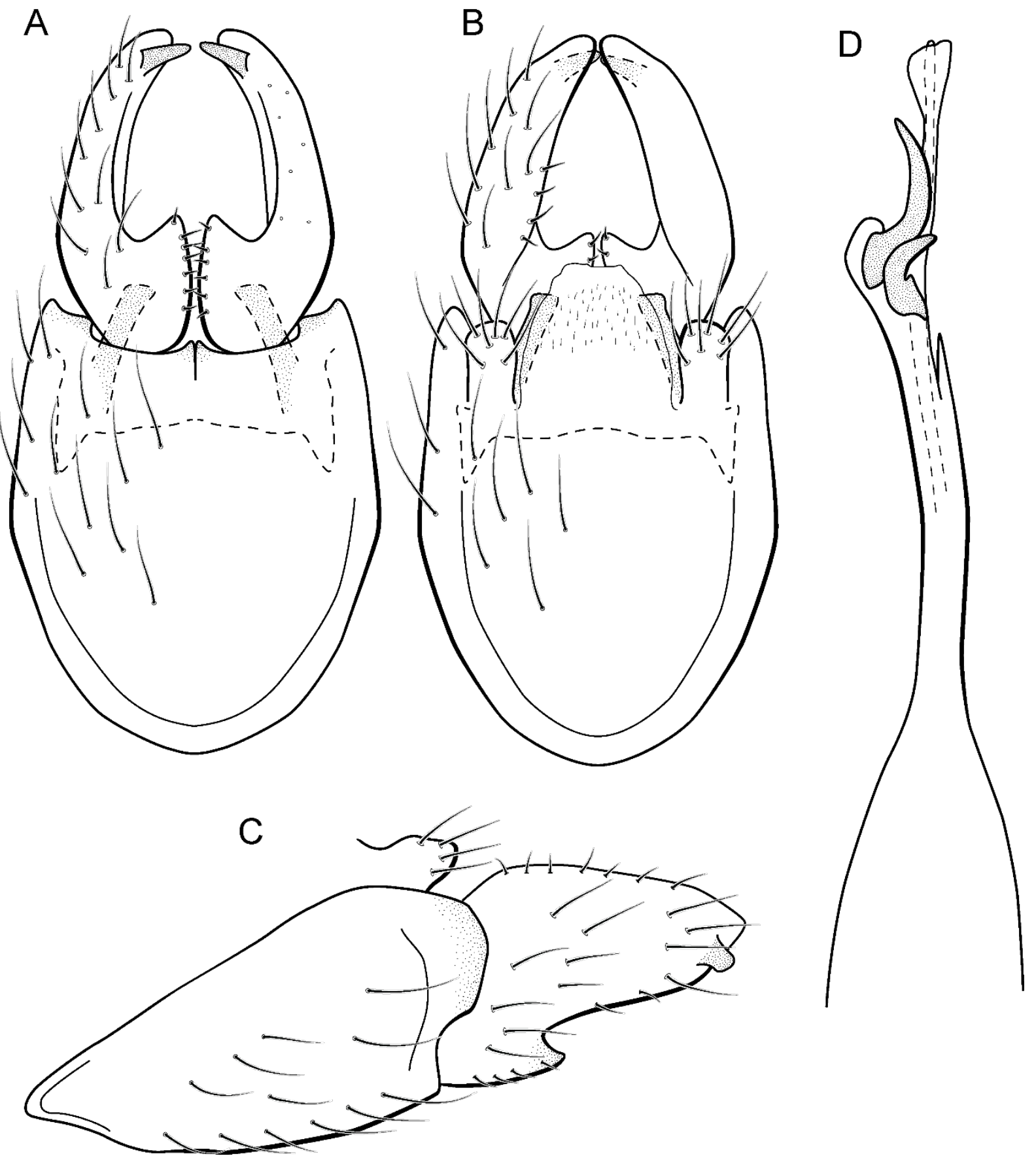

915 Figure 22. Metrichia talhada sp. nov., male genitalia: (A) ventral view; (B) dorsal view; (C) 916 lateral view; (D) phallus, dorsal view.

917 Remarks. The new species belongs to the nigritta group because of their internal pouches 918 between abdominal segments V and VI and phallus with two subapical curved spines and an 919 acute process near mesal area. Metrichia talhada sp. nov. shares the apical tooth on inferior 
920

921

922

923

924

925

926

927

928

930

931

932

933

934

935

936

937

938

939

940

941

942

943

appendages with M. potosina, M. goiana sp. nov., and Metrichia tere sp. nov. From M. potosina and M. goiana sp. nov., it is easily distinguished by the shape of the inferior appendages, with a deep C-shaped notch on ventral margin and subapical tooth stout and slightly truncate in lateral view, and subapical spines on phallus, one long and another short. Although the male genitalia of M. talhada sp. nov. are very similar to $M$. tere sp. nov., these two species can be separated by the shape of inferior appendages teeth, each slightly truncate and subapical in the former and acute and apical in the later species.

Sequences of M. talhada sp. nov. showed $0.0 \%$ of divergence. Morphological similarity between this species and its sister (M. tere sp. nov.) had a relatively low genetic divergence of $12.6 \%$, the lowest interspecific distance found in our sampling. In addition to minor but stable differences in genital structures, all molecular analyses with COI sequences (NJ, ABGD, GMYC) corroborate the distinction between $M$. talhada sp. nov. and $M$. tere sp. nov., which are formally described here as different species.

\section{Metrichia tere sp. nov.}

urn:1sid:zoobank.org:act:21376F9C-6308-47BA-ADB8-A42848AD8FB5

(Fig. 23)

Adult male. Length 1.9-2.1 mm ( $\mathrm{n}=10)$. General color, in alcohol, brown. Head with no modifications. Ocelli 3. Antenna simple, 18-articulated. Maxillary palpus 5-articulated; labial palpus 3-articulated. Mesoscutellum with transverse suture. Metascutellum subtriangular.

Anterior femur with small acute apical process. Tibial spur formula 1-3-4. Wing venation reduced in both wings. Abdominal segment $\mathrm{V}$ with pair of internal pouches and pair of dorsolateral brushes; segment VI with dorsolateral brushes of long setae; segment VII bearing specialized setae dorsally. Ventromesal process on segment VII absent. Segment VIII shorter ventrally than dorsally. Male genitalia. Segment IX reduced dorsally; sternum subpentagonal (Fig. 23A); in 
944 lateral view, narrower anteriorly than posteriorly (Fig. 23C). Inferior appendage elongate, apex

945 with an acute projection; with a deep C-shaped notch in ventral view (Fig. 23A); in lateral view,

946 with an acute projection (Fig. 23C). Dorsal hook short, less than half length of inferior

947 appendage; in lateral view, downturned (Fig. 23C). Preanal appendage short, rounded and bearing

948 very long setae (Fig. 23B). Subgenital plate apparently absent. Tergum X membranous and

949 truncate (Fig. 23B). Phallus tubular, elongate and slender, slightly constricted mesally, with a

950 median process; with two curved subapical spines, one short and another long; apex rounded and

951 sclerotized; ejaculatory duct sclerotized, straight and protruding apically (Fig. 23D).

952 Holotype. BRAZIL: Rio de Janeiro: Teresópolis, Parque Nacional da Serra dos Órgãos, Rio 953 Paquequer, 22²7’25”S 4259'52”W, el. 1100 m, 15-18.ix.2011, APM Santos, DM Takiya, BM

954 Vasconcelos \& RA Carvalho cols., Malaise trap, male (DZRJ).

955 Paratypes. Same data as holotype, 9 males (MNRJ), 19 males (DZRJ).

956 Etymology. This species is named in reference to the city of Teresópolis (= "City of Teresa"),

957 affectionately called as "Terê". The city was named in honor of Teresa Cristina, Brazilian

958 Empress from 1843 to 1889, wife of Dom Pedro II.

959 Remarks. This new species is very similar to the preceding one, also belonging to the nigritta

960 group. Metrichia tere sp. nov. can be distinguished from M. talhada sp. nov. by inferior

961 appendages with an apical acute projection, whereas in M. talhada sp. nov. inferior appendages

962 have a subapical tooth, which is more truncate than acute.

963 Molecular data agree with the morphological distinction of M. tere sp. nov., as

964 commented on above. Intraspecific K2P divergence among specimens sampled $(n=3)$ of this

965 species was $0.0 \%$, and as mentioned in the previous description, M. talhada sp. nov. and M. tere

966 sp. nov. showed the lowest observed interspecific distance (12.6\%). 

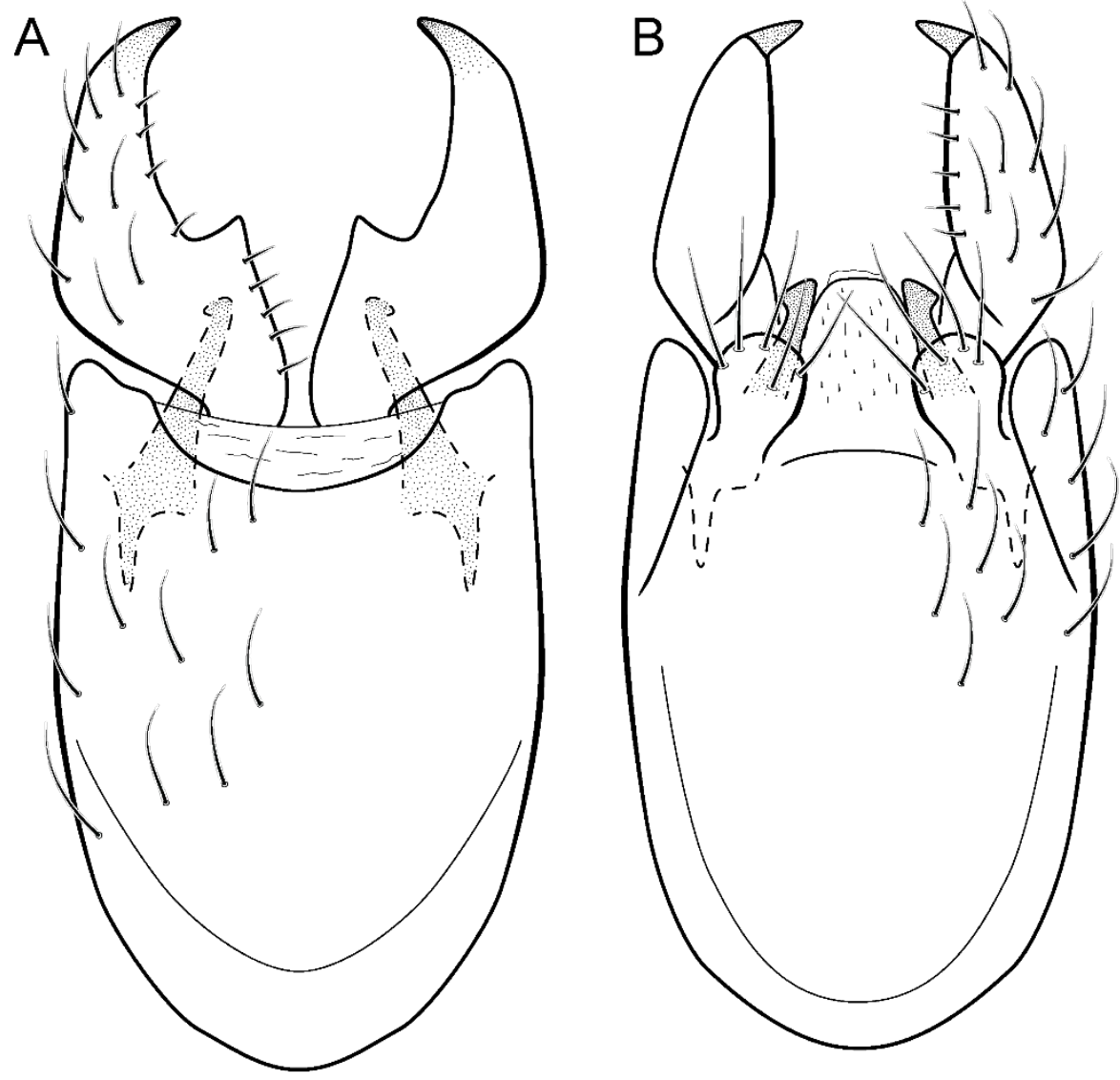

D
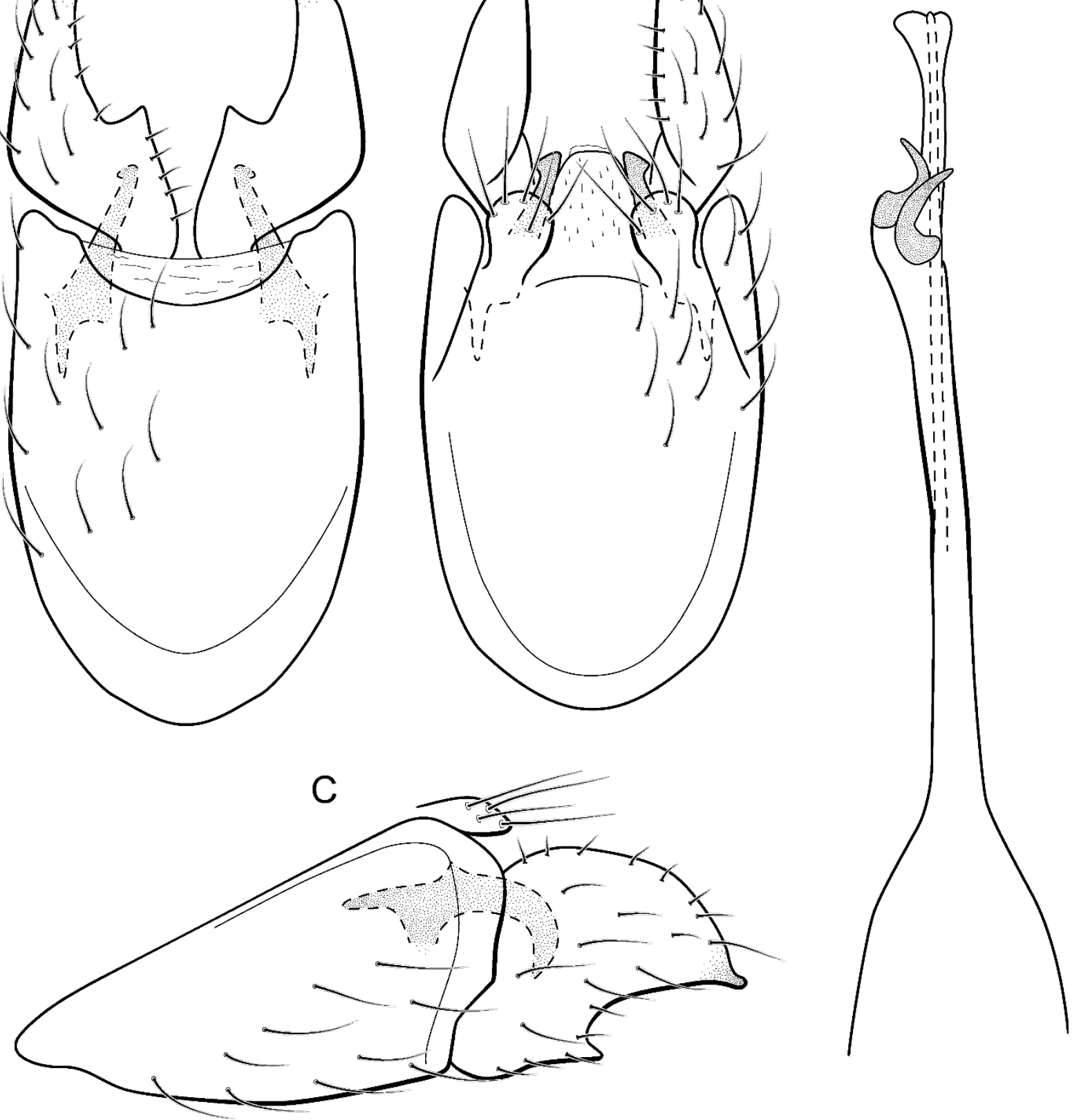

967

Figure 23. Metrichia tere sp. nov., male genitalia: (A) ventral view; (B) dorsal view; (C) lateral 968 view; (D) phallus, dorsal view.

971 (Fig. 24) 
972 Adult male. Length 2.0-2.7 mm (n=12). General color, in alcohol, brown. Head with no

973 modifications. Ocelli 3. Antenna simple, 18-articulated. Maxillary palpus 5-articulated; labial

974 palpus 3-articulated. Mesoscutellum with transverse suture. Metascutellum subtriangular.

975 Anterior femur without processes. Tibial spur formula 1-3-4. Wing venation reduced in both

976 wings. Abdominal segment V with pair of internal pouches and median internal plate in posterior

977 region; with specialized setae on dorsum; segment VI with pair of internal pouches in

978 posterodorsal area. Ventromesal process on segment VII absent. Segment VIII shorter ventrally

979 than dorsally. Male genitalia. Segment IX reduced dorsally; sternum subrectangular (Fig. 24A);

980 in lateral view, narrower anteriorly than posteriorly (Fig. 24C). Inferior appendage covered by

981 long setae, apex rounded; elongate and narrow in ventral view (Fig. 24A); in lateral view,

982 rounded (Fig. 24C). Dorsal hook short, less than half length of inferior appendage; apex

983 downturned; basally with a wide and sclerotized projection; in lateral view, C-shaped (Fig. 24C).

984 Preanal appendage elongate, but shorter than half length of inferior appendage, and bearing stout

985 and striate setae (Fig. 24B). Subgenital plate apparently absent. Tergum X membranous and

986 truncate (Fig. 24B). Phallus tubular, elongate and slender, slightly constricted mesally; with two

987 long, curved, subapical spines; apex rounded and folded; ejaculatory duct sclerotized, sinuous,

988 and protruding apically (Fig. 24D).

989 Holotype. BRAZIL: Ceará: Ubajara, Parque Nacional de Ubajara, Rio das Minas, 0349’58”S

990 4053’53”W, el. 420 m, 20-23.iv.2012, DM Takiya, JA Rafael, F Limeira-de-Oliveira et al. cols.,

991 Malaise trap, male (CZMA).

992 Paratypes. Same data as holotype, 1 male (CZMA); same data, except 13-17.ix.2012, 25 males

993 (CZMA), 12 males (DZRJ); same data, except 18-30.xi.2012, 9 males (INPA); same data, except

994 14-16.ii.2013, 5 males (MZUFBA); same data, except Rio das Minas, 0350'03’'S 4054'18’W,

995 el. 524 m, 14-16.ii.2013, DM Takiya, JA Rafael, RR Cavichioli \& APM Santos cols., Malaise

996 trap, 5 males (MNRJ). 
997 Etymology. This species is named in reference to Ubajara National Park, in the municipality with 998 the same name, where the types were collected from.

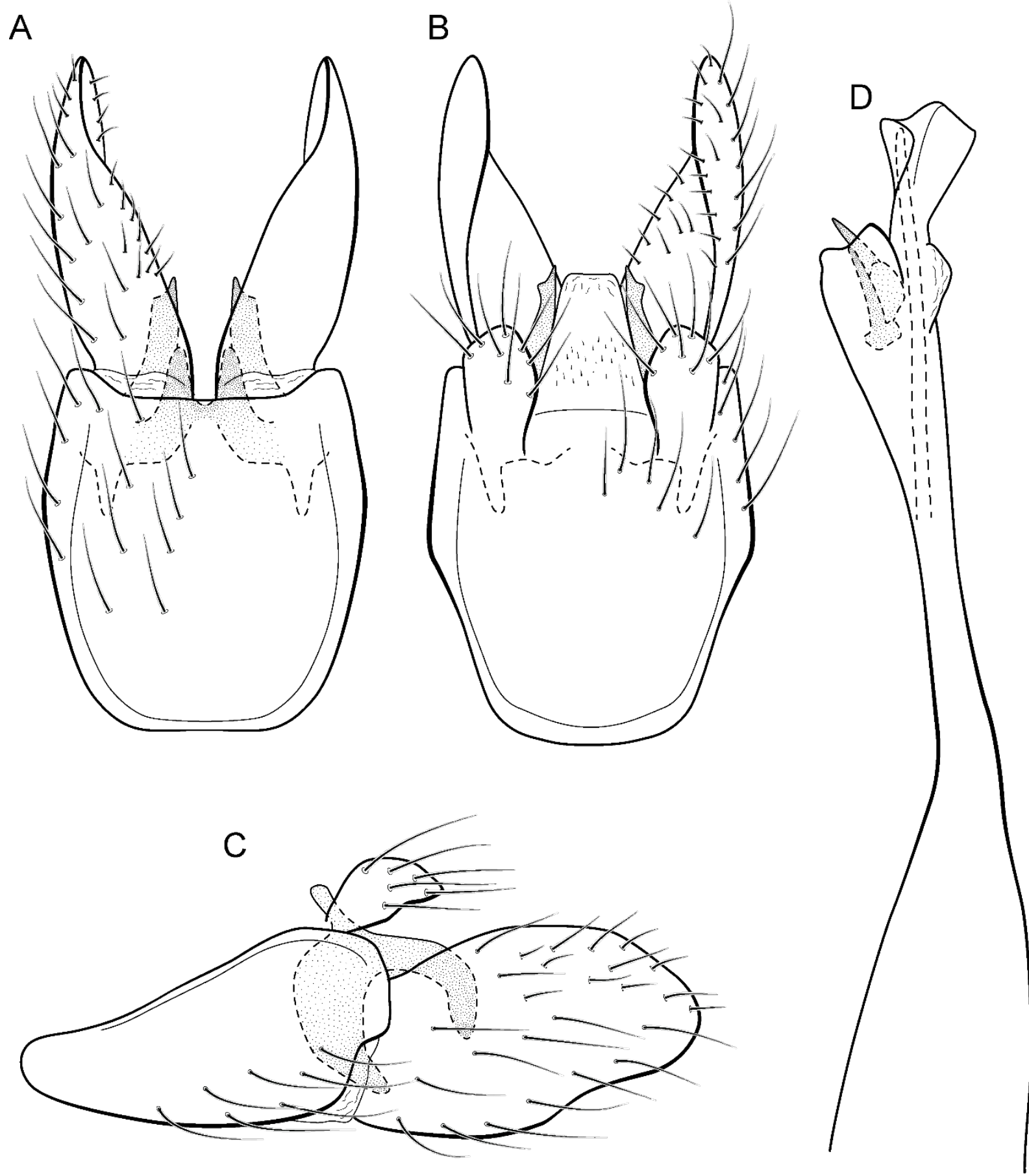

999 Figure 24. Metrichia ubajara sp. nov., male genitalia: (A) ventral view; (B) dorsal view; (C) 1000 lateral view; (D) phallus, dorsal view. 
1001 Remarks. This new species appears to be a member of the nigritta group because of their 1002 internal pouches between abdominal segments V and VI and the presence of two long subapical 1003 spines on phallus. Metrichia ubajara sp. nov. resembles M. potosina and M. goiana sp. nov. 1004 because of the rounded and elongate inferior appendages in lateral view. However, in M. ubajara 1005 sp. nov. the inferior appendages lack the "tooth" mentioned for these two species. As well, $M$. 1006 ubajara sp. nov. can be recognized by the phallic apex with a broad sclerotized plate wrapping 1007 the ejaculatory duct.

\section{Metrichia vulgaris sp. nov.}

(Fig. 25)

Adult male. Length 2.7-3.1 mm ( $\mathrm{n}=12)$. General color, in alcohol, brown. Head with no modifications. Ocelli 3. Antenna simple, 21-articulated. Maxillary palpus 5-articulated; labial palpus 3-articulated. Mesoscutellum with transverse suture. Metascutellum subtriangular. Anterior femur without processes. Tibial spur formula 1-3-4. Wing venation reduced in both wings. Abdominal segment VI with pair of internal pouches in posterodorsal area. Ventromesal process on segment VII present. Segment VIII shorter ventrally than dorsally. Male genitalia. Segment IX reduced dorsally; sternum subquadrangular (Fig. 25A); in lateral view, narrower anteriorly than posteriorly (Fig. 25C). Inferior appendage covered by long setae, apex excavated, posterodorsal margin acute and sclerotized; subtrapezoidal in ventral view (Fig. 25A); in lateral view, subretangular (Fig. 25C). Dorsal hook long and stout, almost reaching the inferior appendage apex; in lateral view, downturned (Fig. 25C). Preanal appendage elongate, rounded and bearing very long setae (Fig. 25B). Subgenital plate apparently absent. Tergum X membranous and rounded (Fig. 25B). Phallus tubular, elongate and slender, slightly constricted 
1024 mesally; with two short subapical spines; apex rounded and folded; ejaculatory duct sclerotized 1025 and protruding apically (Fig. 25D).

1026 Holotype. BRAZIL: Rio de Janeiro: Itatiaia, Rio Palmital, 22²5’34’S 44³2'52”W, el. 637 m, 1027 07.iii.2008, LL Dumas, JL Nessimian \& MR de Souza cols., light trap, male (DZRJ).

1028 Paratypes. Same data as holotype, 1 male (DZRJ), 1 male (MNRJ); same data, except Rio das 1029 Pedras, 22²4’33”S 44³3'08’W, el. 706 m, 06.iii.2008, LL Dumas, JL Nessimian \& MR de 1030 Souza cols., light trap, 4 males (MNRJ). Ceará: Ubajara, Parque Nacional de Ubajara, Rio 1031 Gameleira, 0350’25’S 4054'19’W, el. 874 m, 20-22.iv.2012, F Limeira-de-Oliveira et al. cols., 1032 Malaise trap, 1 male (CZMA). Goiás: Alto Paraíso, Rio Bartolomeu tributary, 1407’25”S $103347^{\circ} 30^{\prime} 30^{\prime \prime} W$, el. 1270 m, 22-25.iii.2013, APM Santos \& DM Takiya cols., Malaise trap, 3 males 1034 (DZRJ).

1035 Etymology. This new species is named in allusion to its unusually wide distribution throughout 1036 Brazil. From the Latin "vulgaris" meaning "common".

1037 Remarks. This new species belongs to the campana group due to their internal pouches between 1038 segments VI and VII and the two small subapical spines in phallus. Metrichia vulgaris sp. nov. 1039 shares with M. campana, M. similis, and M. itabaiana sp. nov. the general aspect of inferior 1040 appendages, with an excavated posterior margin. From these species, M. vulgaris sp. nov. can be 1041 distinguished by their inferior appendages, in lateral view, excavated but with ventral corner more 1042 rounded than acute and short and stout dorsal hook and tergum X short and rounded. 


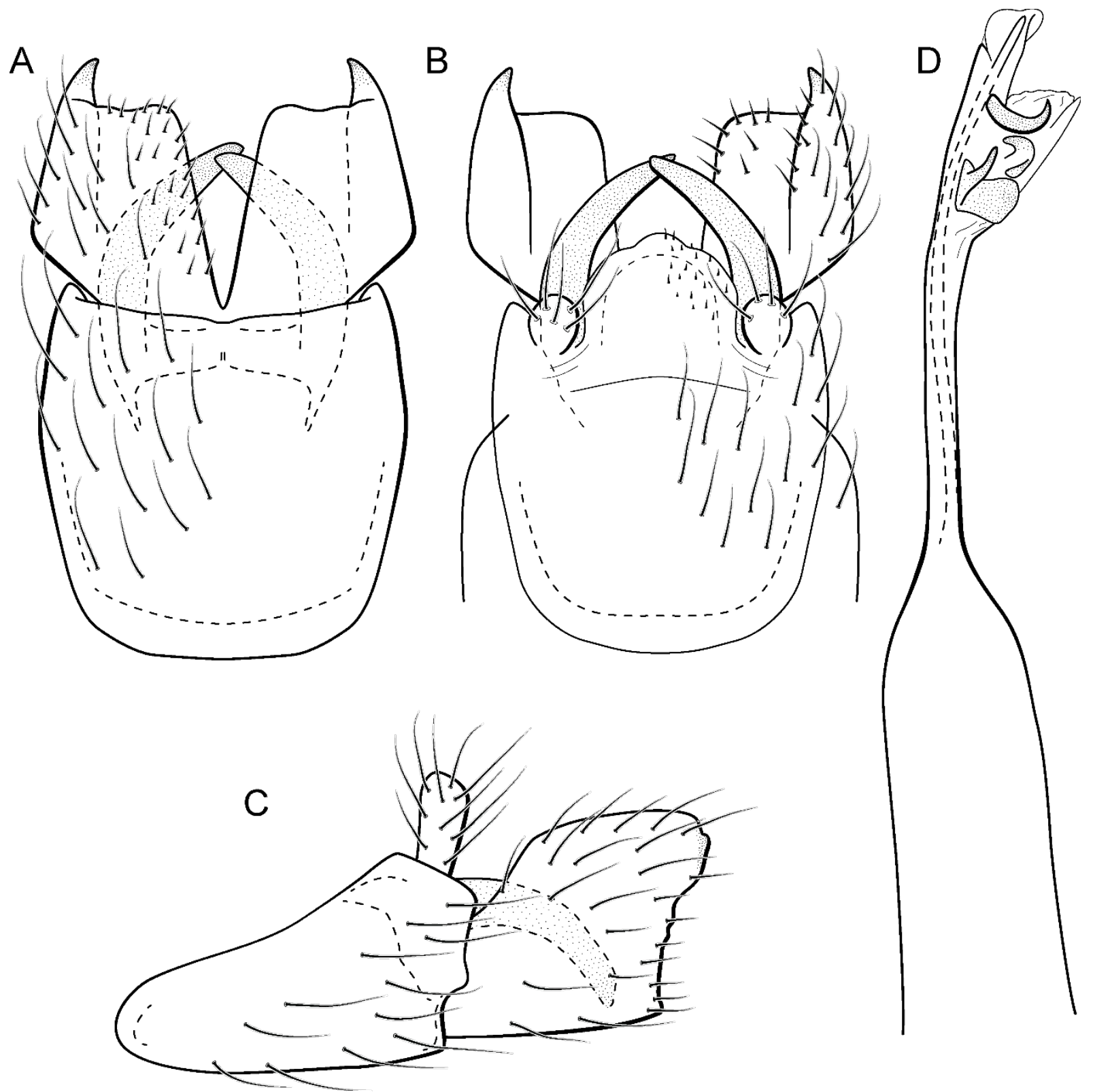

1043 1044 Metrichia vulgaris sp. nov. has an interesting distributional pattern, occurring in very 1046 distant localities in Southeastern, Centralwestern, and Northeastern Brazil. In addition to their 1047 geographic distance, these localities are included in very distinctive areas: encompassing three 1048 biomes (Atlantic Forest, Cerrado, and Caatinga) and four large river basins (East North Atlantic, 1049 Southeast Atlantic, São Francisco, and Araguaia-Tocantins). Barcode sequences corroborate these 
1050 different populations as the same species, with K2P intraspecific divergences up to $4.8 \%$. This is

1051 the highest intraspecific divergence found in our work, but this value is still lower than that

1052 observed among species in other caddisfly groups (Pauls et al., 2010, Zhou et al., 2011). GMYC

1053 analyses grouped sequences into two 'species', but these groups were not related to their

1054 geographic distribution: one group included samples from Rio de Janeiro and Minas Gerais and

1055 the other group, samples from Rio de Janeiro, Minas Gerais, and Goiás. The broader

1056 geographical and specimen sampling of this species, which is directly associated with its higher

1057 intraspecific divergences, may explain the oversplitting by the GMYC method, as discussed by

1058 Talavera et al. (2013).

1059 Although such wide distribution is not common for Metrichia species, other

1060 microcaddisflies can show continental distributions (e.g., Oxyethira tica). Because the knowledge

1061 about Neotropical microcaddisflies is very poor, this pattern may be more common than currently 1062 thought.

\section{DISCUSSION}

1064 Although GMYC analysis overestimated the number of Metrichia species in our study 1065 (suggesting the split of M. circuliforme sp. nov. and M. vulgaris sp. nov. each into two 'species'), 1066 COI sequences strongly corroborated species limits previously defined based on morphological 1067 features. In general, COI sequences of caddisflies show a robust 'barcoding gap' (Pauls et al., 1068 2010, Zhou et al., 2011), making this molecular marker appropriate as a source of additional 1069 information to corroborate species delimitation or associations of different life stages.

1070 Microcaddisflies are extremely diverse and poorly known, and when associated with the 1071 morphological data, the use of molecular information can result in a more robust taxonomy for 1072 this group. Although methods such ABGD and GMYC should not be used alone to determine 1073 'species', they are useful tools to identifying 'potential species' (Puillandre et al., 2012; Talavera 
1074 et al., 2013), especially in very diverse groups and/or with dubious morphology-based

1075 identification. The wide distribution of Metrichia vulgaris sp. nov. could indicate the existence of

1076 different cryptic species, however morphology and barcode data agreed to define this group as a

1077 single species. Although GMYC overestimated the number of Metrichia species in our analysis,

1078 we consider this method an important tool for preliminary distinction when taxonomic

1079 information is poor.

1080 Based on the presence of abdominal modifications, such as internal pouches, external 1081 sclerotized plates, and brushes of long setae, and features of male genitalia, six species groups

1082 have been proposed for Metrichia (Flint, 1972; Bueno-Soria \& Holzenthal, 2003). These

1083 abdominal modifications usually arise from segments V, VI, and VII, and, in general aspect, are

1084 very distinctive from each other (Fig. 26), possibly representing non-homologous structures.

1085 Nevertheless, most of the species described herein fit in these previously defined groups. Present

1086 analyses of COI sequences (Fig. 2 and Supp. 4) recovered neither the monophyly of Metrichia

1087 nor any of the species groups tested (aberrans, campana, and nigritta groups). However, these

1088 relationships need to be analyzed further with better taxon and molecular marker sampling. 


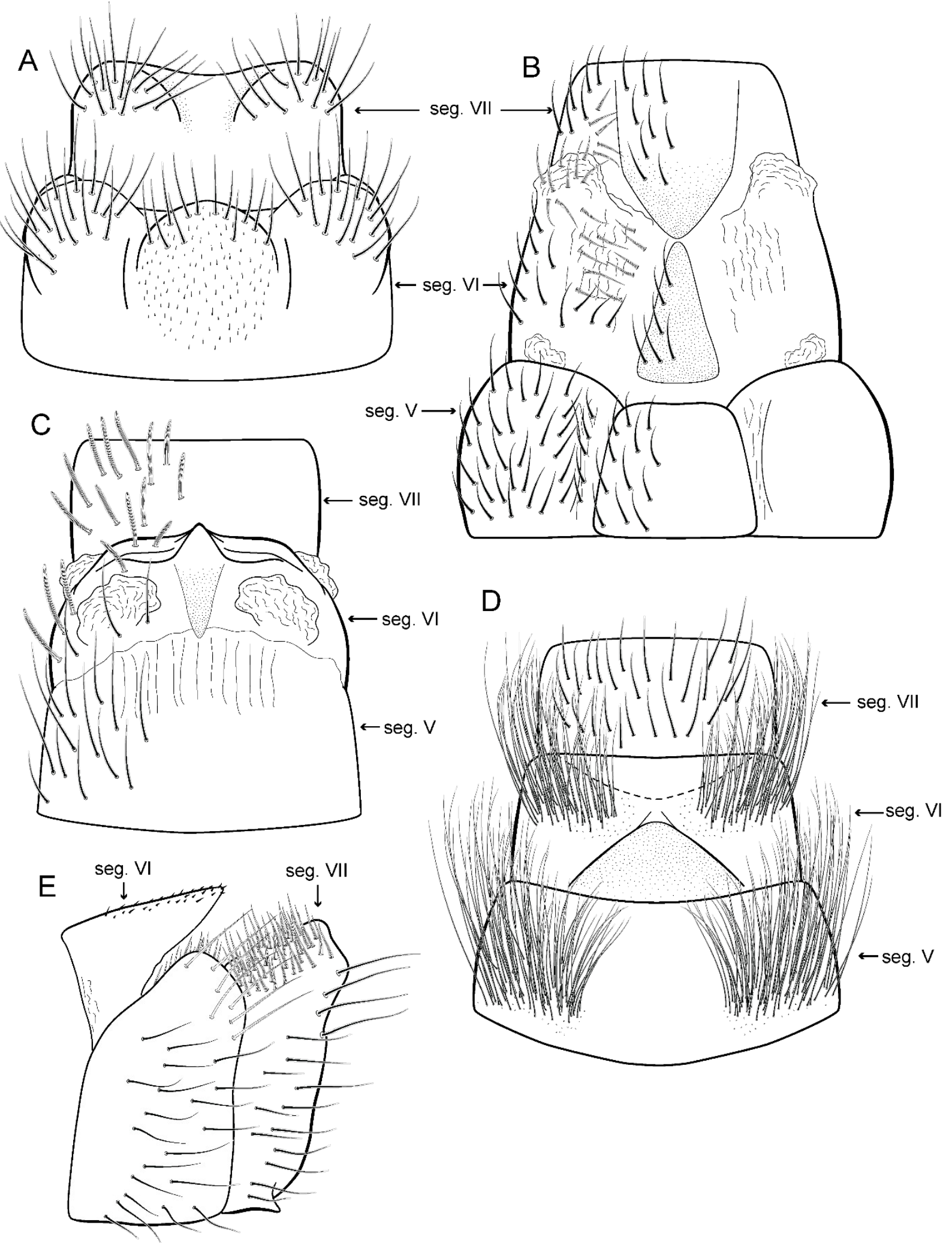

Figure 26. Abdominal modifications of Metrichia species: (A) M. acuminata sp. nov., segments

1090 VI and VII, dorsal view; (B) M. itabaiana sp. nov., segments V, VI, and VII, dorsal view; (C) $M$. 
1091 longissima sp. nov., segments V, VI, and VII, dorsal view; (D) M. peluda sp. nov., segments V, 1092 VI, and VII, dorsal view; (E) M. simples sp. nov., segments VI and VII, lateral view.

nov. Larvae remain unknown for most Neotropical species of Trichoptera, and they are even less 1095 known for microcaddisflies. Rearing immatures is very difficult and association based in co1096 occurrence with adults is not possible when several species of the same genus co-occur. In this 1097 way, DNA barcodes are a powerful tool, allowing the association and description of immature 1098 stages (Shan et al., 2004; Pauls et al., 2010; Ruiter et al., 2013). Barcode reference libraries for 1099 caddisflies are available for specimens from other regions (Zhou et al., 2009; Zhou et al., 2011; Ruiter et al., 2013) and represent an important source of information for taxonomic work as well as for ecological and evolutionary studies. We expect that molecular data will become increasingly common for Neotropical caddisflies as it facilitates the understanding of their 1103 diversity in this region.

\section{SUPPLEMENTAL INFORMATION}

1105

1106

\section{Collecting sites}

Detailed list of collecting sites in Brazil where new species of Metrichia were found.

\section{Georeferences of collecting sites}

Google Earth (.kmz) file with collecting localities of new Metrichia species.

\section{COI sequence alignment}

FASTA format alignment of COI sequence data of Metrichia and related microcaddisflies. 


\section{Bayesian inference estimated tree}

1112 Consensus phylogram (50\% majority-rule) from $\mathrm{BI}$ analyses of COI sequences (mean $\operatorname{lnL}=$

1113 -5464.29) of Metrichia and related microcaddisflies. Values displayed near branches are posterior 1114 probabilities.

\section{K2P pairwise divergences}

1116 Pairwise K2P divergences of COI sequences of Metrichia and related microcaddisflies.

\section{ACKNOWLEDGEMENTS}

1118 We thank the Laboratório de Entomologia, UFRJ team for helping in field trips. Additional 1119 specimens used in this study were provided by J. A. Rafael (INPA), M. L. Monné (Museu 1120 Nacional, UFRJ), and C. H. Dietrich (University of Illinois at Urbana-Champaign). We also thank 1121 the academic editor J.D. Reimer and two anonymous reviewers for valuable comments and A. M. 1122 Ray (Xavier University) for conducting an English review.

\section{REFERENCES}

Botosaneanu L, Flint OS Jr. 1982. On some Trichoptera from northern Venezuela and Ecuador (Insecta). Beaufortia 32:13-26.

Bueno-Soria J, Holzenthal RW. New species and records of the microcaddisfly genus Metrichia Ross from Costa Rica (Trichoptera: Hydroptilidae). Studies on Neotropical Fauna and Environment 38:173-197. DOI: 10.1076/snfe.38.3.173.28164.

Dallwitz MJ, Paine TA, Zurcher EJ. 1999. User's guide to the DELTA editor. http://deltaintkey.com/

Dummond AJ, Ho SYW, Phillips MJ, Rambaut A. 2006. Relaxed phylogenetics and dating with confidence. PLoS Biology 4:e88. DOI: 10.1371/journal.pbio.0040088. 
1133

1134

1135

1136

1137

1138

1139

1140

1141

1142

1143

1144

1145

1146

1147

1148

1149

1150

1151

1152

1153

1154

1155

1156

1157

1158

1159

1160

1161

1162

1163

Drummond AJ, Suchard MA, Xie D, Rambaut A. 2012. Bayesian phylogenetics with BEAUti and the BEAST 1.7. Molecular Biology and Evolution 29:1969-1973. DOI: 10.1093/molbev/mss075.

Drysdale RN. 1998. Aquatic insect larvae as geomorphic agents in travertine-building: a case study from Barkly Karst, Australia. Supplement Geografia Fisica Dinamica Quaternaria 4:53-59.

Drysdale RN. 1999. The sedimentological significance of hydropsychid caddis-fly larvae (Order: Trichoptera) in travertine-depositing stream: Louie Creek, northwest Queensland, Australia. Journal of Sedimentary Research 69:145-150. DOI: 10.2110/jsr.69.145.

Drysdale RN, Gale SJ. 1997. The Indarri Falls travertine dam, Lawn Hill Creek, northwestern Queensland, Australia. Earth Surface Processes and Landforms 22:413-418. DOI: 10.1002/ (SICI)1096-9837(199704)22:4<413::AID-ESP761>3.0.CO;2-K.

Edwards SW, Arnold CR. 1961. The caddis flies of the San Marcos River. The Texas Journal of Science 13:398-415.

Ezard T, Fujisawa T, Barraclough TG. 2009. SPLITS: SPecies' LImits by Threshold Statistics. R package version 1.0-18/r45. Available from: URL http://R-Forge.Rproject.org/projects/splits/, last accessed September 2015.

Felsenstein J. 1985. Confidence limits on phylogenies: an approach using the bootstrap. Evolution 39:783-791.

Flint OS Jr. 1964. The caddisflies (Trichoptera) of Puerto Rico. University of Puerto Rico, Agricultural Experiment Station, Technical Paper 40:1-80.

Flint OS Jr. 1968. The caddisflies of Jamaica (Trichoptera). Bulletin of the Institute of Jamaica, Science Series 19:1-68.

Flint OS Jr. 1972. Studies of Neotropical caddisflies, XIII: the genus Ochrotrichia from Mexico and Central America (Trichoptera: Hydroptilidae). Smithsonian Contributions to Zoology 118:1-28.

Flint OS Jr, Holzenthal RW, Harris SC. 1999. Catalog of the Neotropical Caddisflies (Insect: Trichoptera). Columbus: Ohio Biological Survey.

Folmer O, Black M, Hoeh W, Lutz R, Vrijenhoek R. 1994. DNA primers for amplification of mitochondrial cytochrome $\mathrm{C}$ oxidase subunit I from diverse metazoan invertebrates. Molecular Marine Biology and Biotechnology 3:294-299. 
1164 Fujisawa T, Barraclough TG. 2013. Delimiting species using single-locus data and the

1165 Generalized Mixed Yule Coalescent approach: a revised method and evaluation on simulated 1166 data sets. Systematic Biology 62:707-724. DOI: 10.1093/sysbio/syt033.

1167 Graf W, Lubini V, Pauls S. 2005. Larval description of Drusus muelleri McLachlan, 1868

1168 (Trichoptera: Limnephilidae) with some notes on its ecology and systematic position within

1169 the genus Drusus. Annales de Limnologie - International Journal of Limnology 41:93-98.

1170 DOI: $10.1051 / \operatorname{limn} / 2005012$.

1171 Harris SC, Armitage BJ. 1997. New member of the Chilean genus Nothotrichia from North

1172 America (Trichoptera: Hydroptildiae). In: Holzenthal RW, Flint OS Jr. (Eds.) Proceedings of

1173 the 8th International Symposium on Trichoptera. Ohio Biological Survey, Columbus, Ohio.

1174 pp 123-128.

1175 Hebert PDN, Cywinska A, Ball SL, Waard JR. 2003. Biological identifications through DNA

1176 barcodes. Proceedings of the Royal Society of London, Biological Science 270:313-321.

1177 DOI: $10.1098 /$ rspb.2002.2218

1178 Kimura M. 1980. A simple method for estimating evolutionary rates of base substitutions through comparative studies nucleotides sequences. Journal of Molecular Evolution 16:111-120.

Lohse K. 2009. Can mtDNA barcodes be used to delimit species? A response to Pons et al. (2006). Systematic Biology 58:439-442. DOI: 10.1093/sysbio/syp039.

Malm T, Johanson KA, Wahlberg N. 2013. The evolutionary history of Trichoptera (Insecta): a case of successful adaptation to life in freshwater. Systematic Entomology 38:459-473. DOI: 10.1111/syen.12016

Marshall JE. 1979. A review of the genera of the Hydroptilidae (Trichoptera). Bulletin of the British Museum (Natural History) Entomology series 39:135-239.

Müller F. 1879. Notes on the cases of some south Brazilian Trichoptera. Transactions of the Entomological society of London 1879:131-144.

Müller F. 1880. Sobre as casas construídas pelas larvas de insectos Trichopteros da Província de Santa Catarina. Archivos do Museu Nacional, Rio de Janeiro 3:99-134, 210-214.

Oláh J, Johanson KA. 2011. New Neotropical Hydroptilidae. Annales Historico-Naturales Musei Nationalis Hungarici 103: 1-143. 
1196 Pauls SU, Blahnik RJ, Zhou X, Wardwell CT, Holzenthal RW. 2010. DNA barcode data confirm

1197 new species and reveal cryptic diversity in Chilean Smicridea (Smicridea) (Trichotera:

1198 Hydropsychidae). Journal of North American Benthological Society 29:1058-1074.

1199 Pes AMO, Hamada N, Nessimian JL. 2005. Chaves de identificação de larvas para famílias e

1200 gêneros de Trichoptera (Insecta) da Amazônia Central, Brasil. Revista Brasileira de

$1201 \quad$ Entomologia 49:181-204.

1202 Pons J, Barraclough TG, Gomez-Zurita J, Cardoso A, Duran DP, Hazell S, Kamoun S, Sumlin

1203 WD, Vogler AP. 2006. Sequence-based species delimitation for the DNA taxonomy of

$1204 \quad$ undescribed insects. Systematic Biology 55:595-609. DOI: 10.1080/10635150600852011.

1205

1206

Posada, D. (2008) jModelTest: Phylogenetic Model Averaging. Molecular Biology and Evolution, 25, 1253-1256.

Puillandre N, Lambert A, Brouillet S, Achaz G. 2012. ABGD, Automatic Barcode Gap Discovery 1208 for primary species delimitation. Molecular Ecology 21:1864-1877. DOI:10.1111/j.1365294X.2011.05239.x.

R Development Core Team. 2010. R: a language and environment for statistical computing. Vienna (Austria): R Foundation for Statistical Computing.

Rambaut A, Drummond AJ. 2007. Tracer v1.4, available: http://beast.bio.ed.ac.uk/Tracer.

Ronquist F, Teslenko M, Mark P, Ayres DL, Darling A, Höhna S, Larget B, Liu L, Suchard MA, Huelsenberck JP. 2012. MrBayes 3.2: Efficient Bayesian phylogenetic inference and model choice across a large model space. Systematic Biology 61:539-542. DOI: $0.1093 /$ sysbio/sys029.

Ruiter DE, Boyle EE, Zhou X. 2013. DNA barcoding facilitates associations and diagnoses for Trichoptera larvae of the Churchill (Manitoba, Canada) area. BMC Ecology 13:5. DOI: 10.1186/1472-6785-13-5.

Santos APM, Nessimian JL, Takiya DM. 2016. Revised classification and evolution of leucotrichiine microcaddisflies (Trichoptera: Hydroptilidae) based on morphological and molecular data. Systematic Entomology 41: 458-480. DOI: 10.1111/syen.12168. larvae (Trichoptera: Hydrobiosidae). Acta Zootaxonomica Sinica 29: 434-439.

Simon C, Frati F, Beckenbach A, Crespi B, Liu H, Flook P. 1994. Evolution, weighting and phylogenetic utility of mitochondrial gene sequences and a compilation of conserved polymerase chain reaction primers. Annals of the Entomological Society of America 87: 651701. 
1229

1230

1231

1232

1233

1234

1235

1236

1237

1238

1239

1240

1241

1242

1243

1244

1245

1246

1247

1248

1249

1250

1251

1252

1253

1254

1255

1256

1257

1258

1259

1260

Spies MR, Froehlich CG, Kotzian CB. 2006. Composition and diversity of Trichoptera Kirby, 1813 (Insecta) larvae communities in Jacuí River middle section and some tributaries, Rio Grande do Sul State, Brazil. Iheringia Serie Zoologia 96:389-398.

Spies MR, Froehlich CG. 2009. Inventory of caddisflies (Trichoptera: Insecta) of the Campos do Jordão State Park, São Paulo State, Brazil. Biota Neotropica 9:211-218. DOI: 10.1590/S1676-06032009000400021.

Srivathsan A, Meier R. 2012. On the inappropriate use of Kimura-2-parameter (K2P) divergences in the DNA-barcoding literature. Cladistics 28:190-194. DOI: 10.1111/j.10960031.2011.00370.x.

Tamura, K., Stecher, G., Peterson, D., Filipiski, A. \& Kumar, S. (2013) Mega6: molecular evolutionary genetics analysis version 6.0. Molecular Biology and Evolution, 30, 2725-2729.

Talavera G, Dincă V, Vila R. 2013. Factors affecting species delimitations with GMYC model: insights from a butterfly survey. Methods in Ecology and Evolution 4:1101-1110. DOI: 10.1111/2041-210X.12107.

Waringer J, Graf W, Pauls SU, Vicentini H, Lubini V. 2007. DNA based association and descrition of the larval stage of Drusus melanchaetes McLachlan, 1876 (Trichoptera: Limnephilidae: Drusinae) with notes on ecology and zoogeography. Limnologica - Ecology and Management of Inland Waters 38:34-42. DOI: 10.1016/j.limno.2007.09.001.

Wells A, Wichard W. 1989. Caddisflies of Dominican Amber. VI. Hydroptilidae (Trichoptera). Studies on Neotropical Fauna and Environment 24:41-51.

Wells A, Johanson KA, Mary-Sasal N. 2013. The New Caledonian genus Caledonotrichia Sykora (Trichoptera: Insecta) reviewed, with descriptions of 6 new species. ZooKeys 287:59-89. DOI: $10.3897 /$ zookeys.287.4615.

Wiggins GB. 1996. Larvae of the North American caddisfly genera (Trichoptera). 2nd edition. Toronto: University of Toronto Press.

Zhou X, Kjer KM, Morse JC. 2007. Associating larvae and adults of Chinese Hydropsychidae caddisflies (Insecta: Trichoptera) using DNA sequences. Journal of the North American Benthological Society 26:719-742. DOI: 10.1899/06-089.1.

Zhou X, Robinson JL, Geraci CJ, Parker CR, Flint OS Jr, Etnier DA, Ruiter D, DeWalt RE, Jacobus LM, Hebert PDN. 2011. Accelerated construction of a regional DNA-barcode reference library: caddisflies (Trichoptera) in the Great Smoky Mountains National Park. Journal of the North American Benthological Society 30:131-162. DOI: 10.1899/10-010.1. 